University of Louisville

ThinkIR: The University of Louisville's Institutional Repository

\title{
Analysis of trauma symptomology, trauma-informed care, and student-teacher relationships in a residential treatment center for female adolescents.
}

Amy Backert Gonshak

University of Louisville

Follow this and additional works at: https://ir.library.louisville.edu/etd

\section{Recommended Citation}

Gonshak, Amy Backert, "Analysis of trauma symptomology, trauma-informed care, and student-teacher relationships in a residential treatment center for female adolescents." (2011). Electronic Theses and Dissertations. Paper 516.

https://doi.org/10.18297/etd/516

This Doctoral Dissertation is brought to you for free and open access by ThinkIR: The University of Louisville's Institutional Repository. It has been accepted for inclusion in Electronic Theses and Dissertations by an authorized administrator of ThinkIR: The University of Louisville's Institutional Repository. This title appears here courtesy of the author, who has retained all other copyrights. For more information, please contact thinkir@louisville.edu. 


\title{
ANALYSIS OF TRAUMA SYMPTOMOLOGY, TRAUMA-INFORMED CARE, AND STUDENT-TEACHER RELATIONSHIPS IN A RESIDENTIAL TREATMENT
}

\section{CENTER FOR FEMALE ADOLESCENTS}

\author{
By \\ Amy Backert Gonshak \\ B.A., Xavier University, 1995 \\ M.C., University of Phoenix, 2003

\begin{abstract}
A Dissertation
Submitted to the Faculty of the

College of Education and Human Development of the University of Louisville in Partial Fulfillment of the Requirements for the Degree of
\end{abstract} \\ Doctor of Philosophy \\ Department of Educational and Counseling Psychology \\ University of Louisville \\ Louisville, Kentucky
}

August 2011 
Copyright 2010 by Amy Backert Gonshak

All rights reserved 


\section{ANALYSIS OF TRAUMA SYMPTOMOLOGY, TRAUMA-INFORMED CARE, AND}

STUDENT-TEACHER RELATIONSHIPS IN A RESIDENTIAL TREATMENT

\section{CENTER FOR FEMALE ADOLESCENTS}

By

Amy Backert Gonshak

B.A., Xavier University, 1995

M.C., University of Phoenix, 2003

A Dissertation Approved on

November 19, 2010

by the following Dissertation Committee:

Kathleen Rudasill

Dissertation Chair

Natalie Stipanovic

Patrick Possel

Jesse Owen

Gene Foster 


\section{DEDICATION}

This dissertation is dedicated to

my mother who continues to provide me a secure foundation and my daughters, Chloe \& Merra, who inspire me to explore. 


\section{ACKNOWLEDGEMENTS}

Thank you to my dissertation committee, most of whom embarked on this journey with me at the beginning of my program. I deeply appreciate the willingness of Dr. Kathleen Rudasill to be my dissertation chair. As soon as I began recruiting any faculty willing to listen to my "big idea," her enthusiastic support was evident and it fueled my fire. This is also true for my committee members Dr. Patrick Pössel, Dr. Natalie Stipanovic, and Dr. Gene Foster who also dedicated their valuable time to implementing this study and share in my commitment to provide a voice for kids who need one. I must also thank Dr. Jesse Owen for offering me a fresh perspective and being so kind when teaching (or re-teaching!) statistical analyses.

I would like to acknowledge my many amazing friends in the doctoral program (and now in life), especially Andrew Nichols, Aaron Banister, and Natalie Pickering, who provided me perspective, support, and humor when it was desperately needed.

My mom, dad, and step-parents have been enormously supportive throughout my educational journey both within the schoolhouse walls and in the real world. There is no way I would be who I am without their abundant love.

Finally, the person I am most excited to thank here is my husband, Chris. He encourages me to discover and become more of myself every year we are together and for that I am eternally grateful. I believe happiness is only real when shared, so I feel extremely blessed to share this accomplishment with him and our two incredible daughters. This is certainly a collective achievement. 


\title{
ABSTRACT \\ ANALYSIS OF TRAUMA SYMPTOMOLOGY, TRAUMA-INFORMED CARE, AND STUDENT-TEACHER RELATIONSHIPS IN A RESIDENTIAL TREATMENT CENTER FOR FEMALE ADOLESCENTS
}

Amy Backert Gonshak

November 19,2010

\begin{abstract}
Although there is a vast body of literature to support multiple positive outcomes related to positive student-teacher relationships, no prior study has investigated studentteacher relationships within the context of a residential treatment center for abused and neglected adolescents, students who theoretically could benefit from this relationship the most. The first goal of this study was to investigate the effects of student trauma symptomology, teacher beliefs about trauma-informed care, and teachers' emotionally supportive behavior in the classroom on student-teacher relationship quality. Results revealed that teacher beliefs about trauma-informed care and student trauma symptomology, particularly as it is related to 'Other-Control,' are statistically significant predictor variables of student-teacher relationship quality $\left(F_{7,45}=3.002, p=.011, R^{2}=\right.$ $\left..318, \Delta R^{2}=.212\right)$.

Additionally, teachers in on-campus schools within residential treatment centers are rarely trained to work with the traumatized students in their classrooms. Therefore, the second goal of this study was to examine the effects of a trauma-informed training intervention for teachers called Risking Connection. Changes in teachers' knowledge
\end{abstract}


about the training material, beliefs about trauma-informed care, and their emotionally supportive behavior in the classroom were evaluated before and after the teacher training as well as the subsequent changes in students' reported trauma symptomology and their perceptions of the student-teacher relationship. Results revealed no statistically significant change in teacher scores; however, this was not expected due to the low sample size of teachers $(n=6)$. Descriptive statistics suggest that if teacher changes occurred initially, they did not sustain. There was no statistically significant difference in the amount of change in students before and after the teacher training; however, a trend of slightly higher student scores was noted at the third data collection time point directly following the teacher training.

Overall, the findings indicate that characteristics of both the students and teachers impact the student-teacher relationship in the residential treatment center setting. Specifically, students' trauma symptomology and teachers' beliefs about the effectiveness of trauma-informed care are predictive of student perceptions of their relationship with their teachers. Implications for research, clinical practice, and effective training for teachers of this population are discussed. 


\section{TABLE OF CONTENTS}

PAGE

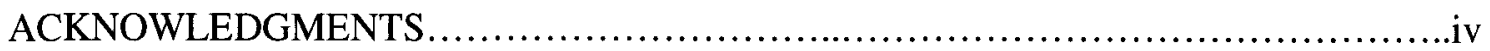

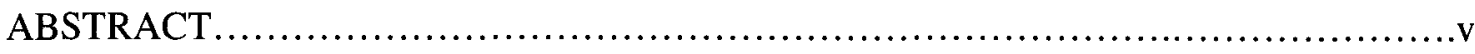

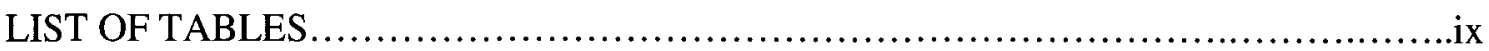

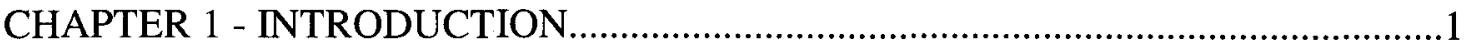

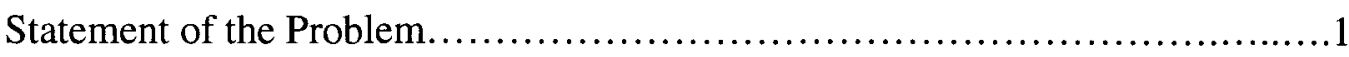

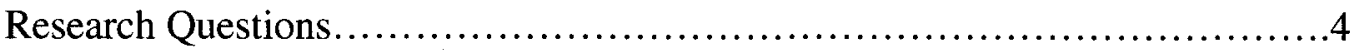

CHAPTER 2 - REVIEW OF THE LITERATURE $\ldots \ldots \ldots \ldots \ldots \ldots \ldots \ldots \ldots \ldots \ldots \ldots \ldots$

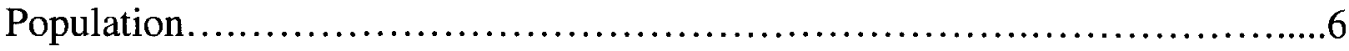

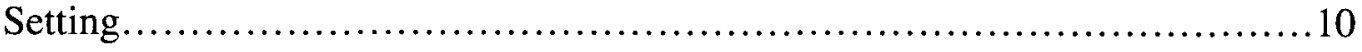

Theoretical Framework....................................................

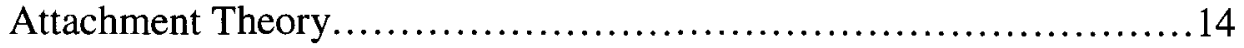

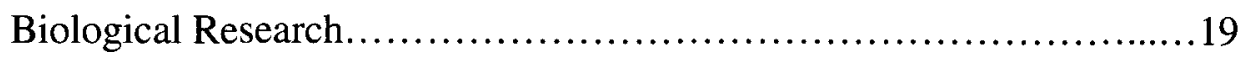

Constructivist Self Development Theory..............................24

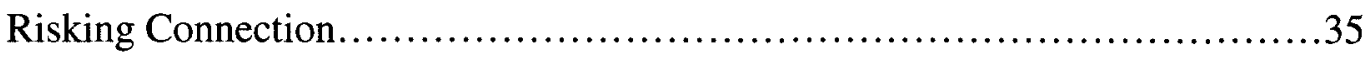

Components of the Risking Connection Training Curriculum..............36

Empirical Support for Trauma-Informed Care (Sanctuary Model).........42

Student-Teacher Relationships.............................................46

Integration of School in the Residential Treatment Setting..............49

Summary and Restatement of Research Questions...........................54 


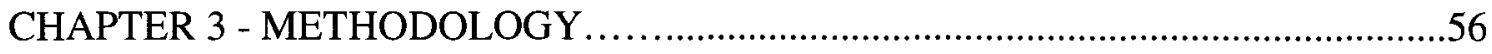

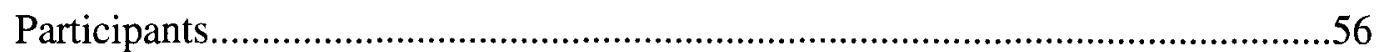

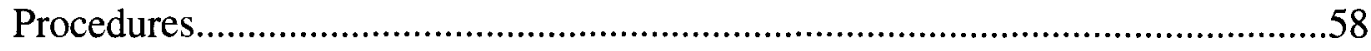

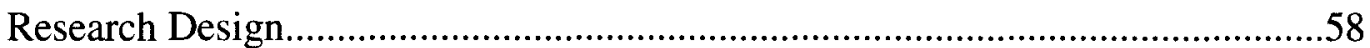

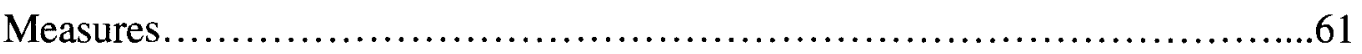

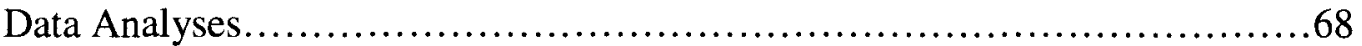

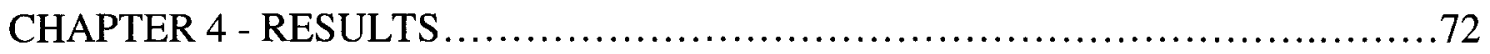

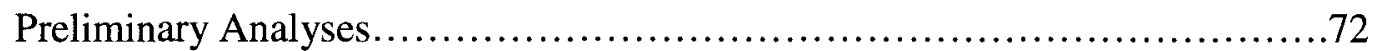

Research Question Analyses............................................ 78

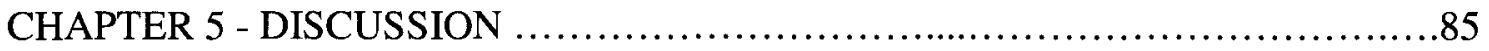

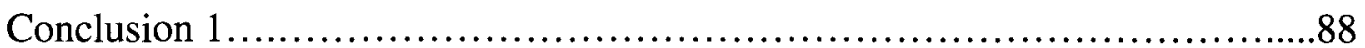

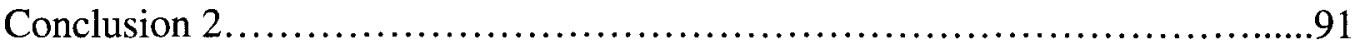

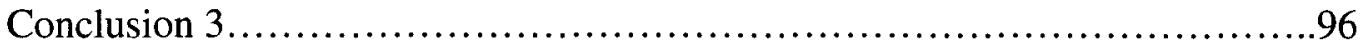

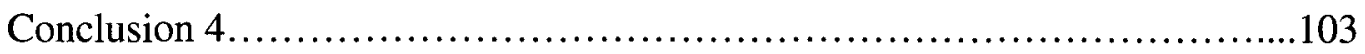

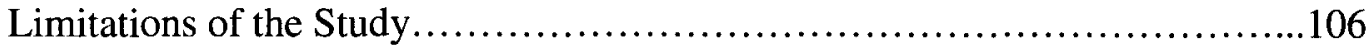

Directions for Future Research............................................. 110

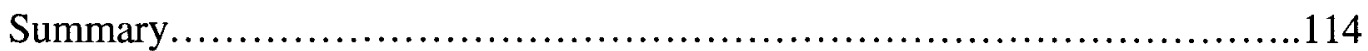

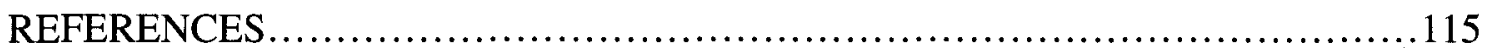

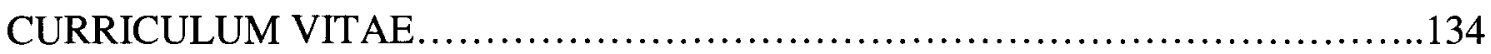




\section{LIST OF TABLES}

TABLE

PAGE

1. Diagram of the Research Design.

2. Student Data Collection Time Points and Measures

3. Teacher Data Collection Time Points and Measures.

4. Bivariate Correlations of Your Relationship with This Teacher, Trauma-

Informed Care Beliefs Measure, CLASS-Emotional Support, and TABS.

5. Grade Level and Race/Ethnicity of Students who Participated in Time Point $1 \ldots . . . .75$

6. Variability of TABS Global and Subscale Scores for Students at Time Point 1.......76

7. First Regression Predicting Student Perceptions of the Student-Teacher

Relationship by Student Trauma Symptomology, Teacher Trauma-Informed

Beliefs and Teacher Classroom Behavior.

8. Second Regression Predicting Student Perceptions of the Student-Teacher

Relationship by Specific Student Trauma Symptomology (TABS-subscales),

Teacher Trauma-Informed Beliefs and Teacher Classroom Behavior.

9. Means, Standard Deviations, and Ranges for Teacher Variables 


\section{CHAPTER 1}

\section{INTRODUCTION}

\section{Statement of the Problem}

In the United States, there were an estimated 510,000 children and adolescents in foster care on September 20,2006, approximately $17 \%$ of which were in an institution or group home. The majority of these children attend school on site instead of in the community public school setting (USDHHS, 2009). These individuals are the most likely to have histories of extreme or ongoing trauma and multiple placements within the foster care system (Brady \& Caraway, 2002; Kalke, Glanton, \& Cristalli, 2007; Rivard, McCorkle, Duncan, Bloom, \& Abramowitz, 2003). As a result, they generally have the most significant socio-emotional and behavioral problems. For example, adolescents in these programs have substantial interpersonal and relationship problems and exhibit many high risk behaviors, including self-harm, aggression toward others, and significant property damage (Kalke et al, 2007; Nickerson, Brooks, Colby, Rickert, \& Salamone, 2006). Of the fifty-four residential treatment centers in Kentucky that serve adolescents who are committed to the state's custody because of abuse and neglect, thirty-three have on-site schools (Children's Alliance, 2007). However, teachers within these schools do not systematically receive any additional training related to teaching students who have experienced childhood abuse and neglect, nor are they required to have had such training prior to being hired. 
The problem is that the population of students who have experienced significant trauma interact with others and think in a fundamentally different way than students who have not experienced such trauma, but are generally "taught" similarly (Bergin \& Bergin, 2009; Schwartz \& Davis, 2006). Currently, residential schools work hard to balance their accountability to various governmental agencies without compromising the integrity of their therapeutic programs; however, budgetary constraints and the inherent difficulty in having different professions (e.g. social workers, psychologists, teachers, administrators) understand and agree with each other on how to best work with this population is often challenging (Carman, Dorta, Kon, Martin, \& Zarrilli, 2004). The approach most often used includes a form of behavior management using operant conditioning principals to reinforce positive learning behavior and extinguish problem behaviors, rather than focusing on what motivates an individual's behavior and how the behavior impacts relationship building. Education for children who have been traumatized by experiences of physical abuse, sexual abuse, and neglect should be different - it should be focused on the core issues that lead to behavior problems (Carman et al, 2004; Schwartz \& Davis, 2006). This understanding is informed by attachment theory, trauma theory, specifically Constructivist Self Development Theory, and biological research.

A key issue associated with the proper instructional methods for traumatized youth is the fact that teachers in schools within residential treatment centers are typically not trained to work with this unique population. At the same time, students spend approximately forty hours a week in school while in residential treatment, and therefore have regular and long-term contact with their teachers. This is eight hours of each day they interact with other adults who could play a significant role in developing a trusting, 
safe relationship. The potential impact of a healthy student-teacher relationship in this context is enormous, and currently may be a missed opportunity within these facilities. If teachers are trained to understand the benefit of creating a nurturing environment in which their traumatized students are safe to explore and begin trusting a consistent, mentally healthy adult, the educational setting can become an integrated part of the overall treatment. For these reasons, it is imperative that researchers investigate the dynamics of the student-teacher relationship in the residential treatment center setting and that teachers of these students be informed about the impact of trauma and the role they can take in improving students' educational, as well as psychological, outcomes.

It is hypothesized that there are associations among students' trauma symptomology, teachers' beliefs about trauma-informed care, classroom interaction quality, and students' perceptions of the student-teacher relationship, all of which are under-represented in the research literature. It is further hypothesized that training teachers and other school personnel about the effects of trauma and how to build relationships with these traumatized students, will yield significant improvements in student outcomes via changes in teachers' knowledge, beliefs, and behaviors. Hypothesized changes in teachers include increased knowledge about trauma, more informed beliefs about how to treat traumatized individuals, and change in classroom behavior (i.e. quality interaction with students via emotional support). As a result of the teacher changes, hypothesized changes in students include more positive perceptions of their relationship with their teachers and decreased trauma symptomology. 


\section{Research Questions}

The specific questions and measures for the study follow.

To what extent is students' trauma symptomology (as measured by the Trauma and Attachment Belief Scale) associated with the students' perception of the studentteacher relationship (as measured by the Your Relationship with this Teacher questionnaire)?

To what extent are teacher beliefs about trauma-informed care (as measured by the Trauma-Informed Care Beliefs Measure) and the quality of their classroom behaviors and interactions with students (as measured by the Classroom Assessment Scoring System - CLASS Emotional Support subscale) associated with the students' perception of the student-teacher relationship (as measured by the Your Relationship with this Teacher questionnaire)?

To what extent is training teachers of traumatized students in residential treatment in a trauma-informed framework, Risking Connection, associated with:

- Increase in teachers' knowledge about trauma (measured by Risking Connection Curriculum Assessment)

- Increase in teachers' positive beliefs about trauma-informed care (measured by Trauma-Informed Care Beliefs Measure)

- Increase in quality teacher classroom behaviors and interactions (measured by CLASS -Emotional Support and Risking Connection Teacher Fidelity Measure)?

- Improvement in student perception of teacher relationship (measured by Your Relationship with this Teacher questionnaire)? 
- Decrease in student report of trauma symptomology (measured by Trauma and Attachment Belief Scale)? 


\section{CHAPTER 2}

\section{REVIEW OF THE LITERATURE}

\section{Population}

The population of interest for this study is adolescents who have been traumatized by physical or sexual abuse or neglect, and are currently placed in a residential treatment center. By virtue of their placement in residential care (the highest level of care besides psychiatric hospitalization) these adolescents are typically the most severely abused and neglected, and have the additional trauma associated with being removed from their homes. Adolescents who have been abused and neglected by primary caregivers have experienced trauma within the context of a relationship that is supposed to be nurturing and protective. As a result, they experience attachment related disturbances, such as not believing the world is safe, that others cannot be trusted, and that they are not worthy of love and nurturance (O'Connor \& Zeanah, 2003; Chaffin et al., 2006). As such, this kind of trauma is the etiological foundation for serious emotional and behavioral disorders (Chaffin et al., 2006). In fact, no other social risk factor has a stronger association with developmental psychopathology in adulthood than maltreatment in childhood (Zeanah \& Zeanah, 1989; Cicchetti \& Toth, 1995; Svanberg, 1998).

Individuals who experience early traumatic abuse are at risk for impairment in social interaction and communication (Mukaddes, Bilge, Alyanak, \& Kora, 2000; Sheperis, Renfro-Michel, \& Doggett, 2003), having low empathy (Hall \& Geher, 2003), 
developing somatic complaints, Post Traumatic Stress Disorder and other anxiety disorders, depressive symptoms (Kaufman \& Cicchetti, 1989; Salinger, Feldman, Hammer, \& Rosario, 1993; Stafford, Zeanah, \& Scheeringa, 2003) and externalizing behaviors, substance abuse, and criminal behavior (Clausen, Landsverk, Ganger, Chadwick, \& Litrownik, 1998; Dozier et al., 2006). Furthermore, they suffer from more cognitive deficits and academic difficulties than non-traumatized individuals (Eckenrode Laird, \& Doris, 1993; Egeland, Sroufe, \& Erickson, 1983; Dozier et al., 2006; Shonk \& Cicchetti, 2001).

While there is a great deal of research on the impact of abuse, little attention has been given to the other experiences of children who have been removed from their homes (Brady \& Caraway, 2002). Brady and Caraway (2002) contend that in addition to the trauma related to abuse and neglect, those individuals who have been removed from their families' care are likely to have had a number of additional traumatic experiences in the context of their community and in foster care (particularly in residential treatment) that impact their current functioning. These experiences include witnessing violence, losing primary caregivers, decreased contact with siblings and other family members, and frequent moves in schools and placements (Albus \& Dozier, 1999; Sprang, Clark, Kaak, \& Brenzel, 2004; Vacca, 2008). Because these children are either temporarily or permanently parentless and have experienced such pervasive trauma, their ability as an adolescent to take guidance from caring adults is compromised (Peacock \& Daniels, 2006). For these individuals, developing social support from other caregivers, peers, and people within the school setting is more challenging due to their abuse experience (Schwartz \& Davis, 2006) but plays an increasingly important role in fostering their 
feelings of security, safety, and trust with adults (i.e. decreasing trauma symptomology) (Brady \& Caraway, 2002; Catalano, Haggerty, Oesterle, Fleming, \& Hawkins, 2004; Greenberg et al., 2003; Seeman, Singer, \& Ryff, 2002). Although there is a growing appreciation for the high level of need among these individuals who: (a) have experienced severe early relational trauma at the hands of their caregivers, (b) have spent many years involved in the foster care system, and/or (c) have experienced multiple placements, the appreciation is, unfortunately, not matched by an accumulation of knowledge about the nature of the attachment and trauma-related disturbances these individuals exhibit or strategies for evidence-based intervention (O’Connor \& Zeanah, 2003; Wethington et al., 2008).

The varied terms in the literature to describe this population (those with attachment disorder, attachment problems, insecurely attached), although increasingly used, have no clear, specific, or consensus definitions. There is no official "attachment disorder" as such in the Diagnostic and Statistical Manual of Mental Disorders (DSM) or International Classification of Diseases (ICD), but "the term is not arbitrary. It refers to a fairly coherent domain of severe relational and behavioral problems" resulting from early caregiving trauma (Chaffin et al., 2006). A recent (2006) Task Force report on attachment related issues by the American Professional Society on the Abuse of Children (APSAC), indicated that these terms are often applied to individuals "who are maltreated, particularly those in the foster care, kinship care, or adoption systems" and therefore include the adolescent population in residential treatment (Chaffin et al., 2006, p. 76). The narrower, more tightly defined, and official diagnosis of Reactive Attachment Disorder or RAD is described in the DSM-IV-TR (American Psychiatric Association, 
2000). The essential feature of Reactive Attachment Disorder (313.89) as defined in the DSM-IV-TR is "markedly disturbed and developmentally inappropriate social relatedness in most contexts that begins before age 5 years and is associated with grossly pathological care (Criterion A)." There are two presentation types, Inhibited Type (in which the child persistently fails to initiate and to respond to most social interactions in a developmentally appropriate way) and Disinhibited Type (in which there is a pattern of indiscriminate sociability with marked inability to exhibit appropriate selective attachments, lack of appropriate physical boundaries, lack of stranger wariness) (American Psychiatric Association, 2000; O’Connor \& Zeanah, 2003).

Because diagnosing RAD according to the DSM-IV-TR criteria "is often a difficult process due to problems with differential diagnosis as well as disagreement among professionals regarding the etiology of RAD" (Sheperis et al., 2003, p. 292), the adolescent population of interest for this study may or may not have this formal diagnosis. Sheperis, Renfro-Michel, and Doggett (2003) assert that RAD symptoms mimic those of many childhood disorders found in the DSM-IV-TR and according to these researchers, "not only can we attribute RAD's symptoms to another disorder, but RAD is often overlooked as a possible diagnosis for children who are potentially meeting it's criteria" (Sheperis et al., 2003, p. 292). Several researchers suggest that a formal recognition of the complex mixture of symptoms and patterns of RAD and other attachment and trauma related disturbances be addressed (Zeanah, 2002; O'Connor, 2003; Marvin \& Whelan, 2003; van der Kolk, Roth, Pelcovitz, Sunday, \& Spinazzola, 2005). Specifically, Marvin and Whelan (2003) found in their clinical work that a combination of RAD features and those of disorganized or other insecure attachment 
classifications (described below) are more common than a 'pure' version of either. As a result of increased study, it is likely that criteria for diagnosis of attachment related disturbance will change.

For purposes of clinical description and design of intervention goals, the most useful approach may be to think in terms of a complex spectrum of disturbance (Zeanah et al., 2002; van der Kolk et al., 2005). Therefore, the common thread that describes the adolescent population of interest is their experience of early childhood trauma in the context of their primary caregivers (i.e. abuse or neglect), their subsequent removal from their primary caregivers, and their current placement in a residential treatment center, all of which place an individual at high risk for attachment disorder (Gauthier, Fortin, \& Jeliu, 2004). Another common feature of the population was also confirmed by the APSAC Task Force; that is individuals who are maltreated as children show genuine and extreme behavioral and relationship disturbances throughout development and may be at risk for placement failures.

\section{Setting}

The treatment setting of interest for this study is residential treatment centers. In 1992 there were nearly 500 residential treatment centers in the United States serving over 27,000 emotionally disturbed children (Center for Mental Health Services, 1996, as cited in Brady \& Caraway, 2002). In 2006, the number had grown to an estimated 87,000 children and adolescents placed in an institution or group home, including residential treatment centers (USDHHS, 2009). States currently spend approximately 903 million dollars a year on residential care, almost as much as the billion dollars a year spent on 
family foster care (Bess, 2002). Care in these facilities is quite expensive; as such, there is pressure to account for an individual's placement in such a facility and to provide evidence of significant behavioral and emotional issues that are best addressed in such a restrictive setting (Hussey \& Guo, 2005). There remains a lack of research about the specific characteristics of children and their experiences within these facilities (Brady \& Caraway, 2002; Hussey \& Guo, 2005; Jones \& Lansdverk, 2006; Moses, 2000). Even so, the consensus among professionals and policymakers is that there are situations where placement in a residential facility is needed (Jones \& Lansdverk, 2006). Adolescents are placed in residential care, with its more restrictive and supervised environment, because of increasing behavioral and emotional difficulty. There is a positive linear relationship between level of restrictiveness and youth behavior problems. Behaviors of adolescents placed at this level of care often include chronic truancy, self-harm, physical aggression, property destruction, stealing, substance abuse, and sexual misbehavior. Many placed in residential care do not have parents or other healthy family members on which to rely. "The common denominator for the majority of children in the[se] program[s] is traumatic exposure, usually of a pervasive and interpersonal nature" (Peacock $\&$ Daniels, 2006). As a result, it is a priority for administrators, funding sources, and mental health professionals to better understand how to most effectively treat the individuals who are placed in this setting, but again, very little empirical data have been collected to provide this understanding (Brady \& Caraway, 2002; Hussey \& Guo, 2005; Jones \& Lansdverk, 2006; Moses, 2000).

The history of care in residential treatment is filled with recurring debates about the goal of residential treatment, the etiology of the problems that bring children to the 
treatment, and the most effective therapeutic approach to use. Post World War II, care generally focused "blame" for bad behavior on the child, rather than the environmental stressors such as neglect or abuse (Peacock \& Daniels, 2006). Additionally, the psychoanalytic emphasis on the separation of individual treatment from the other components of the program led to the often fragmented services that continue to occur in residential treatment (Abramowitz \& Bloom, 2003). In recent decades residential treatment centers added components such as clinical treatment, medical care, recreational activities, and occupational therapies, to the already existing school and group living components, in order to meet the increasingly complex needs of children in care (Abramowitz \& Bloom, 2003; Jones \& Lansdverk, 2006). Unfortunately, the treatment and behavioral management approaches among these disciplines (i.e. clinical, medical, recreational, educational) often remain isolated and disconnected. In the therapy components of treatment in residential care, the psychoanalytic approach was generally replaced by behavioral interventions and contingency management efforts, but even among clinical therapy teams there are often disagreements about what specific therapeutic orientation is most suitable for this population. Debate also occurs related to how much, if at all, adolescents should be in contact with their families while placed in residential treatment. Residential treatment centers have not adequately assessed the degree to which they encourage family involvement and the extent to which this affects post-discharge outcomes (Nickerson et al., 2006). In findings from their study of family involvement, Nickerson (2006) and her colleagues further indicate that stakeholders in residential treatment centers differ in their perceptions about reasons for placement and 
the importance of specific treatment goals. Consequently, few residential treatment centers can articulate a clear, cohesive treatment model (Wells, 1991).

Complications arise because each of these approaches is based on theories that contain different underlying assumptions. For example, many individual approaches follow the medical model, which assumes that "sick" youth have an internal, mental disease and should be passive recipients of expert treatment. In contrast, the group, milieu, and therapeutic community approaches adhere to a model which assumes that the resident's problems stem from the interaction between the individual and the environment and that the youth themselves are capable of active, responsible participation (Abramowitz \& Bloom, 2003).

So, one very understandable but problematic issue is that residential treatment centers historically do not have an overarching theoretical model for the care they provide. There is an effort, however, to use more empirically based treatment. For example, Kalke and his colleagues (2007) recently explored evidence-based practices that emphasized positive approaches to modifying behavior and promoting growth that focused on collaborative, respectful, and strength-based relationships with the emotionally disturbed children in residential care. They found a reduction in the use of safety holds and in the use of out-of-class support referrals. Overall, though, it is remarkable, "in spite of two decades of extensive reform efforts to treat children in the least restrictive environments, residential treatment remains a prominent and understudied treatment option along the continuum of care" (Hussey \& Guo, 2005).

Although a number of attachment-based treatment approaches have been developed that purport to help this population, the benefits and risks of many attachment related treatments remain scientifically undetermined (Chaffin et al., 2006; Marvin \& Whelan, 2003); even so, it is beginning to be recognized that this population's treatment 
should be focused in relationships, rooted in attachment theory (Becker-Weidman, 2006; Chaffin et al., 2006; Moses, 2000; Wilson, 2001), and, most recently, within a traumainformed framework (Abramowitz \& Bloom, 2003; Pearlman \& Courtois, 2005; Rivard, 2004).

\section{Theoretical framework}

\section{Attachment Theory}

At least since Freud, the field of psychology has recognized that the infant-mother relationship is pivotal to the child's emerging personality. Studies have clearly demonstrated the importance of early mother (and father)-infant interactions for healthy development (Armstrong et al., 2000; Bakermans-Kranenburg, Van IJzendoorn, \& Juffer, 2005; Bates \& Dozier, 2002; Lyons-Ruth et al., 1990; Nylen, Moran, Frankline, \& O'Hara, 2006; Wan \& Green, 2009). In 1954, as a result of his work in a London child guidance clinic (as well as his personal experiences of losing his loving nanny at eighteen months, his governess at age four, and being sent to boarding school at age eleven), John Bowlby began putting forward his viewpoint about how best to diagnose and treat psychological disorders in childhood, stressing the innate importance of the child's relationship with his primary caregiver (Bowlby, 1969, 1982; Blum, 2004). Also, impressed by the effects of separation in children who were moved to the physical safety of the country during the London Blitz of World War II, as well as primate research, Bowlby became the pioneer of attachment theory.

Bowlby $(1969,1982)$, defined attachment from a bio-evolutionary perspective, concluding that attachment is a fundamental need based in biology and intimately related 
to the survival of the species. It is an affective bond to a specific figure (e.g. mother, father, other primary caregiver) characterized by a set of behaviors designed to achieve proximity, security, safety, and affective regulation (Bowlby, 1982; Schore, 2001). "Most parent-child relationships can be viewed as an intricate, reciprocal 'dance' composed of each partner's signals and responses to the other's signals" (Marvin \& Whelan, p. 286, 2003). Bowlby believed that in order to stay connected to a caretaker (usually the mother), a child develops organized patterns of coping with her personality, including making great cognitive distortions and emotional sacrifices, if need be (Coates, 2004). For example, when a child depends on an adult for nurturance, safety, love, and connection, he or she should not be taking a risk (Saakvitne, Tennen, \& Affleck, 2003), but if the caregiver is inconsistent because of her own mental illness, substance abuse, or involvement in a domestically violent partnership, the child does, in fact, risk being betrayed when asking (crying) for something and getting no response (Stafford, Zeanah, \& Scheeringa, 2003.) Even worse is if the child gets an abusive response from the person who is also the provider of basic needs and the one who is supposed to be there to assist in emotional soothing (Bakermans-Kranenburg et al. 2005; Dozier et al., 2006). A child does not, however, typically have only one attachment relationship. Bowlby (1982) offered that infants and young children routinely form multiple attachment relationships that are arranged hierarchically with a preferred attachment figure to whom he or she will turn in times of distress if that person is available. The presence of a responsive, nurturing caregiver helps regulate the infant's arousal state and emotions, resulting in the infant's expanding and growing capacity to learn the skills necessary for self-regulation and the ability to cope with stress (Schwatrz \& Davis, 2006; Sroufe, 1996). In the context 
of a secure attachment, children are thus likely to be better equipped to regulate their own emotions. As the child develops, attachment bonds increase in number and this continues across the lifespan. Insecure attachment, however, that develops in children with early relational trauma, histories of maltreatment, and disruptions in relationships, has been shown to put an individual at considerable risk for both internalizing and externalizing behavior problems (Kennedy \& Kennedy, 2004). Children who are maltreated exhibit poor self-esteem and self-regulation, poor peer relations, and developmental and cognitive delays (Aber, Allen, Carlson, \& Cicchetti, 1989; Dozier et al., 2006; Schwartz \& Davis, 2006).

Bowlby (1969) referred to an internal working model that evolved from the infant's early experiences. In early attachment experiences, the child learns what expectations to have of what will happen when he or she is vulnerable and in need. The internal working model reflects these interpersonal perceptions, attitudes, expectations, and beliefs about the self, others, and the world. Tobin and his colleagues (2007) studied the internal working model described by Bowlby (1969) through early recollections of children and adolescents diagnosed with RAD and found the following major themes: a view of self as alone, others as hostile or abandoning, and events as unfair or frustrating. Lastly, another extremely valuable contribution from Bowlby's (1954) understanding of diagnosis and treatment is his explicit emphasis on the importance of evaluating symptoms as symptoms. "There has been a tendency to stress the symptom too much in the past so that it has sometimes come to be regarded almost as the illness itself rather than as a particular manifestation of a more general disturbance with the total personality of the child" (p. 62). 
Attachment theory further progressed through the innovative research work of Ainsworth and her colleagues (1978). Ainsworth (1989) added that "the defining characteristic of an attachment bond is that it is marked by one person seeking a sense of security from the other. If the seeker is successful, and a sense of security is attained, the attachment bond will be a secure one. If the seeker does not achieve a sense of security in the relationship, then the bond is insecure." In 1978, Ainsworth and her colleagues developed a laboratory procedure known as the 'Strange Situation' which involves two short separations from the mother while the young child is left with a stranger. The child's behaviors are then observed and the quality of attachment is classified. Ainsworth and her colleagues (1978) described three basic patterns of attachment: securely attached (those who actively seek out contact with their mothers and are easily comforted by her), avoidant (those who demonstrate a clear avoidance of their mother and may appear to be more comforted by the stranger), and resistant (those who initially seek contact with their mothers, then turn away from her, and who may appear angry toward the mother and the stranger.) Strange Situation classifications of attachment are not clinical diagnoses of psychopathology. Rather, insecure attachment (avoidant or resistant attachment) is a risk factor while secure attachment is a protective factor associated with increased or decreased probability of maladaptation (American Academy of Child and Adolescent Psychiatry, 2002). Secure attachment provides the growing child the trust and ability to regulate emotion and develop cognitive self-reflecting capacities. Ultimately, insecure attachment cannot be equated with psychopathology but it must be regarded as an important vulnerability factor (Svanberg, 1998). 
Main and Solomon (1990) later added a fourth pattern of attachment behavior called disorganized/disoriented attachment. When observed, these young children seemed to have no clear strategy for responding to their caregivers. Main and Hesse (1990) originally hypothesized that disorganized infant attachment behavior arises when the baby regards the attachment figure herself as frightening. This has been subsequently confirmed in an important meta-analysis by Bakermans-Kranenburg and her colleagues (2005). The risk factors associated with the development of this type of insecure attachment include child abuse, neglect, and extremely inconsistent caretaking (Juffer, Bakermans-Kranenburg, \& van Ijzendoorn, 2005). Associations between specific family phenomena and attachment disorganization have been established in several studies. In samples of maltreated children, a disproportionate number of infants appeared to be classified as disorganized (Cicchetti \& Barnett, 1991; Lyons-Ruth, Connell, Grunebaum, Botein, 1987); parental unresolved loss or trauma appeared to be significantly associated with infant disorganized attachment (Van Ijzendoorn, 1995); and the link between frightening or frightened parental behavior and disorganized attachment has been tested and demonstrated (Bakermans-Kranenburg et al., 2005). Many studies have also demonstrated a higher incidence of disorganized/disoriented attachment patterns in infants whose mothers report high levels of intimate partner violence (Larrieu, Heller, Smyke, Zeanah, 2008) and infants whose parents abuse alcohol and other substances (Edwards, Eiden, \& Leonard, 2004; Larrieu et al., 2008; Lyons-Ruth \& Jacobivitz, 1999). Furthermore, parental depression is suggested as a precursor of attachment disorganization (Teti, Gelfland, Messinger, \& Isabella, 1995; Toth, Rogosch, Manly, \& Cicchetti, 2009). In the research review on disorganized attachment, Bakermans- 
Kranenburg et al. (2005) demonstrate how this type of insecure attachment is predictive of problematic stress management, an elevated risk of externalizing behavior problems, lower emotional health at school age, and dissociation in adolescence. Given the critical function of the caregiver, it is not surprising that loss of or abuse by the caregiver is associated with dysregulation, or a breakdown in normal functioning of behavioral and biological systems for the child (Dozier et al., 2002). Patterns evolved from insecure attachment, particularly disorganized attachment, are evident in the adolescent population of interest in this study, including having parents with many of the behaviors and circumstances indicated as problematic. It is clear how attachment theory informs the understanding of adolescent beliefs about self and others and the resulting behaviors seen in residential treatment because they have experienced abuse and neglect in their primary relationships. Most in this population have also experienced multiple changes in caregivers which places them even further at risk for these attachment related issues (Brady \& Caraway, 2002; Svanberg, 1988).

\section{Biological Research}

There are two important points that can be gleaned from biological and neuropsychological research that serve to additionally inform the understanding of treatment for adolescents who have experienced early trauma in the context of primary caregiving relationships and build upon attachment theory. First, from a neurological perspective, the neuronal connections that are formed during infancy and early childhood as a result of experiencing a safe, nurturing environment become the foundation for many later abilities. In fact, research extended to humans that developed from work with primates who were experimentally "neglected" describes how there are distinct brain 
differences between subjects that were nurtured and those who were not. The clinical observations of Bowlby $(1969,1982)$, Ainsworth and her colleagues (1978), Main and Solomon (1990) and others continue to be reinforced by extensive experimental biological research. The second important point is that neuropsychological research demonstrates the extensive change and development that occurs during adolescence.

Several features of the non-human primate literature deserve special attention. One notable feature is the concept of developmental timing. For example, the timing of maternal deprivation in rhesus monkeys revealed higher rates of disturbance (i.e. fear and lack of comfort seeking) among those monkeys who experienced the earliest deprivation (Cameron, 2004 as cited in O'Connor \& Cameron, 2006). A more marked effect was that the type of disturbance differed qualitatively. Monkeys who experienced separation at 1 week displayed severe social disturbances not found in any other group. For example, the monkeys who experienced disruption (removal from their mother) at 1 month of age sought social comfort when anxious and were hyper-vigilant of social cues, but the monkeys who experienced disruption at 1 week of age did not seek social comfort at all and fear behaviors increased. These disturbances "were reflected in lasting changes in brain anatomy in the prefrontal cortex and lasting changes in gene expression in the amygdala [an area of the brain associated with fear-related memory and known to be involved in stress induced anxiety behaviors]" (Ledoux, 1996; McEwen, 2003; O'Connor $\&$ Cameron, 2006, p. 177). The amygdala, for humans and primates, is an important brain site for the activation of both behavioral and physiological stress responses. Chemical imbalances in neurotransmitters that involve the amygdala and related brain areas can be the cause and/or the result of fear and traumatic experiences (McEwen, 2003). For 
humans, this is particularly important given the role of the amygdala in the interpretation of emotions and subsequent emotional learning. Early traumatic experiences create states of chemical imbalance and can bias the ways in which the amygdala performs (McEwen, 2003).

In a study of marmoset monkeys, Pryce and his colleagues (2004) found that monkeys who were exposed to early isolation had elevated dopamine and dopaminelinked behavioral inhibition. O'Connor \& Cameron (2006) indicate that other groups doing similar research found a consistent pattern emerging, in which early deprivation had varied effects on serotonin, norepinephrine, and dopamine systems which have documented links with a range of social relationship deficiencies (Winslow, 2005). Low brain serotonin in humans is linked to impulsive aggression, suicide, and alcohol and substance abuse (McEwen, 2003). Moreover, a history of abuse and neglect interferes with the normal functioning of the HPA [hypothalamus-pituitary-adrenal] axis, resulting in altered circadian rhythm and reduced cerebral volume. The effects can be long-lasting, "leading to exaggerated HPA responses to challenges, hippocampus atrophy, and cognitive impairment in adulthood" (McEwen, 2003, p. 152). In other words, the biological effects of trauma and other childhood adversities are very broad and do not appear specific for any one type of psychiatric or other disorder, but it remains very important that the breadth and strength of the effects of such early life trauma be appreciated along with the behavioral manifestations (McEwen, 2003). It is equally important to note that these problems that are caused by unstable or abusive caregiving in childhood are not necessarily irreversible. There is evidence that social support in the form of loving and caring relationships later in life appear to have powerful ameliorative 
effects to lower cumulative physiological burden and reduce allostatic load, defined as the "cost" or "wear and tear" on the body produced by repeated activation of stressresponses (McEwen, 2003; Seeman et al., 2002).

Secondly, neuropsychological research demonstrates that adolescents' brains are very much still 'works in progress,' and continue to change in important ways throughout early and late adolescence (Casey, Guidd, \& Thomas, 2000; Nelson et al., 2002). In fact, adolescence is characterized by more biological, psychological, and social role changes than any other stage of life except infancy (Holmbeck \& Kendall, 2002; McClure \& Pine, 2007). Several recent studies show the marked structural and neural changes that occur throughout the brain between childhood and adulthood (Giedd, 2004; Sowell et al., 2004). Longitudinal studies with humans using contemporary non-invasive neuroimaging methods have provided evidence of linkages between brain maturation and increases in cognitive competencies and show that cognitive milestones in development match the sequence in which the cortex matures (Alloy \& Abramson, 2007). Developmentally, regions of the brain serving primary functions such as motor and sensory systems mature earliest, and higher-order areas, such as the prefrontal cortex, mature more slowly, and not completely, until early adulthood. The prefrontal cortex is responsible for integrating sensori-motor processes and control executive functions such as reasoning, planning, communicating, attention, memory, and decision-making (Alloy \& Abramson, 2007; Sowell et al., 2004) Neurologically, beginning at about age twelve, frontal lobe gray matter volume, representing dense concentrations of neuronal cell bodies, begins to decline following a rise throughout childhood (Giedd, 2004). Gray matter loss during adolescence is thought to involve synaptic pruning and the elimination 
of connections that are not needed (Alloy \& Abramson, 2007). Associated with the loss of gray matter, white matter in the prefrontal cortex increases in volume throughout adolescence and may reflect increased myelination of axons which enables them to conduct electrical charges more quickly and effectively. The gray matter reduction and white matter increase occur in parallel, suggesting that connections are being fine-tuned during this ever-changing time in development (Alloy \& Abramson, 2007). Thus, the period from late childhood to early adolescence may represent a 'window of opportunity' to implement programs that prevent developing adolescent psychopathologies from reaching adulthood (Alloy \& Abramson, 2007; Chang, Gallelli, \& Howe, 2007).

It is also clear that the period of adolescence is marked by heightened vulnerability for affective dysregulation and distress, likely caused by the stressful biological and social transitions that characteristically occur during this time (McClure \& Pine, 2007). The regions of the brain engaged by reward and punishment, and responsible for the evaluation of emotional significance of relevant stimuli, appear to undergo relatively abrupt changes in functioning with puberty and the associated changes in hormone production (McClure \& Pine, 2007). As a result, research that integrates biological and social perspectives appears to be critical if we are to understand why adolescence is such a risky period for the onset of psychopathology (Nelson et al., 2002), and/or a "window of opportunity" (Alloy \& Abramson) to effectively treat the effects of early childhood trauma. 


\section{Constructivist Self-Development Theory}

The knowledge provided by attachment theory and biological research undoubtedly indicates that a trauma framework is essential to further understand how to effectively interact with and treat the adolescents of interest in this study. Understanding historically how trauma has been viewed within the psychology field, as well as how trauma theories have developed over time, also provides a foundation on which to treat these vulnerable individuals. The theory of trauma and adaptation known as Constructivist Self-Development Theory (CSDT) is helpful in conceptualizing effective care and treatment for those who have experienced childhood physical and sexual abuse, neglect, ongoing exposure to familial and community violence, and removal from caregivers, such as the adolescents of interest in this study. This is also the underlying theory of both the teacher intervention (Risking Connection) and the trauma symptomology measure (Trauma \& Attachment Beliefs Scale) used in this dissertation. Although both CSDT and the Risking Connection curriculum have strong clinical and theoretical support (discussed below), both are only beginning to be empirically evaluated. Building this research support was another important reason to do this study.

\section{History}

Historically, there have been different understandings of the effects of trauma, what constitutes a traumatic event, and approaches to its treatment. "As social and behavioral scientists we are asked to explain the behavior of those affected by traumatic life events and to account for individual differences in response to trauma. We are also asked to help those suffering the pain of traumatic stress and loss. Both the challenges 
and the stakes of these are great" (Saakvitne et al., 1998, p. 180). Beginning with Freud who initially hypothesized that hysterical symptoms were representations of repressed memories of abuse, he later dismissed his patients' sexual abuse recollections as mere fantasies of unacceptable oedipal longings. This reversal from acknowledging traumatic abuse to dismissing it influenced the field for many decades. "The problem of childhood sexual abuse remained largely hidden for many years until the two world wars renewed interest in the psychological impact of extreme stress" (McCann \& Pearlman, 1992b, p.186). After observing that many WWI veterans experienced nightmares and startle reactions, Freud (1920) acknowledged that a trauma of a certain magnitude would affect almost anyone who was exposed to it. Freud (1939 as cited in McCann \& Pearlman, 1992b) described the tendency to re-experience a trauma as an attempt to master it, thus integrating notions of the repetition compulsion into theories of trauma. He also introduced the use of denial as a defense against the painful emotion that accompanies repetition. This original thinking continues to influence how professionals conceptualize the effects of trauma and its treatment (McCann \& Pearlman, 1992b).

As a result of the Vietnam War and the feminist movement's focus on violence against women, a renewed interest in trauma emerged. Indeed, a number of theorists (Horowitz, 1975; Roth \& Cohen, 1986; van der Kolk et al., 2005; Wilson, Friedman, \& Lindy, 2001) have attempted to explain how trauma results in the cycling of reexperiencing symptoms (i.e. nightmares and flashbacks), denial or avoidance, and symptoms of hyper-arousal (i.e. startle responses and over-activity.) The process of reexperiencing and denial, depending on the individual's needs at the time, are viewed by many as a hallmark of trauma (McCann \& Pearlman, 1992b; Wilson et al., 2001). Epstein 
(1985) formulated how trauma disrupts a person's schemas, which are beliefs and assumptions about the self, other people, and the world. This disruption of schemas produces a state of disequilibrium and therefore the individual must develop a modified theory of reality. Saakvitne and her colleagues (1998) as well as others (Cooper at al., 2007; Rivard, 2003; van der Kolk et al., 2005) acknowledge the many factors that contribute to the uniqueness of an individual's response to trauma, including the particular meaning ascribed to the trauma, the individual's experience of self, age and developmental stage, biological and psychological resources, interpersonal experiences and expectations, and his or her social, cultural, and economic milieu. The literature clearly indicates that not all victims experience the same responses and that some fare better than others. As a result, McCann and Pearlman (1992a) began asking questions about these differences in response patterns, wondering if they have to do with an individual's pre-trauma history or to the unique characteristics of the trauma experience. As interest in the field of traumatic stress has grown, the need for a theory that explicitly addresses the impact of trauma on self-development emerged. These concepts as well as the interest in why some trauma survivors "are shattered by their victimization and others

are able to resolve their experiences" influenced Constructivist Self-Development Theory (CSDT) (McCann \& Pearlman, 1992a, p. 189).

\section{Major Concepts of CSDT}

CSDT describes personality development as the interaction between selfcapacities related to early relationships or attachments, ego resources, and constructed schemas related to the meaning attributed to cumulative experiences (Saakvitne et al., 1998). Assumptions of this theory include: (1) individuals construct their own realities; 
(2) the self develops over the life-span within a particular social and cultural context; (3) the psychological needs that motivate behavior and are shaped through experience are safety, trust, esteem, control, and intimacy; and (4) cognitive schemas are beliefs and expectations about the self and others. The cognitive portion of CSDT parallels the trauma theories of other contemporaries (Epstein, 1985; Horowitz, 1986; Janoof-Bulman, 1989; Roth, 1989) but extends trauma theory by describing both distinct and overlapping schemas about self and the world that are most vulnerable to disruption as a result of severe trauma. CSDT emphasizes the influence of the individual's developmental, social, and cultural contexts and, therefore, the adaptation to trauma involves a complex interplay between life experiences and the developing self (Saakvitne et al., 1998). The meaning of the traumatic event is in the survivor's experience of it. For example, in response to an acute adult trauma, changes are more likely to be short-term and modified over time because of the strength of previously existing lifelong beliefs. Recurrent traumas in childhood, however, lead to beliefs that are protective in some way. Beliefs developed in childhood are reinforced, and therefore highly resistant to change, because they have helped the young person make sense of his or her experience and protect him or her from unbearable truths or feelings. "When it is unbearable to be helpless as a witness and victim of abuse, a child may come to believe, 'If I were smarter, I could have protected my mother and me from my father's beatings' and deny the belief that 'there was nothing I could have done because I was too small and helpless as a child"' (p. 284).

\section{Cognitive Schemes}

Major concepts underlying CSDT are also derived from Jean Piaget's cognitive development theory. Specifically, as individuals develop, their cognitive structures 
become increasingly complex and differentiated through the processes of assimilation and accommodation. Assimilation is the process of responding to a new event in a way that is consistent with an existing scheme (belief); whereas accommodation is the process of responding to a new event by either modifying an existing scheme (belief) or forming a new one (McDevitt \& Ormrod, 2009). For example, as described by McCann and Pearlman (1992a) and espoused in Bowlby's (1969) attachment theory, when a child consistently experiences interactions with adults who are responsive to his or her basic needs, these experiences are gradually assimilated in a way that shapes generally positive schemas (or internal working model) about the self and the world. The child believes that his or her needs are acceptable and he or she can depend on others to help meet those needs. When a child encounters other people who frustrate or hurt him or her, on the other hand, this creates a need to modify positive schemas (or the internal working model). If a child is beaten, sexually molested, or otherwise badly hurt or neglected by a family member, this experience cannot be readily assimilated. The child needs to modify previous schemas through the process of accommodation. The child may then believe that only some of his or her needs are acceptable or develop a new belief that he or she cannot always depend on others. On the other hand, for the individual who experiences very early childhood trauma, he or she has already developed beliefs about the self and the world that are based in experience, i.e. the world is unsafe and unpredictable, and I am not worthy of having my basic needs met. The child's frame of reference has incorporated the traumatic experiences. According to CSDT, these schemas may be conscious or subconscious, generalized or specific, and disrupt one's ability to meet central psychological needs. Disrupted or over-generalized schemas generally have a 
defensive value in that they protect an individual from both painful emotions and traumatic memories. Healthy early childhood development results in an individual with solid self-esteem and the capacities to tolerate strong affect, to modulate emotion, and to be alone without being lonely.

\section{Psychological Needs}

The psychological needs that motivate behavior and are shaped through experience described by CSDT theory are safety, trust, esteem, control, and intimacy. Our needs shape our perceptions of events (Pearlman, 2003). CSDT postulates that the areas of greatest sensitivity for each individual are those which were inadequately gratified in early childhood. "As imperfect parenting is inevitable, not all needs are met with perfection. Thus, almost everyone has some vulnerabilities related to psychological needs" (p. 28). Understanding these needs and how they are transformed cognitively in the context of self and others after experiencing trauma is a useful framework for those treating survivors of childhood abuse and neglect.

Safety. It is fundamental to psychological well-being to believe that one is safe. It is this primary and central need that is most often disrupted by traumatic life events. McCann and Pearlman (1992b) describe the following positive safety schemas: belief that one can protect oneself from physical and emotional harm, injury or loss, and that the world is fundamentally a safe place. Disruptions in safety arise from experiences of violation or credible threats of violation of one's body, home, property, or loved ones (Pearlman, 2003). For survivors of childhood abuse, there may be so many stimuli associated with danger that safety schemas become over-generalized and pervasive. The 
behaviors that were originally adapted as a defense against danger may persist into later years and interfere with functioning. Affect regulation is often difficult for trauma survivors (Pearlman \& Courtois, 2005) and survivors may at times be overwhelmed with strong feelings like rage, terror, or grief. As a result, difficulties with affect management can lead to concerns about harming oneself and harming others (Pearlman, 2003).

Trust. The psychological need to feel understood and respected by others is related to trust schemas. McCann and Pearlman (1992b) describe the following positive trust schemas: belief that one can rely on one's own perceptions and judgments, and the belief that one can rely upon the word or promises of other people. Betrayals and violations by early caretakers make trust an extraordinary developmental task for many survivors because trust schemas are developed through early childhood interactions (Bowlby, 1969; Svanberg, 1998). Disrupted trust follows from experiences of abandonment, betrayal, broken promises, and extreme unresponsiveness (Pearlman, 2003). Individuals with over-generalized negative trust schemas often maintain a suspicious, guarded stance toward other people as a way of protecting themselves from future violations and have chronic interpersonal difficulties. The feeling states most associated with disturbed trust schemas are self-doubt and feelings of chronic anger, disappointment, betrayal, or bitterness toward others (McCann \& Pearlman, 1992a).

Control. The need to direct or control forces outside oneself is another fundamental human need that is often disrupted after experiencing trauma. Positive control schemas involve the belief that one can affect future outcomes in interpersonal relations or take a leadership role in a group. Disruptions in the need for control are often associated to traumatic experiences in which one was unable to help while others 
suffered, as when a child must watch siblings or parents take abuse or being forced to collaborate in administering harm to others (Pearlman, 2003). Disturbed needs for control are often reflected in interpersonal conflicts related to aggression as a defense against vulnerability or grief. The related feeling states are weakness, helplessness, and depression. "Here one may observe a learned helplessness pattern, a concept originally conceived by Seligman (1975) and later applied to victims of domestic violence (Walker, 1978)" (McCann \& Pearlman, 1992b). Another manifestation of disturbed control schemas is the belief that one must control or dominate others before being dominated.

Esteem. Esteem schemas are reflected in the basic human need to be recognized and validated. Experiences that inhibit the development of positive self-esteem or damage it are characterized by degradation, humiliation, and rejection (Pearlman, 2003). McCann \& Pearlman (1992b) describe the following positive esteem schemas: the belief that self and others are valuable and worthy of respect, whereas disrupted esteem schemas include: the belief 'I am bad, flawed, or damaged' and feelings of despair, self-loathing, and worthlessness. Regarding others, disturbed esteem schemas are associated with cynicism, contempt, and anger. Behavioral manifestations may include antisocial life patterns or general withdrawal from the world.

Intimacy. As also indicated in attachment theory, human beings have a fundamental need for connection to other human beings (Bowlby, 1969). Positive intimacy schemas related to the self may include the beliefs that one can be alone without being lonely or empty and be a friend to oneself. With regard to others, positive intimacy schemas including being able to connect with others in a meaningful way. Experiences that give rise to disruptions in intimacy include the loss of an important attachment 
figure, alienation from others (i.e. when a sexual abuse perpetrator tells the victim he or she is special or different) and loss of community (i.e. an individual being taken from his home or family without explanation or preparation) (Pearlman, 2003). Disturbed intimacy schemas are often manifested in panic when one is alone or in an overreliance on drugs, alcohol, sex, food, self-mutilation, vomiting, spending money, or other addictive or compulsive behaviors as sources of inner comfort and calm (Horner, 1986 as cited in McCann \& Pearlman, 1992b). With regard to others, disturbed intimacy schemas may include reporting having friends but nonetheless chronically feeling alone and alienated. The feeling states associated with these disturbed schemas are a pervasive sense of emptiness, loneliness, alienation, or estrangement. "In essence, individuals have given up on the interpersonal world and can find little comfort in human connection" (McCann \& Pearlman, 1992b, p. 200).

\section{Inter-relationship of Schemes, Needs, and Experiences}

With each of these areas, it is important to understand their inter-relationship and adaptive significance. For example, regarding intimacy,

some survivors will reveal fears that if they allow themselves to feel connected to others, that others will die, go away, or otherwise abandon them. This may relate to beliefs that other people are basically unreliable or that the individual is unworthy of loving and care. Other survivors' fears of intimacy may relate to an inability to set boundaries between self and others and the related fear of being overwhelmed or of dissolving if they become too close to another person (p. 200).

Based on their histories of abuse and neglect by their primary caregivers and the subsequent removal from their home, it is not difficult to understand why the adolescents in residential care generally believe that adults will hurt, betray, violate, abandon, overpower, or otherwise re-victimize them. This belief is 
transferred to most relationships they encounter in residential treatment. The schemas described above developed originally as a way of making sense of painful and incomprehensible situations, and, therefore, have adaptive value for the individual. They often serve to protect the adolescent from some emotion or experience that is viewed as dangerous. Viewing these behaviors through the lens of a trauma theory such as CSDT can be the first step in honoring an adolescent's journey in healing. Without such a framework, adolescents who are acting out may be prematurely challenged and potentially re-traumatized by adults with good intentions. CSDT explains that the way individuals in treatment might transfer their disrupted schemas into new relationships are usually linked to the disturbed need areas that are most prominent for that individual. Pearlman (2003) describes how needs and experiences are linked:

A child who was betrayed and abandoned by his or her parents is likely to experience difficulties with trust. A child whose parents shamed and humiliated him of her is likely to experience difficulties with esteem. A child who was held captive and tormented will probably show disruptions in control. A child whose bodily integrity was threatened (which is true for most sexual and other physical abuse survivors) will experience disruptions in safety. A child who loses an important attachment figure will show disruptions in intimacy. These sensitivities will manifest as disrupted cognitive schemas in the various need areas. Note that these areas of disruptions are not mutually exclusive. Some survivors will exhibit elevations in multiple areas (Pearlman, 2003, p. 28).

Pearlman (2003) offers one way to explore the defensive value of disturbed schemas with survivors of abuse by repeatedly exploring the question, "What would it be like if you imagine allowing yourself to trust, to feel safe, connected, etc. in here with me?" With regard to disturbed safety schemas, adolescents will 
often express, in their own words, the conviction that these schemas enable them to remain vigilant and watchful. They may fear that letting down their guard will make them vulnerable to repeated violation. "In the words of one client who had seriously disturbed safety schemas, 'I would feel defenseless, like a turtle without a shell. What if I got too careless and the same thing happened again?'” (p.201). In a similar way, adolescents with disturbed trust schemas are often protecting themselves from being betrayed by others. The possibility of trust within the treatment setting may be perceived as dangerous because of the threat of making themselves too vulnerable again. This is particularly true for adolescents who have experienced multiple placements and are just waiting to be moved again. Thus, learning to trust is a process that must take place gradually. The angry or aggressive adolescent may be fearful that giving up this form of power will result in repeated victimization. Intimacy and attachment, having been associated with intense pain and hurt, may be far more threatening than enduring chronic feelings of alienation. Finally, a disturbed frame-of-reference, such as the belief that 'I am to blame for everything bad that happens,' may be adaptive in that it provides an illusory sense of control over events in one's life or may protect the survivor from overwhelming feelings of rage toward the perpetrator. Overall, CSDT creates a framework to understand basic human needs and how related schemas (or beliefs) are influenced by traumatic experiences. This therapeutic approach with trauma victims encourages as much involvement and engagement with the adolescent as possible without violating boundaries. "Most clients who have been severely traumatized want and need to experience a relationship with a real, warm, 
concerned human being who is actively involved with them in an empathic, responsive way" (p. 191).

\section{Risking Connection}

The foundation of attachment theory, CSDT, and neurobiological research discussed thus far are directly and/or indirectly linked to the intervention that was evaluated in this study, Risking Connection. Risking Connection is a training curriculum for working specifically with survivors of childhood abuse that is different than the traditional treatment model used in most mental health settings. It is a part of the recent trend that mental health systems are now recognizing a need for more specialized training to help these systems, including residential treatment centers, work effectively with clients who have histories of abuse and trauma (Saakvitne et al., 2003, p. xiii). Traditionally, work with survivors of childhood abuse and neglect has emphasized control of dangerous behaviors. The authors of the Risking Connection curriculum, Saakvitne, Gamble, Pearlman, and Lev (2003) assert that when control takes precedence over collaboration, use or overuse of physical or chemical restraints, locked doors, contracts, denial of privileges, and withdrawal of treatment occurs. This is typical of a traditional treatment system, the kind which had previously been used in the residential treatment center in this study (Maryhurst, Inc.). As mentioned earlier, the traditional model is a medical, or 'disease' model, in which the 'patient' will or will not be cured by the doctor. The patient's job is to follow the treatment plan that the professional authority developed and those who do not cooperate with or respond to the demonstrated treatment protocols are thought to be demonstrating 
signs of weakness or are labeled as resistant. Furthermore, the mental health professionals, or 'treaters' (as they are referred to in the Risking Connection curriculum), are not believed to be affected by working with the trauma survivors and if they show signs of distress, this is viewed as weak or unprofessional. The authors of Risking Connection acknowledge that not all traditional medical models are this extreme or reflect all of these beliefs and assumptions, but emphasize that the traditional model is oriented in this way.

\section{Components of the Risking Connection Curriculum}

The three areas emphasized in the Risking Connection curriculum are: (1) an overarching theoretical framework to guide work with trauma and abuse survivors; (2) specific intervention techniques to use with survivor clients; and (3) a focus on the needs of trauma workers as well as those of their clients.

Regarding the theoretical foundation of Risking Connection, two of the four authors of the curriculum, Laurie Anne Pearlman and Karen W. Saakvitne, also developed Constructivist Self-Development Theory (CSDT). As such, CSDT, already described in detail, is the framework for the curriculum. It emphasizes (1) the healing power of the relationship between the treater and the survivor; (2) views symptoms as adaptations (i.e., seeks to understand the meaning of behaviors rather than solely focusing on controlling them); (3) posits that crises can best be managed and eventually reduced through the development of 'feeling skills;' and (4) expects the work to have an impact on the treater that parallels the impact of trauma on the survivor (Saakvitne et al., 2003). Most importantly, this trauma framework assumes that just as people can harm each other 
deeply within their relationships, they can also help each other heal profoundly. As such, the Risking Connection curriculum emphasizes how relationships can be transformative, whether they are brief or long-term, whether in a one-to-one or in a group context. Finally, this relationship-building occurs in the context of hope. Because "connection requires hope, and hope always carries the risk of disappointment," clients (and treaters) are, indeed, taking a significant risk (p. xiii).

\section{Understanding Trauma}

The very first part of the training curriculum deals with understanding trauma. The authors argue that "working from a trauma framework and understanding clients and their symptoms in the context of their life experiences, their cultures, and their society is the most helpful, respectful, and empowering clinical model for helping childhood abuse survivor clients" (p. 1). They further offer their definition of psychological trauma (which can differ among experts). The RC curriculum and CSDT both emphasize an individual's subjective experience that determines whether an event is or is not traumatic. Thus, those using this curriculum learn that psychological trauma occurs "when [an event or situation] overwhelms the individual's perceived ability to cope, and leaves that person fearing death, annihilation, mutilation, or psychosis. The individual feels emotionally, cognitively, and physically overwhelmed. The circumstances of the event commonly include abuse of power, betrayal of trust, entrapment, helplessness, pain, confusion, and/or loss" (p. 5). Risking Connection specifically teaches the treater about trauma and also, as a specific strategy to help the client, encourages the treater to teach the adolescent survivor about trauma as well. Because clients often come with "huge holes in their understanding about both the effects of trauma and that which constitutes normal human 
development," this strategy helps the client change what she believes about herself and others (p. 43). The curriculum suggests the treater be alert to "teachable moments"- times when the client can use the specific information, dispute a belief, or when the treater can directly model a desired skill or offer a new perspective.

\section{Importance of Relationship}

Consistent with attachment theory is the assumption of the Risking Connection curriculum that the connection or relationship between the client and the treater is itself part of the clinical intervention. The survivor's healing takes place through and because of his or her caring relationships with others. In fact, the authors directly acknowledge the contributions of John Bowlby's attachment theory and research as how they conceptualize the profound impact of childhood abuse and neglect. The curriculum teaches how attachment plays both a psychological and physiological role in mental health by explaining that early attachment experiences shape how one views relationships, as well as the direct affect on one's ability to interpret and regulate emotions. The practical guidance provided by the Risking Connection curriculum begins with how to and why a treater must build a positive connection with the client. "The alliance you form with a client is your major clinical tool. Without an alliance, techniques will not work" (p. 35). A therapeutic alliance with a survivor of childhood abuse works in the following ways: (1) it contradicts the client's assumptions that all relationships will be abusive or exploitive; (2) when alliances last over time, the client can use them as a basis for forming a secure attachment, this can be to one person, a team, or to an agency or system; and (3) it diminishes the isolation experience by many survivor clients, i.e. "you don't have to do this alone" (p. 38). Using the acronym R.I.C.H., Risking 
Connection identifies the four components of a growth-producing therapeutic relationship: Respect (validation), Information, Connection, and Hope.

The authors further discuss the biological function of attachment. Consistent with the neurobiological research that supports attachment theory, the Risking Connection authors are informed by how nurturing decreases the neurological arousal that accompanies chronic fear. Unfortunately, "survivors of childhood trauma have the dilemma of having experienced both the overwhelming arousal of abuse, and the absence of adequate soothing and comforting" (p.19). Those trained in Risking Connection learn that healthy development occurs within the context of secure attachment, and a child gradually internalizes the external soothing and calming from caregivers, another specific strategy offered to help clients emotionally regulate. When treaters make it a priority to help the adolescent calm down physiologically and later help her understand and interpret her emotions, she is increasingly able to self-regulate and make connections between her past traumatic experiences and her current functioning.

The specific intervention techniques are clearly guided by the underlying framework; that is, symptoms are adaptations to terrible life experiences and therapeutic connections are the key to healing. Specific strategies include: prioritizing relationshipbuilding; directly teaching about the effects of trauma; providing assistance with and role modeling effective calming techniques; collaboration of treatment goals; and using what are called "restorative tasks" as a consequence when an adolescent has done something to harm a relationship. For example, if an adolescent becomes verbally aggressive in a classroom and then rips down a bulletin board, after being helped to calm herself and regulate her emotions, her restorative task might be to interview her teacher about how 
the disruption affected her ability to teach and remaking the bulletin board. The objective of the restorative task (which ideally is collaboratively created) is to connect the behavior to the natural consequence, particularly as to how it may have harmed a relationship. This encourages the adolescent and the treater to express how the event affected them. The treater might be encouraged to tell the adolescent, "Your behavior was frightening to the class and affected how much I can trust you. We can build back our trust if you explain a little to me about what you were thinking and feeling at that time and if I see that you did not mean to destroy part of our learning environment by putting it back together. Maybe I can even help you while we talk." The task might conclude with the client apologizing to the class in some way that relays her sincerity. In this way, the treater is keeping a trauma framework in mind during a crisis. In a traditional behavior-management approach, the same scenario could have resulted in the student being removed from the class, "punished" by some other staff that was not there when it happened, going to a time out room and losing a privilege. While this may seem reasonable, for adolescents with trauma histories this approach does not allow the client to gain an understanding of how their trauma affects their thoughts and behaviors, nor does it encourage relationshipbuilding and healing with the person(s) who the behavior affected the most.

\section{Safety}

Another key component emphasized in the Risking Connection curriculum is the importance of maintaining overall physical and emotional safety while establishing healthy boundaries with others. As discussed in CSDT, a sense of safety is one of the primary losses experienced by those who survive child abuse trauma, and therefore critically important to provide in a treatment setting. For this reason, the curriculum trains 
how to recognize and respond to dissociative episodes and flashbacks that are common for this population, and how to keep a trauma framework when responding to lifethreatening or other dangerous behaviors (Saakvitne et al., 2003). Some of the most distressing events working with the traumatized adolescent population described in this study are: self-injury and self-destructive behavior; dealing with clients' hostility, verbal and/or physical aggression toward the treater (e.g. the treater is perceived as a perpetrator of abuse); responding to clients' dissociations or flashbacks; and the frequency and intensity of these severe symptoms and crises. The trauma framework helps the treaters manage their own anxiety, keep events in context, and points them toward helpful responses to the clients' symptoms. Treaters focus on self capacity development such as (1) managing feelings (i.e., recognizing, tolerating, modulating, and integrating feelings); (2) building an inner connection to others; and (3) increasing self-worth (Saakvitne et al., 2003).

\section{Transforming Vicarious Trauma}

Finally, the Risking Connection curriculum includes a significant portion related to acknowledging and understanding vicarious trauma experienced by the treater. This term was first coined by McCann and Pearlman in 1990 at which time it was unusual to discuss the impact of trauma work on the treater. This concept and related ideas such as "secondary traumatic stress" and "compassion fatigue" has become increasingly acknowledged and researched within the medical and mental health fields, but not necessarily in education (Figley, 1995; Pearlman \& Saakvitne, 1995). It is assumed that vicarious trauma is an "inescapable effect of trauma work" and "the natural consequence of our being human, connecting to and caring about our clients as we hear about and see 
the effects of trauma in their lives" (p. 157). Treaters cannot influence change in and meet the needs of the adolescents of interest in this study if they ignore their own needs, levels of stress, and emotional experiences. When this is ignored, treaters are more likely to respond to clients in ways that create distance and disconnection, or discontinue working with them altogether and increasing turn-over rates of staff. If treaters are unable to maintain working relationships with clients because they are ignoring their own needs, the treater inadvertently reinforces many of the negative cognitive schemas the adolescent is working to change. As a result, the Risking Connection training acknowledges these feelings, teaches treaters to assess their own levels of vicarious traumatization, and teaches treaters to address it with strategies of self-care, selfnurturing activities, and healthy ways to emotionally escape. Ultimately, treaters learn to transform their vicarious trauma by creating meaning, challenging negative beliefs, and participating in community building; all of which is modeled to the adolescent client.

\section{Empirical Support for Trauma-Informed Care (The Sanctuary Model)}

As stated, residential programs have historically lacked an overarching model, specifically one that has been empirically validated for the population it serves. This remains an important understudied setting. Although one other trauma informed model, The Sanctuary Model (Bloom, 1997 as cited in Rivard et al., 2003), is currently being used and evaluated in three residential centers in New York, there are no outcome data available regarding the model's impact within the residential school setting specifically. There is evidence, however, that using a trauma recovery framework such as the Sanctuary Model as an overarching model of care is effective in reducing critical 
incidents such as physical aggression and the use of physical restraints, increasing a sense of community, and increasing shared responsibility in decision making (Rivard, 2004).

The Sanctuary Model initiative is one of several projects being used by a large nonprofit mental health and social service agency to better meet the treatment needs of children and adolescents who have been traumatized and their families. Like the Risking Connection curriculum being evaluated in this study, the Sanctuary Model recognizes the need "to incorporate a trauma-focused intervention to address the special needs of youth with serious emotional disturbances and histories of maltreatment and/or exposure to domestic and community violence" (Rivard et al., 2005, p. 80). The Sanctuary Model integrates an enhanced therapeutic community philosophy, trauma theories (Bloom, 1997) and Freidrich's (1996) recommendations that address post-traumatic symptoms, developmental disruptions, and unhealthy accommodations to traumatic experiences. Specifically, the treatment recommendations include strategies for modeling healthy attachments, using cognitive behavioral techniques and psychoeducation to teach skills in accurately processing information, problem-solving, reducing agitation and managing anxiety, identifying and discriminating feelings, increasing self efficacy, and using feedback from others (Rivard et al., 2005). The Sanctuary Model gives meaning to the trauma recovery framework by referring to "SELF," which represents Safety, Emotional management, Loss, and Future. Sessions in the Sanctuary Model are similar to the Risking Connection curriculum evaluated in this study in that they both focus on understanding trauma and its effects, building healthy coping strategies, understanding safety and boundaries, learning about emotions and emotion management, healing from loss, and thinking about the future (Rivard, et al., 2005). 
As an intervention, the Sanctuary Model is a trauma-informed systems approach because it holds as its fundamental premise that the treatment environment is a core modality for modeling healthy relationships and interdependence (Rivard, 2004). It was originally developed for adult trauma victims in short-term, inpatient treatment, but has been adapted for adolescents in residential treatment programs (Rivard et al, 2003). In the study of this trauma-informed model, funded by the National Institute of Mental Health, Rivard and her colleagues, (2003) randomly assigned residential care units of adolescents to the trauma-focused intervention or to the standard residential program and measured (1) change in the therapeutic environment (i.e. outcomes related to trends in the occurrence of critical incidents such as harm to self, others, and property), and (2) change in youth functioning and behavior (i.e. self-report measures including attachment, distress, coping, and problem solving). Measurement occurred at baseline, three months and six months. Preliminary findings include: no significant differences between groups during the first waves of measurement, but by the final measurement (6 months), significant differences were found in favor of the Sanctuary Model group on the following constructs related to the therapeutic environment: support, spontaneity, autonomy, personal problem solving, and perceptions of personal safety (Rivard, 2004). Regarding individual youth outcomes, there were no significant differences at three months, but were at six months for tension management and verbal aggression (Rivard, 2004). Results were modest and consistent with a newly implemented intervention that varied across units, but the few positive youth findings offer promise that full implementation may yield greater results (Rivard, 2004). Milieu counselors, supervisors, 
and clinicians were trained in the basic principles of the trauma framework, but school staff were not trained.

It is increasingly clear that utilizing a trauma-informed framework is beneficial to the traumatized client as well as the treaters working to help them. The Risking Connection curriculum was adopted by the clinical and milieu staff of the residential treatment center in this study approximately one year prior to the data collection process; however the school was not involved. Prior to the implementation of Risking Connection, the entire agency used a traditional model that included a behavioral management system of points and levels. Specifically, the adolescents in care carried around a "point sheet" labeled with all the components of their day (breakfast, school, therapy, outings, etc.) and whoever was in charge of that part of the day gave them points for positive behaviors or took points away for negative behaviors. Anyone who "caught" an adolescent behaving negatively asked for the point sheet and took away points. At the end of the day, milieu staff totaled the sheets and this led to what level the adolescent was placed. Levels were then directly tied to privileges. Although potentially effective in other populations, this behavior modification approach does not emphasize relationship building or connect behaviors with thoughts and feelings that relate to prior experiences, each of which are necessary for treatment of traumatized individuals. In this study, the school within the residential treatment center had no specific framework for addressing problematic behaviors other than what the teacher personally believed to be beneficial for his or her classroom including having the student removed, i.e. the proverbial "sent to the office." This is similar to many schools even though there is significant literature to support the 
effectiveness of focusing on the relationship within the classroom, regardless of whether the students have trauma histories or not (Bergin \& Bergin, 2009; Catalano et al., 2004).

\section{Student-Teacher Relationships}

In general, the literature examining student-teacher relationships demonstrates a whole host of positive outcomes for students when they believe their teachers care about them, providing further support for the hypotheses in this study. It additionally follows that teachers, because of their ability to formulate transformative relationships with students as evidenced in the literature, can be one of the "treaters" in residential treatment as outlined in the Risking Connection curriculum. Positive student-teacher relationships are characterized by high degrees of warmth and trust (Pianta, 1999). This has been demonstrated in both regular and special education classes in community settings throughout the developmental stages. For example, children's relationships with their kindergarten teachers predict grades and standardized test scores through fourth grade, and positive student-teacher relationships are associated with fewer disciplinary actions and increased work habits through middle school (Hamre \& Pianta, 2001). In middle school, the influence of perceived teacher support has corresponded to increases in selfesteem and decreases in depressive symptoms (Reddy, Rhodes, \& Mulhall, 2003). In high school, feelings of relatedness to teachers are associated with positive school attitudes, including motivation and success expectations and interest in school (Roeser, Eccles, \& Sameroff, 1996; Wetzel, 1998) as well as improved achievement and self-esteem (Martin, Marsh, McInerny, Green, \& Dowson, 2007). For elementary students with significant behavioral problems, teacher relationships characterized by warmth, trust, and low degrees of conflict have been found to be associated with positive school outcomes such 
as improved behavior in the classroom and improved social development (Baker, Archer, \& Curtis, 2008). Baker and her colleagues (2008) suggest that during this period, teachers may act as compensatory resources for vulnerable children by providing emotional security. It is noted, however, that in some studies of aggressive children, conflict seems more predictive of future outcomes than does the aspect of closeness to their teachers (Hamre \& Pianta, 2001; Henricsson \& Rydell, 2004).

Much of what this dissertation seeks to further understand is the student-teacher relationship in the context of residential treatment centers and how teachers can play a role in helping adolescents heal from the traumatic experiences of early childhood abuse and neglect. It is a concern that teachers are not trained to work with these adolescents and they are in such an important position to be able to help them. When an adolescent has experienced major disruptions in attachment caused by neglect, abuse, or repeated changes in caregivers, they are likely to experience significant emotional and behavioral problems in a variety of contexts, including school (Bergin \& Bergin, 2009). Many educators report that children with disordered attachment are "disrespectful, argumentative toward authority figures, appear to have no empathy, lack academic motivation, have severe attention problems, have violent emotional outbursts, do not bond with teachers or form close attachments with friends, typically do not respond well to counseling, and have behaviors that seem resistant to the best behavior management programs" (Shaw \& Paez, 2007).

While the mission of schools is to educate students, adolescents with traumatic childhood histories are primarily concerned with internal issues of safety, security, and trust. The need for survival, given their history of maltreatment, can be overwhelming, 
leaving them unable to profit from the learning environment. Oftentimes, the adolescent's preoccupation with survival and his or her acute hyper-vigilance works against the organizational skills and emotional regulation necessary for school functioning (Bergin \& Bergin, 2009; Schwartz \& Davis, 2006). "Schools are places where success is often the result of working, collaborative relationships; [adolescents] who have core deficits in relational functioning may experience many challenges in their effort to succeed" (Schwartz \& Davis, 2006, p. 476).

From an attachment perspective, the teacher-student relationship is conceptualized as an extension of the parent-child relationship (Davis, 2003). For example, Kennedy and Kennedy (2004) suggested that the teacher-student relationship, and by extension other relationships in and out of school, are inextricably tied to a child's internal working model of the parent-child relationship. As such, there is a clear need to recruit stable adults who can serve as adjunct caregivers (Bergin \& Bergin, 2009; Shaw \& Paez, 2007). Schwartz and Davis (2006) suggest that teachers and other school staff should be guided and directed in ways to enhance the student's sense of security. For example, they advise educating school personnel on the role of attachment and interpersonal styles of relating in order to sensitize teachers to the plight of the students and be more helpful to them. Teachers and school personnel have the unique opportunity to act as a secure base and as such, can help adolescents learn how to regulate and modulate their affect and behavior (Kobak et al., 2001). The strategies used in work with infants and parents can serve as a model for student-teacher relationships (Lieberman, 1992). For example, teachers who learn about the effects of trauma, who are aware of their own capacity to modulate their affect, and understand the student's internal working 
model, will recognize that the student's difficulties symbolize a history of disrupted attachment (Schwartz \& Davis, 2006) Teachers who are capable of this type of thinking can be prompted to engage with attachment-disordered students in a quality, empathic, and attuned manner (Bergin \& Bergin, 2009). Through their nurturing and responsiveness to students' needs, teachers can provide a foundation from which children can learn (Davis, 2003). On the other hand, a teacher who is unaware of his or her own schemas of relationships or is prone to punitive discipline has more difficulty sympathizing with students with attachment problems (Schwartz \& Davis, 2006). Teachers who are knowledgeable about attachment and trauma and value the importance of relationships will be the best at fostering and enhancing not only the student's functioning at school, but overall (Bergin \& Bergin, 2009; Kennedy \& Kennedy, 2004).

\section{Integration of School in the Residential Treatment Setting}

Regarding education in the context of residential treatment, research studies have developed "an alarming picture for youth leaving foster care indicating that many of these youth leave foster care without adequate education or life skills to emerge as independent self-sufficient individuals able to function in the adult world" (Jones \& Lansdverk, 2006; Ryan et al., 2007). In fact, education within the residential treatment centers has been called into question. For example, there are concerns about the lack of qualified and certified teachers, low-level academics, mixed age groupings of students ranging from 11-17 in the same classroom, poor educational facilities, and limited, if any, extracurricular activities (Zetlin, 2006). These concerns along with the extensive behavioral and emotional needs of students in residential treatment, make it obvious that 
residential treatment centers must decide how best to educate the adolescents in their care.

While one concern about the care provided in residential treatment is the lack of an overarching theoretical model, a second concern is specifically how the on-campus school may or may not contribute to the overall treatment model of the program. The adolescents in care spend approximately eight hours a day, five days a week in the residential treatment facility's on-campus school but the school teachers are minimally, if at all, trained in a treatment model or, frankly, even trained at all to specifically work with a population of students who have experienced significant trauma. There were no empirical studies found in my literature review examining effective practices for educating adolescents in residential treatment who have survived physical and sexual abuse.

Regardless of the treatment model espoused, common among residential treatment agencies is the assumption that caring human relationships create an environment of safety and growth (Moses, 2000). It is anecdotally recognized and further described by Moses (2000), that direct care staff are more influential on adolescents in care than therapists, as they have more direct contact with the adolescents, and therefore the greatest opportunity to make a lasting impression. But, where are the teachers and the other school personnel in this conversation? For older adolescents in particular, who are the most likely to remain in out-of-home care or to age out of the system, it makes sense to have as many trauma-informed adults within the residential facility as possible so that adolescents can maximize opportunities to practice healthy relationship-building and develop socio-emotionally (Moses, 2000). Overall, it is a missed opportunity not to 
include school personnel, especially teachers, in the treatment of adolescents placed in residential centers.

\section{Advantages (and Disadvantages) of School-Treatment Integration}

There have historically been two predominant educational approaches within residential treatment, the autonomous school and the integrated psycho-educational model (Mansheim, 1982). The psycho-educational model integrates education as a part of treatment and is likely the most effective approach when teaching the population of students discussed. Mansheim (1982) argues, however, that this may cause role diffusion among staff of different disciplines. The autonomous school, on the other hand, has a degree of administrative autonomy from the residential treatment center (and is the current model of the Maryhurst School in this study.) Based on his clinical experience as a director of an adolescent treatment unit served by an autonomous school, Mansheim (1982) offers that the principle advantage of the autonomous school "is the role clarity that results when teachers are expected to teach and clinicians are expected to do clinical work" (p. 845) and the disadvantages generally have to do with the fragmentation of the clinical effort. Regarding the psycho-educational model, Mansheim (1982) acknowledges the advantages of having staff and educators work together as a team in order to know each other personally and have increased communication about the adolescents in care. Each member has an increased knowledge of and familiarity with how each discipline fits in a child's overall treatment.

Support for integrating the school personnel into the overall treatment approach is demonstrated by Hooper (2000) and his colleagues who found promising results for a 
similar population (of the adolescents served in his study, $80 \%$ had experienced some type of documented abuse, approximately $85 \%$ had previously been living in an out-ofhome placement, and $91 \%$ had prior unsuccessful residential placements). Although the study did not specifically examine the use of a treatment model within the residential treatment center school, the school personnel were actively involved. Within the residential treatment center, they examined post-discharge effects of a model based on resolving emotional conflicts and providing community oriented wraparound services. Hooper (2000) and his colleagues found nearly $58 \%$ of the students were rated as performing satisfactorily across 24 months in all three domains they studied (school, legal involvement, and level of care). When two out of the three domains were examined, $90 \%$ of students were found to be doing satisfactorily. Acknowledging that there are other factors contributing to outcome variance, the authors attributed successful outcomes in part to interagency (i.e. school) collaboration. Hooper (2000) and his colleagues suggested that a treatment model that unites mental health, educational, and communitybased elements is best practice for this population. Other researchers (Scherr, 2007; Zetlin, 2006) also agree that a more cooperative and collaborative effort is needed in which systems work together to more proactively provide services to foster care children who have special education needs and that greater training is necessary for educators to understand the unique characteristics of foster care children.

Finally, in a study conducted by Jones and Lansdverk (2006), outcomes for the first three graduating classes of a residential educational program for foster care youth are cautiously optimistic. This program, called the "Academy" is meant to provide an innovative long-term placement option for adolescent foster youth who did not have other 
placement options, and who would likely not return to their biological families. What is unique about this program design is the concept of "residential education," "an approach that is rarely used for foster care children" (p.1154), where the emphasis is on education and social development rather than a treatment orientation. Unlike many other residential treatment programs, students in this program are able to stay in the Academy until emancipation, and the focus becomes building long term relationships with teachers. This program, although residential, is innovative in that is it not meant to be "residential treatment," but aims to provide low-level mental health treatment to adolescents who have experienced multiple placements and school changes. Adolescents who have a severe emotional diagnosis, however, are not eligible. Regardless, what can be gleaned from this study is the positive improvement in social, behavioral, and academic functioning found in the initial graduating classes of a very similar, if not as severe, population using an integrated approach that emphasizes relationship-building with teachers.

Overall, the integration of school into treatment appears to be supported by the modest research that exists in this area. What is very clear is what is at stake. That is, how we are preparing these emerging adults for life outside the treatment center and foster care system. It is well documented that youth involved with the foster care system are uniquely challenged in fulfilling the tasks necessary to be self-sufficient, productive community members and are at risk for negative outcomes in areas such as education, employment, and mental health (Jonson-Reid \& Barth, 2003; Johnson-Reid, Scott, McMillen, \& Edmond, 2007; McMillen \& Raghavan, 2009; Pecora et al., 2006; Vacca, 2008; White et al., 2009). The challenges associated with placement in foster care include 
educational deficits that result from multiple placements, the emotional trauma of abuse and loss, the potential disruption of family and community ties, and the abrupt and certain termination of support from care, making this an extremely difficult transition (Jones \& Lansdverk, 2006) and worthy of attention.

\section{Summary and Restatement of Research Questions}

Drawing from attachment theory, biological research, and trauma theory, the emerging importance for traumatized adolescents to build as many relationships as possible with healthy adults who are informed about the effects of trauma is obvious. For adolescents in residential care, the adults who they spend the most time with on a consistent, long-term basis are their teachers in the oncampus school. Taken together with the positive outcomes for students evident in the vast research on student-teacher relationships in other populations, the opportunity to use teachers in residential treatment centers for this important role is palpable. Currently, there is a lack of an overarching trauma-informed framework (or any empirically based framework) in residential treatment. Additionally, there is a clear need to investigate the dynamics and significance of the student-teacher relationship within residential treatment for traumatized adolescents. Ultimately, if all resources available to this vulnerable population are not fully realized, then these individuals will not be cared for in a way that is most beneficial, and as a result, they may continue to suffer the vicious effects of trauma unnecessarily. Therefore, this study sought to answer: to what extent is (1a) student trauma symptomology, and (1b) teachers' beliefs about traumainformed care and teachers' quality interactions with students in the classroom 
related to students' perceptions of the their relationships with their teacher; (2) to what extent is training these teachers in a trauma-informed framework (Risking Connection) associated with increased teacher knowledge about trauma, increased beliefs about the effectiveness of trauma-informed care, and increased quality teacher classroom behaviors; (3) as well as improved student perceptions of teacher relationships and decreased student report of trauma symptomology. 


\section{CHAPTER 3}

\section{METHODOLOGY}

A pilot study was conducted at Maryhurst Inc. by University of Louisville faculty researchers, Drs. Stipanovic, Rudasill, and Pössel. Data were collected beginning in January 2009 and is currently archived. This study used the archival data from the pilot study.

\section{Participants}

Participants for this study were female adolescent students and their teachers at a residential treatment center, Maryhurst, Inc., located in Louisville, KY. Adolescents who are placed at the facility have "severe emotional disabilities, most often caused by traumatic experiences of abuse and neglect" (Maryhurst, Inc., 2009). Maryhurst, Inc. further describes the "severely emotionally disabled" population it serves in the following way:

Maryhurst provides treatment programs for severely traumatized children who most often are victims of sexual, physical, and/or emotional abuse. Children in our care turn to risk-taking behaviors to cope with their pain. These behaviors can include such actions as running away, truancy, suicidal gesturing, delinquency, and substance abuse. Their issues are further complicated by years of multiple placements in foster care and hospital settings. In fact, prior to their involvement with Maryhurst, any one of our children is likely to have experienced an average of 20 out-ofhome placements (Maryhurst, Inc., 2009). 
Maryhurst Inc. is fully licensed as a child caring, child placement and adoption service provider in Kentucky, is nationally accredited by the Council on Accreditation for Children and Family Services, and a member of the Children's Alliance described as "Kentucky's voice for at-risk children and families" (Maryhurst, Inc., 2009). The average length of stay for the adolescents in residential treatment at Maryhurst, Inc. is nine months. Adolescents who are admitted to the residential program are assessed as having developmental delays, are moderately to severely emotionally disabled, able to participate in their own self care, and are not in need of medical detoxification or actively suicidal or homicidal at the time of admission. The educational needs of the adolescents in residential care are primarily served through the on-campus Maryhurst School in partnership with Jefferson County Public Schools (JCPS). Services are coordinated between Maryhurst treatment staff and JCPS academic staff through the Maryhurst Dean of Students. The students are typically two to four years behind in their academics and have a history of school adjustment problems co-occurring with their mental health issues and high risk behaviors. Additionally, many adolescents have been identified as having emotional and behavior disability (EBD), mild mental retardation (MMR), and specific learning disability (SLD).

There were a total of 92 female adolescent and 7 teacher participants who agreed to participate in the pilot study. The students ranged in age from 11 to 18 , with an average of 16.2 years. Racially, the student participants were $67 \%$ Caucasian, $31 \%$ African-American, and 2\% Hispanic. The teachers ranged in age from 28 to 61 and all were female. Five teachers were Caucasian, one was African-American, and one was listed as Other. Five of the teachers were certified in regular education and two were 
certified in both regular and special education. The subject areas taught at the Maryhurst School include English, reading, science, math, social studies, humanities, art, computer, PE, health, and GED preparation.

\section{Procedures}

Procedures included classroom observations and the administration of surveys to both teachers and students. The goal of teacher observations and surveys was to examine changes in teacher knowledge, beliefs, and behavior after the implementation of the Risking Connection training intervention. The goal of student observations and surveys was to examine student change associated with the teacher changes after the implementation of the Risking Connection training intervention.

Prior to data collection, IRB approval for the protected adolescent population and teachers was obtained and consent and assent forms were explained to participants and collected. Data for use in this study were then collected at four time points from students and two time points from teachers within a five month period beginning in late January 2009. Data collection was completed by university faculty researchers and graduate research assistants with the assistance of direct-care staff from Maryhurst. Standardized instruction was provided to the participants at each time point of data collection.

\section{Research Design}

The pilot study was a quasi-experimental, pretest-posttest design using four total data collection time points for students (two pretests and two posttests) and two total data collection time points for teachers (one pretest and one posttest). This research design is illustrated graphically in Table 1. 
Table 1

Diagram of the Research Design

\begin{tabular}{|c|c|c|c|c|}
\hline \multicolumn{5}{|c|}{ Students } \\
\hline O1 & $\mathrm{O} 2$ & $X$ & $\mathrm{O} 3$ & $\mathrm{O} 4$ \\
\hline \multicolumn{5}{|c|}{ Teachers } \\
\hline $\mathrm{O} 1$ & & $X$ & & $\mathrm{O} 2$ \\
\hline
\end{tabular}

Note: $O 1=$ time point $1, O 2=$ time point $2, O 3=$ time point $3, O 4=$ time point $4 ; X=$ teacher training intervention

Having one pretest provides information about the inference concerning what might have happened to teacher participants had the Risking Connection intervention not occurred. However, maturation and history effects are of particular concern related to the adolescents in the study. They are expected to change, regardless of the teacher intervention, by the very nature of being in a treatment setting and the fact that adolescence is a time of rapid development. Adding another pretest for students, therefore, allows the researcher to account for change occurring that is not attributable to the intervention. "The two pretests function as a 'dry run' to clarify the biases that might exist in estimated the effects of treatment from $\mathrm{O} 2$ to $\mathrm{O} 3$ [time point 2 and time point 3 ]" (Shadish, Cook, \& Campbell, 2002). Two pretests and two posttests function as a method of stabilization across time.

Data collection occurred at approximately one month intervals. For students, two data collection time points (late January and early March) occurred prior to the implementation of the Risking Connection teacher training in mid-March and two data collection time points (mid April and late May) occurred after the implementation. 
Overall, the population of students was relatively stable over the course of the pre-test administrations, $81 \%(\mathrm{n}=59)$ completed both pretests. Additionally, $94 \%$ of students who were administered one of the posttest measures also completed both pretests. For teachers, one data collection time point occurred prior to the Risking Connection teacher training (late January) and one occurred after the training (late May). One of the seven teacher participants did not complete the post test. Tables 2 and 3 list the data collection time frames for students and teachers, and the measures used with each.

Table 2

Student Data Collection Time Points and Measures

\begin{tabular}{|l|l|l|l|}
\hline $\begin{array}{c}\text { O1 = January } \\
\text { Data Collection }\end{array}$ & $\begin{array}{c}\text { O2 = March Data } \\
\text { Collection }\end{array}$ & $\begin{array}{c}\text { O3 = April Data } \\
\text { Collection }\end{array}$ & $\begin{array}{c}\text { O4 = May Data } \\
\text { Collection }\end{array}$ \\
\hline $\begin{array}{l}\text { Your Relationship } \\
\text { with this Teacher }\end{array}$ & $\begin{array}{l}\text { Your Relationship } \\
\text { with this Teacher }\end{array}$ & $\begin{array}{l}\text { Your Relationship } \\
\text { with this Teacher }\end{array}$ & $\begin{array}{l}\text { Your Relationship } \\
\text { with this Teacher }\end{array}$ \\
\hline $\begin{array}{l}\text { Trauma and } \\
\text { Attachment Belief } \\
\text { Scale - TABS }\end{array}$ & $\begin{array}{l}\text { Trauma and } \\
\text { Attachment Belief } \\
\text { Scale - TABS }\end{array}$ & $\begin{array}{l}\text { Trauma and } \\
\text { Attachment Belief } \\
\text { Scale - TABS }\end{array}$ & $\begin{array}{l}\text { Trauma and } \\
\text { Attachment Belief } \\
\text { Scale - TABS }\end{array}$ \\
\hline
\end{tabular}

Table 3

Teacher Data Collection Time Points and Measures

\begin{tabular}{|l|l|}
\hline O1 = end of January Data Collection & \multicolumn{1}{|c|}{ O2 = end of May Data Collection } \\
\hline $\begin{array}{l}\text { Classroom Assessment Scoring System } \\
\text { - CLASS }\end{array}$ & $\begin{array}{l}\text { Classroom Assessment Scoring System - } \\
\text { CLASS }\end{array}$ \\
\hline $\begin{array}{l}\text { Teacher Fidelity to the Risking } \\
\text { Connection Program }\end{array}$ & $\begin{array}{l}\text { Teacher Fidelity to the Risking Connection } \\
\text { Program }\end{array}$ \\
\hline $\begin{array}{l}\text { Risking Connection Curriculum } \\
\text { Assessment }\end{array}$ & $\begin{array}{l}\text { Risking Connection Curriculum } \\
\text { Assessment }\end{array}$ \\
\hline Trauma Informed Care Belief Measure & Trauma Informed Care Belief Measure \\
\hline
\end{tabular}




\section{Measures}

\section{Observational Measures}

\section{Classroom Assessment Scoring System (CLASS)}

The Classroom Assessment Scoring System (CLASS) (Pianta, LaParo, \& Hamre, 2008) is a measure of the quality of student-teacher interactions across ten observed dimensions rated on a Likert scale from 1 (low) to 7 (high). There are three latent domains (emotional support, classroom organization, and instructional support) indicated by the ten observed dimensions. This three factor model has been validated using confirmatory factor analysis (Hamre et al., 2007). The four dimensions that indicate Emotional Support are positive climate, negative climate, teacher sensitivity, and regard for adolescent perspectives. Classroom Organization is indicated by the three dimensions, behavior management, productivity, and instructional learning formats. The final dimensions that indicate Instructional Support are procedures and skills, content understanding, analysis and problem solving, and quality of feedback. Domain scores are computed based on compositing the dimensions with each domain. The CLASS dimensions are based on developmental theory and research suggesting that interactions between students and adults are the primary mechanism of student development and learning (Pianta et al., 2008). The Emotional Support subscale is the only one that will be used for evaluation in this study.

The CLASS was originally developed to assess classroom quality in preschool through third grade and has been used extensively in these settings. The instrument was then adapted to accurately reflect classroom interactions in grades six through twelve. 
Therefore, the CLASS-Secondary is an upward extension of the CLASS-Primary. According to the middle/secondary version of the CLASS manual, observations using CLASS have been demonstrated to be reliable and valid in many studies.

Regarding reliability, first, the authors of CLASS require observers to be trained and certified before conducting observations and $80 \%$ of the observers ratings have to be within one scale point of the master codes in order to reach reliability. In a study of interrater agreement for the CLASS-primary, percentage values of agreement within one scale point ranged from $96.9 \%$ for the productivity dimension to $78.8 \%$ for the instructional learning formats dimension (Pianta et al., 2008). CLASS scores have also been demonstrated to be stable across observations. Correlations between scores taken across multiple time points within one day ranged from .79 to .91 for preschool, and from .76 to .89 for third grade and multiple time points within a week ranged from .73 to .85 (Pianta et al., 2008).

Regarding validity, the CLASS was developed based on an extensive literature review of classroom practices shown to relate to student's social and academic development in schools. Face validity is suggested by the numerous experts in classroom quality and teaching effectiveness that have agreed that the CLASS measures aspects of the classroom that are of importance in determining student performance. Criterion validity is demonstrated in analyses of the relationship between the high CLASS scores and various other measures of classrooms and teachers, including the ECERS-R (the most commonly used measure of quality in early childhood classrooms), and the Snapshot (a time-sampling method used to assess the percent of time spent on various activities in the classroom) which had statistically significant positive correlations. 
Statistically significant negative correlations were found with teachers who reported depressive symptoms (Pianta et al., 2008).

Teacher Fidelity to the Risking Connection Program - 20 items

CLASS observers additionally completed a behavioral checklist created by Risking Connection trainers designed to assess the teacher's implementation of the Risking Connection program in the classroom as measured by specific behaviors congruent with the program. It is acknowledged that this measure is not a strong indicator of teacher fidelity and is likely not the best way to capture how a teacher is able to implement the training in her classroom. It is simply added as a piece of additional information gathered through the classroom observations.

\section{Teacher Self-Report Measures}

\section{Risking Connection Curriculum Assessment -11 items}

This instrument was created by Trauma Research, Education, and Training Institute, Inc. (TREATI), the agency contracted to implement the Risking Connection training intervention at Maryhurst, Inc., as an evaluation tool for Risking Connection trainings. There are currently no empirical studies to support or not support the reliability and validity of this measure. It consists of 11 multiple choice items about the Risking Connection Program and is used by the trainers to assess the understanding of the Risking Connection program and theory and techniques taught in the training. It is scored by totaling the number of questions correctly answered. Example questions include: "Which of the following is the best definition of vicarious traumatization?," "What does the 
concept 'symptoms are adaptations' mean?," and “A client repeatedly engages in selfcutting behavior. Which would be the most effective response?

\section{Trauma-Informed Care Belief Measure - 19 items}

This instrument was also created by Trauma Research, Education, and Training Institute, Inc. (TREATI) as an evaluation tool for Risking Connection trainings and its reliability and validity has also not been empirically studied. It consists of 19 items that are rated on a Likert scale from 1 (Strongly Disagree) to 5 (Strongly Agree) and is used to assess beliefs about the trauma-informed model that directly relates to the Risking Connection training curriculum. Example items include: "My relationship with clients is my most important tool to change the behavior of clients," "Controlling clients' negative behavior is one of the most important features of an effective treatment approach" (reversed scored), and "It is better not to form close relationships with clients because I will not know them that long" (reverse scored).

\section{Adolescent Self-Report Measures}

\section{Your Relationship with This Teacher - 10 items}

This instrument was adapted from three different measures (Gregory \& Weinstein, in press; Roeser, Eccles \& Sameroff, 1998; Skinner \& Belmont, 1993) and was designed to assess secondary students' perceptions of the quality of their relationship with a specific teacher. For purposes of the pilot study, this measure was modified to be administered in a large group format. To be very clear about the teacher about which the student was referring, the phrase "My first period teacher" was substituted for "This teacher" within the items prior to administration. Students are asked to report on the trust, 
respect, affect, and differential treatment they perceive from a specific teacher using a 4item answer format (Not True at All; Somewhat True; True; Very True) on the first six questions and a similar 5-item answer format (Almost Never; Rarely; Sometimes; Often; Almost Always) for the last four questions. For the current study, values for the 5-item questions were weighted $(1=.08,2=.16,3=2.4,4=3.2,5=4)$ to match the value of the 4 item questions. Items related to perceptions of trust were developed by Gregory and Weinstein (in press) who reported a Cronbach's alpha of .91. Trust related items include, "This teacher never listens to my side." Items related to respect and affection were developed by Skinner and Belmont (1993) who reported a Cronbach's alpha of .79. These items consist of "This teacher likes me," and "This teacher really cares about me." Lastly, items related to differential attention were developed by Roeser, Eccles, and Sameroff (1998) who reported Cronbach's alphas ranging from .70 to .84 . These items include, "This teacher thinks I am less smart than I am because of my race." Although this measure is also being utilized as part of the MyTeachingPartner - Secondary research and development program by Pianta and Allen (2009), it is newly developed and has not been used as a single instrument in any other empirical study. Measures to assess the relationship an individual student has with a specific teacher were not found to currently exist in the literature.

\section{Trauma and Attachment Belief Scale (TABS) - 84 items}

The Trauma and Attachment Belief Scale (TABS) (Pearlman, 2003), formerly known as the Traumatic Stress Institute (TSI) Belief Scale, is based in Constructivist Self-Development Theory. It consists of 84 items designed to assess the disruptions in cognitive schemas within the five areas of psychological need that are vulnerable to 
disruption by traumatic life experiences (described in detail in Chapter 2): Safety, Trust, Esteem, Control, and Intimacy. Using a score based on a Likert scale, the TABS yields a total score as well as ten subscale scores which measure each of the five psychological need areas in relation to the self and other (i.e., Self-Safety and Other-Safety, Self-Trust and Other-Trust, etc.). The scale is a useful tool to identify psychological themes in trauma material, as well as interpersonal and intrapersonal themes that are likely to emerge in treatment. It is also designed to monitor progress and change in treatment. This trauma measure was chosen because it was created specifically to be non-intrusive and non-pathologizing. It was designed to avoid using disempowering labels and the items do not focus on trauma-related symptoms per se, rather on beliefs about self and others that stem from traumatic experiences. Thus, the test is sensitive to specific effects of traumatic experiences, and also measures constructs that pertain to disruptions in relationships (Pearlman, 2003). This measure was additionally chosen because it is based in the same theory (CSDT) and was developed by one of the same authors (Laurie Anne Pearlman) as the Risking Connection curriculum.

Initially the scale was called the McPearl Belief Scale (1988) and 100 items were generated by collecting statements from trauma survivor clients. These were then given to experts in trauma to review and who were asked to assign each item to one of six need areas at the time. (The need area of Independence was eventually subsumed into other subscales.) In subsequent years, data on the instrument was collected from several thousand college students, psychotherapy clients, and psychotherapists. These data made ongoing reliability analyses and further refinement of the instrument possible. New items were generated and others discarded to improve the reliability of some subscales. In 
1991, the name of the instrument changed to the Traumatic Stress Institute (TSI) Belief Scale and the separation of the five need areas into self-oriented and other-oriented was supported clinically and empirically by reliability and correlational analyses. The main difference between the revised Belief Scale and the current TABS is that many items were modified to make them easier to read and four items were added. All of the psychometric properties reported are on either the revised Belief Scale or the TABS. There is strong evidence in support of treating the scores on the revised Belief Scale and the TABS as equivalent. The correlation between the two forms is .95 .

Normative data was developed for the scale on both clinical and non-clinical samples, for adult and adolescent populations, and support the TABS as a reliable and valid measure. It is noted that in the adult standardization sample, African-Americans scores on the Other-Safety, Other-Trust, and Other-Esteem were reliably higher than the expected average $\mathrm{T}$ score. On the whole, these results may be attributed to the relatively lower sample size of those individuals, but may reflect true differences among people from an African-American background. As such, care should be taken to verify hypotheses generated using TABS scores for these individuals.

In the non-clinical sample, an internal consistency estimate of .96 and test-retest correlation of .75 for a 1-2 week interval were obtained. A median internal consistency estimate of .79 was obtained for the subscales (ranging from .67 for Self-Intimacy to .87 for Other-Trust.) The slightly low internal consistency estimate for the Self-Intimacy subscale is offset by good test-retest reliability along with factor-analytic evidence that supports retaining it as a single, separate subscale. A median test-retest value for the 
subscales was. 72 (ranging from .60 for Other-Intimacy to .79 for Other-Trust)

(Pearlman, 2003).

The use of theory to guide the generation of TABS items, and of experts to review TABS items-to-scales assignments during the initial phase of development maximized the TABS construct validity. Patterns of intercorrelations between the TABS and the Trauma Symptom Inventory (Briere, 1995), a measure of symptoms associated with the experience of trauma, also support the construct validity of the TABS (Pearlman, 2003). Scores for outpatients with a history of childhood abuse have scored highest when compared to scores for battered women and homeless women with mental illness, and TABS scores are higher overall for outpatients with a history of traumatic life experiences than for outpatients in general (Dutton et al., 1994; Goodman \& Dutton, 1996; Pearlman, 2003; Mas, 1992), demonstrating criterion-related validity.

\section{Data Analyses}

\section{Goals \& Analyses}

The first and primary goal of the study was to understand the dynamics of the student-teacher relationship within residential treatment centers for adolescents who have experienced childhood trauma. This included evaluating the relationships among (1) the association between students' trauma symptomology (Trauma and Attachment Beliefs Scale) and their perception of the student-teacher relationship (Your Relationship with This Teacher); and (2) the associations between the teachers' beliefs about traumainformed care (Trauma-Informed Belief Measure), teachers' emotionally supportive behavior in the classroom (CLASS-Emotional Support subscale) and student perception 
of the student-teacher relationship (Your Relationship with This Teacher). It is hypothesized that as students report higher levels of trauma symptomology, their perceptions of the student-teacher relationship will be less positive. It is also hypothesized that as teachers report higher endorsements of trauma-informed care and have higher levels of emotional support in the classroom, students' perception of the student-teacher relationship will be more positive.

Goal 1: Determine the extent to which students' trauma symptomology, teacher beliefs about trauma-informed care, and teachers' emotionally supportive behavior are associated with the students' perception of the student-teacher relationship.

To address this goal, scores from the first data collection time point (student global TABS scores, teacher scores on the Trauma-Informed Care Beliefs Measure and teacher scores on the CLASS-Emotional Support subscale) were simultaneously entered as predictor variables into a multiple regression equation where the dependent variable was student ratings of the student-teacher relationship (Your Relationship with This Teacher scores). This analysis estimated the amount of variance in student perceptions of the student-teacher relationship accounted for by the student's overall reported trauma symptomology, teachers' beliefs about trauma-informed care, and the teachers' emotionally supportive behaviors in the classroom. The regression model also provided information about the relative importance of each predictor.

In order to more specifically explore the contributions of trauma symptomology to students' perception of the student-teacher relationship, a second regression model was calculated where five subscale scores of the TABS (rather than the global score) were 
simultaneously entered as predictor variables. These were: Self-Safety (elevated scores indicate worry of victimization by others), Other-Trust (elevated scores indicate inability to trust or rely on others), Other-Intimacy (elevated scores indicate being disconnected and isolated), Other-Control (elevated scores indicate feeling uncomfortable when others are in control), and Other-Esteem (elevated scores indicate viewing others with disdain and disrespect.) These variables were selected based on trauma and attachment theory. As with the first regression model, teacher scores (Trauma-Informed Belief Measure and CLASS-Emotional Support) were also entered as predictor variables. This analysis provided an estimate of the amount of variance in student perception of the relationship accounted for by the student's more specific areas of trauma symptomology and examined the relative importance of each kind of symptom.

Goal 2: Determine the extent to which the Risking Connection training was associated with change in teacher attribute: (1) knowledge related to trauma-informed care; (2) beliefs related to trauma-informed care; and (3) emotionally supportive behavior in the classroom.

The second goal of this study involved the evaluation of change in teacher attributes before and after the teacher training intervention, Risking Connection. Due to the fact that the sample of teachers was quite small $(n=6)$, it was hypothesized that teachers' scores would not be statistically different from time 1 to time 2 . Therefore, this goal was addressed through examination of descriptive statistics. That is, means, standard deviations, and ranges were calculated and results were examined for the following teacher scores: Risking Connection Curriculum Assessment, Trauma-Informed Care Belief Measure, Teacher Fidelity to Risking Connection, and CLASS-Emotional Support 
subscale. It was hypothesized that teachers' knowledge, trauma-informed beliefs and emotionally supportive behavior in the classroom would increase after the training intervention. Regarding the CLASS measure, the CLASS-Emotional Support subscale was chosen because it was hypothesized that while a teacher's overall behavior in the classroom may not change as it pertains to instructional support and classroom organization, behavior related to the specific domain of emotional support was more likely to change as a result of the Risking Connection training. In addition, a paired samples t-test comparing the pre and post time points of data collection was completed for the four teacher measures and effect sizes were calculated.

Goal 3: Determine the extent to which the Risking Connection training intervention with teachers was associated with change in student attributes (perception of teacher relationship, trauma symptomology).

The third goal of this study involved the evaluation of change in student attributes before and after the teacher training intervention, Risking Connection. In order to evaluation this change in students, paired sample t-tests were calculated comparing change between the two pretests $(\mathrm{O} 1$ and $\mathrm{O} 2)$ to change between the two posttests $(\mathrm{O} 3$ and $\mathrm{O} 4)$. It was hypothesized that the change between $\mathrm{O} 3$ and $\mathrm{O} 4$ would be greater due to the teacher intervention. Also, trends across time were examined using means at all four student time points. 


\section{CHAPTER 4}

\section{RESULTS}

Following a description of the preliminary analyses of the data, the findings of the study are presented in three main sections according to the research goals outlined in Chapter 3.

\section{Preliminary Analyses}

\section{Correlation of Variables}

Table 4 provides an overview of the bivariate correlations of all variables included in the first goal of the study. Correlational analyses of the TABS scales revealed moderate correlations among the subscales and high correlations with the global TABS score. All of the specific TABS subscales of interest in the first research goal had statistically significant $(p<.01)$ bivariate correlations ranging from $r=.44$ between SelfSafety and Other-Control and $r=.78$ between Other-Trust and Other-Esteem. The teacher variables used in the multiple regression analyses, Trauma-Informed Care Beliefs and the CLASS-Emotional Support, were also moderately correlated with each other ( $r=$ .45). Therefore, the correlations between the predictor variables used in the multiple regression analyses suggest a certain degree of multicollinearity. 
Table 4

Bivariate Correlations of Your Relationship with This Teacher, Trauma-Informed Care Beliefs Measure, CLASS-Emotional Support, and TABS

\begin{tabular}{llllllllll} 
Variable & 1 & 2 & 3 & 4 & 5 & 6 & 7 & 8 & 9 \\
\hline
\end{tabular}

1. Rel. w/Teacher --

2. Trauma-Informed $.34^{*} \quad--$

3. CLASS-Emot. $.02 \quad .45^{* *}--$

4. TABS-global $\quad-.26 \quad-.04 \quad-.14 \quad--$

5. Self-Safety $\quad-.08 \quad-.04 \quad-.18 \quad .82 * * \quad--$

6. Other-Control $\quad-.33 * \quad-.10 \quad-.06 \quad .72 * * \quad .44 * * \quad--$

$\begin{array}{llllllll}\text { 7. Other-Trust } & -.30 * & -.08 & -.16 & .81 * * & .52 * * & .52 * * & -\end{array}$

8. Other-Intimacy $\quad-.26 \quad-.07 \quad-.12 \quad .86^{* *} \quad .69 * * \quad .55^{* *} \quad .67 * * \quad--$

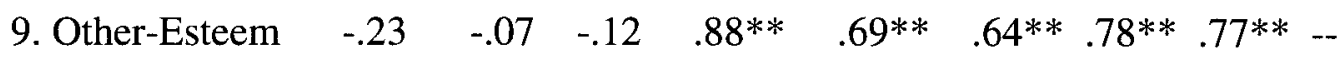

Note: Rel $. w /$ Teacher $=$ Your Relationship with This Teacher; Trauma-Informed $=$ Trauma-Informed Care Belief Measure; CLASS-Emot. = CLASS-Emotional Support subscale; Self-Safety, Other-Control, Other-Trust, Other-Intimacy, Other-Trust = TABS subscales; ${ }^{*} p<.05 .{ }^{*} p<.01$

For the second and third goals of the study, two additional variables were used: the Risking Connection Curriculum Assessment and the Risking Connection Fidelity Measure. Using pre-test teacher scores, The Risking Connection Curriculum Assessment had moderate bivariate correlations with the other teacher measures (i.e., TraumaInformed Belief Measure, $r=.45$; CLASS-Emotional Support, $r=.70$; and Risking Connection Fidelity, $r=.44$.) 


\section{Internal Consistency of Measures}

The internal consistencies of all scale scores for students and teachers were analyzed at all time points and found to be acceptable overall. For the first time point, Cronbach's alphas for the TABS measure ranged from .62 to .76 with the exception of Self-Intimacy $(\alpha=.35)$ and Self-Trust $(\alpha=.44)$. The student scores on the Your Relationship with This Teacher measure at the first time point had high internal consistency $(\alpha=.85)$ and this remained true for each of the following time points ( $\alpha$ s $=$ $.86, .84,80$ for each time point, respectively). Of the teacher measures for pre data collection time point, the Trauma-Informed Care Beliefs Measure had an internal consistency slightly below acceptable $(\alpha=.56)$, while the CLASS-Emotional Support has high internal consistency $(\alpha=.82)$. At the post data collection time point, both teacher measures were acceptable (Trauma-Informed Care Beliefs, $\alpha=.77$, CLASS-Emotional Support, $\alpha=.71$ ). The Risking Connection Curriculum Assessment reliability ranged from $\alpha=.62$ at pre to $\alpha=.90$ at post while the Risking Connection Fidelity measure ranged from $\alpha=.65$ to .68 .

\section{Student Characteristics}

Ninety-two female adolescents participated in at least one time point of data collection throughout the study period; however a total of approximately sixty adolescents reside at Maryhurst at any given time. At time point 1, there were a total of 55 adolescents who participated and completed all measures. As indicated in Chapter 3, data from this time point were used to analyze questions related to the first research goal. At time points 2, 3, and 4, complete measures (i.e 
those with no missing questionnaires) were obtained from 56, 54, and 64 students respectively. The total number of students who completed all measures for all four time points was 32 . Independent-sample t-tests comparing students who had complete measures and those who did not revealed no significant differences in grade or ethnicity. Grade was separated in two groups identified as grades $7^{\text {th }}, 8^{\text {th }}$, or $9^{\text {th }}$ as one group and grades $10^{\text {th }}, 11^{\text {th }}$, or $12^{\text {th }}$ as the other. For this analysis, racial/ethnic categories were identified as Caucasian, African-American, Asian, and Hispanic.

Student Grade and Race/Ethnicity. Table 5 shows grade and race/ethnicity data specifically for the 55 adolescents who had complete data for the first time point (Research Goal 1).

Table 5

Grade Level and Race/Ethnicity of students who participated in time point 1

\begin{tabular}{lclc} 
Grade & Percentage & Ethnicity & Percentage \\
\hline 7 th & $8 \%$ & African-American & $20 \%$ \\
8 th & $19 \%$ & Caucasian & $78 \%$ \\
9 th & $29 \%$ & Other & $2 \%$ \\
10 th & $18 \%$ & & \\
11 th & $10 \%$ & & \\
12 th & $3 \%$ & \\
(Grade undetermined or not reported for 13\%.)
\end{tabular}

Student Trauma Symptomology (TABS). Preliminary analyses of the TABS global and subscale scores revealed that the means were normally distributed at all time points, indicating that students varied in their endorsement of trauma statements. The overall 
means of global and subscale scores ranged from 2.76 to 3.19 while individual means ranged from 1.00 (very low endorsement of trauma) to 6.00 (very high endorsement of trauma). Responses of 1,2 , and 3 on the TABS measure indicate levels of disagreement with the statement and 4, 5, and 6 indicate levels of agreement. A higher score $(4,5$, and 6) reflects a higher level of trauma related cognitions or symptomology (Pearlman, 2003).

Table 6 provides an overview of the TABS scores at the first data collection time point (Research Goal 1).

Table 6

Variability of TABS global and subscale scores for students at time point 1

\begin{tabular}{llllr} 
& \multicolumn{1}{c}{ Minimum } & Maximum & M & SD \\
TABS global & 1.40 & 4.56 & 3.00 & .78 \\
Self-Safety & 1.38 & 5.00 & 2.92 & .93 \\
Self-Trust & 1.00 & 4.86 & 2.96 & .82 \\
Self-Esteem & 1.56 & 5.00 & 2.76 & .97 \\
Self-Intimacy & 1.29 & 5.29 & 3.19 & .88 \\
Self-Control & 1.22 & 5.44 & 3.03 & 1.00 \\
Other-Safety & 1.00 & 5.75 & 3.18 & 1.17 \\
Other-Trust & 1.25 & 4.88 & 3.02 & .90 \\
Other-Esteem & 1.00 & 4.75 & 3.00 & .92 \\
Other-Intimacy & 1.00 & 5.25 & 2.91 & 1.08 \\
Other-Control & 1.00 & 6.00 & 3.07 & 1.04
\end{tabular}

Student Perception of Teacher Relationship. Preliminary analyses of the Your Relationship with This Teacher scores of the students who participated in the first data collection time point (Research Goal 1) revealed a distribution that was negatively skewed (Skewness $=-1.66$, Kurtosis $=2.16)$, indicating that overall students rated their relationship with their teacher as positive. On a 4-point scale in which a higher score 
indicates a student's more positive perception of the relationship with the teacher, the measures of central tendency were generally high $($ Mean $=3.2$, Mode $[20 \%$ of scores] $=$ 3.68). The scores ranged from 1.26 to the modal score of 3.68 . The negatively skewed distribution of scores on the Your Relationship with This Teacher measure was consistent for each of the four data collection time points (Research Goal 3). The negatively skewed distribution indicates the variability on this measure was somewhat restricted.

\section{Teacher Characteristics}

Of the initial seven teachers who agreed to participate in the study, six completed the teacher measures at both data collection time points. Of the six teachers who had complete measures, four were Caucasian, one was AfricanAmerican, and one was listed as Other. The number of years these teachers have been teaching ranged from 1 to 27 ; however their teaching experience was not all related to working with the student population of interest in this study, i.e. adolescent students in residential treatment with trauma histories. Data was not collected on how much experience each teacher had with this population. The average years teaching was 11.5 .

The teacher variables for this study come from the following four measures: Risking Connection Curriculum Assessment, Trauma-Informed Care Measure, CLASS-Emotional Support subscale, and Teacher Fidelity to the Risking Connection Program. Due to the very low sample size of teachers $(n=6)$, the assumption of normality was not expected and did not occur. Because Research Goal 2 was primarily examined using descriptive analyses, discussion of 
descriptive statistics for the four teacher measures is included in the Research Question Analyses section below.

\section{Research Question Analyses}

Research Goal 1: To what extent is students' trauma symptomology, teacher beliefs about trauma-informed care, and teacher's quality of interactions with students (i.e., emotional support in the classroom) associated with the students' perception of the student-teacher relationship?

In order to examine these associations, two multiple regression analyses were calculated. Assumptions of linearity, normality of residuals, collinearity, (via VIF and Tolerance) were examined. Additionally, to determine the potential for influential cases or outliers, residual statistics such as Cook's D and the Centered Leverage Value were also examined. All values were within acceptable limits.

In the first regression model, all the scores used are from time point 1 . Student scores on the Relationship with This Teacher scale were regressed on student global scores on the TABS, teacher scores on the Trauma-Informed Belief Measure, and teacher scores on the CLASS-Emotional Support subscale.

Results for the first model were significant $\left(F_{3,49}=4.519, p=.007\right)$ and revealed that approximately $22 \%$ of the variance in student-teacher relationship scores was accounted for by the predictor variables $\left(R^{2}=.217, \Delta R^{2}=.169\right)$. Table 7 shows that teacher's beliefs about trauma-informed care and student trauma symptomology were statistically significant predictors of students' perception of the student-teacher relationship at time point 1 . Scores on the Trauma-Informed Belief Measure accounted 
for approximately $14 \%$ of the variance in the Your Relationship with This Teacher scores $(\beta=.429, p=.004)$ while students' global trauma symptomology scores accounted for an additional $7 \%$ of variance $(\beta=-.281, p=.033)$. These analyses indicated that as teachers reported a higher endorsement of trauma-informed care, students reported a more positive relationship with that teacher and as students reported higher levels of trauma symptomology, they reported less positive relationship with their teachers. Teachers' emotionally supportive behavior in the classroom was not a statistically significant predictor variable above and beyond the contribution of teacher beliefs and student trauma in this model.

Table 7

First Regression Predicting Student Perceptions of the Student-Teacher Relationship by Student Trauma Symptomology (TABS-global), Teacher Trauma-Informed Care Beliefs (TCBM) and Teacher Classroom Behavior (CLASS-Emotional Support)

Student-Teacher Relationship

$B \quad S E \quad \beta$

Predictor Variable

\begin{tabular}{lccc} 
TABS-global & -.229 & .104 & $-.281^{*}$ \\
Trauma-Informed Beliefs & .784 & .259 & $.429 * *$ \\
CLASS-Emotional Support & -.129 & .086 & -.216 \\
& & & \\
\hline
\end{tabular}

${ }^{*} p<.05 .{ }^{* *} p<.01 ; R^{2}=.217\left(\Delta R^{2}=.169\right)^{* *}$

In the second multiple regression model, student scores on the Relationship with This Teacher measure were regressed on student scores on the following five subscales of the TABS measure: Self-Safety, Other-Control, Other-Esteem, Other-Trust, and OtherIntimacy so that specific student trauma symptomology could be evaluated. Teacher 
scores on the Trauma Care Belief Measure and on the CLASS-Emotional Support subscale were also entered as predictor variables.

This second model was also significant $\left(F_{7,45}=3.002, p=.011\right)$ and revealed that approximately $32 \%$ of the variance in student-teacher relationship scores was accounted for by the predictors in this model $\left(R^{2}=.318, \Delta R^{2}=.212\right)$. Table 8 shows that teachers' scores on the Trauma-Informed Care Belief Measure and students' scores on the Other-Control TABS subscale significantly predicted students' ratings of the studentteacher relationship. Teacher beliefs about trauma-informed care accounted for approximately $15 \%$ of the variance $(\beta=.440, p=.003)$ in student-teacher relationship scores. Again, as teachers had a higher endorsement of trauma-informed care beliefs, students rated the quality of the relationship with that teacher more positively. Of the TABS subscales, the Other-Control student subscale score accounted for an additional $7 \%$ of the variance $(\beta=-.348, p=.041)$ in students' perception of their relationship with their teacher, above and beyond what was accounted for by teacher beliefs about traumainformed care. As students reported higher levels of trauma symptoms related to OtherControl, their perceptions of the relationship with their teacher were less positive. The other four TABS subscales used in this model and the teacher behavior in the classroom (i.e. emotional support) were not statistically significant predictors above and beyond the contributions of teachers' trauma-informed beliefs and students' trauma symptomology specifically related to Other-Control. 
Table 8

Second Regression Predicting Student Perceptions of the Student-Teacher Relationship by Specific Student Trauma Symptomology (TABS-subscales), Teacher Trauma-Informed Care Beliefs (TCBM) and Teacher Classroom Behavior (CLASS-Emotional Support)

Student-Teacher Relationship

$B \quad S E \quad \beta$

\begin{tabular}{lccc} 
Predictor Variable & & & \\
TABS - Self-Safety & .104 & .125 & .154 \\
TABS - Other-Control & -.212 & .101 & $-.348^{*}$ \\
TABS - Other-Esteem & .160 & .182 & .233 \\
TABS - Other-Trust & -.180 & .142 & -.257 \\
TABS - Other-Intimacy & -.102 & .124 & -.175 \\
Trauma-Informed Beliefs & .805 & .255 & $.440^{* *}$ \\
CLASS-Emotional Support & -1.00 & .085 & -.167 \\
& & & \\
\hline * $p<.05 . * * p<.01 ; R^{2}=.318\left(\Delta R^{2}=.212\right) * *$ & & \\
&
\end{tabular}

Due to the very low sample size of teachers in the study $(n=6)$, descriptive statistics such as means, standard deviations, and ranges were primarily used to evaluate the change in teacher attributes before and after the Risking Connection training intervention. Table 9 summarizes these descriptive statistics for the following teacher measures: Risking Connection Curriculum Assessment (trauma knowledge); Trauma- 
informed Care Belief Measure (beliefs about trauma-informed care); CLASS-Emotional Support subscale and Risking Connection Fidelity Measure (classroom behavior).

Table 9

Means, Standard Deviations, and Ranges for Teacher Variables

\begin{tabular}{lcccc} 
& Minimum & Maximum & M & SD \\
\hline RC Knowledge - pre & .20 & .73 & .52 & .20 \\
RC Knowledge - post & .11 & .73 & .55 & .24 \\
Trauma-Informed Beliefs - pre & 2.9 & 3.6 & 3.3 & .38 \\
Trauma-Informed Beliefs - post & 2.9 & 4.1 & 3.4 & .44 \\
CLASS-Emotional Support - pre & 2.5 & 6.0 & 5.0 & 1.26 \\
CLASS-Emotional Support - post & 3.3 & 5.6 & 4.8 & .91 \\
RC Fidelity - pre & 1.6 & 3.1 & 2.1 & .57 \\
RC Fidelity - post & 1.7 & 2.7 & 2.1 & .38
\end{tabular}

Examination of means at both time points revealed that teacher scores on the Trauma-Informed Belief Measure were moderate before the Risking Connection training, indicating that the teachers already endorsed a fair amount of positive beliefs about this type of care for the adolescent population they teach at Maryhurst. Furthermore, the teacher scores for emotionally-supportive behaviors in the classroom were at the high end of moderate (Pianta et al., 2008), also before the Risking Connection training. Regarding the pre and post comparisons, the means on Table 6 illustrate that teacher scores related to knowledge about the Risking Connection curriculum and beliefs about traumainformed care increased slightly, while scores related to emotionally supportive behavior in the classroom (CLASS-Emotional Support and RC Fidelity) decreased after the Risking Connection teacher training; however, paired sample t-tests comparing the pre and post teacher scores also used to evaluate the teacher data produced non-significant 
results. This was not surprising with the very low teacher sample size $(n=6)$. Effect size calculations also revealed very low effects indicating little, if any, meaningful change in scores.

\section{Research Goal 3: To what extent is the Risking Connection training intervention with teachers associated with change in student's reported trauma symptomology and their perception of the relationship with their teacher.}

The third goal of the study was to determine the extent to which the teacher training intervention was associated with positive changes in students' (a) trauma symptomology and (b) perceptions of their relationship with their teachers. Scores for the students who participated in all four time points of data collection were identified $(n=$ 32) so that change between the two student pre-test scores could be compared to the change in the two student post-test scores. Results of the paired sample t-tests revealed no statistically significant differences in the amount of student change in reported trauma symptomology pre to post $(t=.58, p=.56$ ) or in their perception of the student-teacher relationship $(t=-.83, p=.41)$. Figure 1 shows a graphical representation of student means for trauma symptomology and student-teacher relationship scores across all four time points. 


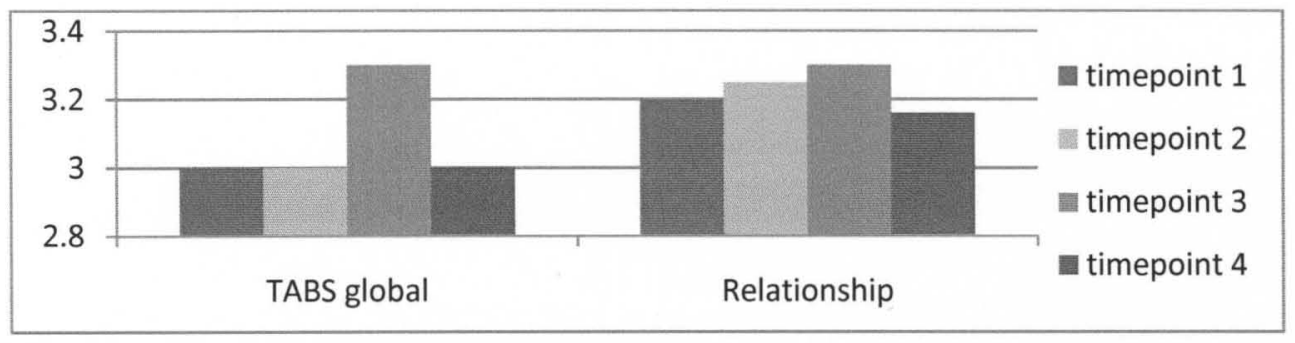

Figure 1 Student Means for Trauma Symptomology and Student-Teacher Relationship across all four time points.

Examination of the means in Figure 1, suggest a trend in the data such that student reports of trauma symptomology and perceptions of student-teacher relationships were both slightly higher at the third time point. It is also noted that the lowest scores for the Relationship with This Teacher measure, although minimally so, occurred at the final time point. Each of these observations is discussed in Chapter 5. 


\section{CHAPTER 5}

\section{DISCUSSION}

In this study, several important problems were explored related to the care of adolescents who have experienced childhood trauma and have been subsequently placed in residential treatment centers. First, residential treatment centers generally do not operate with an overarching empirically-based approach for this population (Garrett, 1985; Hooper et al., 2000; Hussey \& Guo, 2005). Many times these facilities use a medical model instead of a trauma-informed model, and therefore primarily focus on controlling behavior rather than understanding behavior in the context of the adolescent's trauma history (Peacock \& Daniels, 2006). Second, attachment and trauma theories inform us that healing from abuse and neglect occurs in the context of a safe, consistent relationship (Becker-Weidman, 2006; Bowlby, 1954; Kobak, Little, Race, \& Acosta, 2001); however, in the residential treatment setting the student-teacher relationship is not fully understood or maximized for positive outcomes. The adolescents in residential treatment spend eight hours a day, five days a week with their teachers in the on-campus school and yet teachers in this type of setting are typically not trained to work with adolescents who have histories of abuse and neglect trauma. Furthermore, the on-campus school is often disconnected from the other areas of care (i.e. clinical, medical, residential) and not effectively integrated into the 
overall treatment of adolescents (Abromovitz \& Bloom, 2003). Because the student-teacher relationship is such a valuable potential opportunity for these adolescents to experience a healthy, stable relationship with an adult, it is palpable how much is lost if teachers are not effectively included and trained in these settings (Bowlby, 1969, 1982; Downey, 2007; Gauthier et al., 2004; Kennedy \& Kennedy, 2004).

For these reasons, this study examined the dynamics of the student-teacher relationship within a residential treatment center for female adolescents who have histories of abuse and neglect, and my search of the literature revealed it is the only study to do so. Although there is a vast literature base on the benefits of positive student-teacher relationships for students in typical school settings throughout the developmental stages (Catalano et al., 2004; Pianta, 1999; Reddy et al., 2003), there is no published research studying this phenomenon in residential treatment centers. This study also evaluated the impact of a teacher training, Risking Connection, aimed at informing teachers of the effects of abuse and neglect trauma and providing them with strategies to better connect with their students.

The first hypothesis of this study was that there are associations between students' trauma symptomology, teachers' beliefs about trauma-informed care, teachers' emotionally supportive behavior, and students' perceptions of the student-teacher relationship. This hypothesis was generally supported by the data. Students' trauma symptomology, specifically as it relates to beliefs about others being in control, and teachers' beliefs about trauma-informed care were 
statistically significant predictors of how students' perceived their relationships with their teachers.

The second hypothesis of the study was that training teachers about the effects of trauma and how to build relationships with traumatized students will yield positive, sustained changes in teacher knowledge, beliefs about traumainformed care, and emotionally supportive behavior in the classroom. As a result of these teacher changes, it was further hypothesized that improvement will occur in students' perceptions of the student-teacher relationship and in their reported trauma symptomology. The second hypothesis was generally not supported by the data collected in this study; however, the overall results that emerged led to several important conclusions.

Four main conclusions were drawn from the findings in the study. First, the degree to which student trauma symptomology is negatively associated with the student-teacher relationship appears to be related to the type of symptomology the adolescent student reports. Second, in a residential treatment center setting, teachers who endorse trauma-informed treatment beliefs appear to have more positive relationships with students. Third, trainings that attempt to educate teachers about trauma-informed care (and ultimately impact their long-term teaching practices) may need to be more time intensive, more specifically related to the environment of school, or have frequent or intense "booster" sessions following the initial training. Finally, in a residential treatment center school, it may require many months to both implement a new trauma-informed model and to observe considerable changes in the student-teacher relationship. Following is a 
discussion of the conclusions, supportive data and theory, limitations of the study, and implications for clinical practice and future research.

\section{Conclusion 1: Type of Student Trauma Symptomology Matters When Attempting to Understand the Student-Teacher Relationship}

The first conclusion emerged from the finding that, of the student trauma symtpomology, only the TABS-Other Control subscale significantly predicted students' perception of the student-teacher relationship. This suggests that the degree to which student trauma symptomology is negatively related to the student-teacher relationship appears to stem from the type of symptomology the student reports. Results from this study support the hypothesis that trauma symptomology is predictive of how a student will perceive her relationship with her teacher; however, more specifically, it was symptomology related to a particular schema (i.e., negative trauma-induced beliefs about other people being in control) that predicted how the student perceived her relationship with her teacher. The finding that the TABS-Other-Control subscale significantly predicted students' perceptions of the student-teacher relationship suggests that increased trauma-related schema in which the student feels uncomfortable when others are in control of a situation negatively impacts the perceived quality of teacher relationships.

These findings may also have implications for educational practice in the residential treatment center setting. For example, according to Constructivist Self Development Theory (CSDT), a student who scores higher in the Other-Control 
subscale generally feels uncomfortable when she is not in charge, and, as a result, attempts to control others (Pearlman, 2003). If a student is unable, at least to some degree, to be in charge (e.g., with a teacher who values or demands her own authority) the student may become enraged and aggressive. This idea is also understandable in the context of Bowlby's internal working model; a student with a trauma history likely has a model that adults who are in charge are abusive. This internal framework may also include beliefs that "when I am not in charge, I get abused because this has been my experience in the past. I must control or be controlled, abuse or be abused."

In this sort of scenario, it is clear that the student-teacher relationship would have a better chance of developing in a positive direction if the teacher understood the context of the student's reactions to her. If a teacher with this sort of student has not yet learned the specific trauma framework in which to interpret the student's negative behaviors (either through her own experiences with the student or through information provided by clinical staff), it is easy to see how this student-teacher relationship could become conflictual. On the other hand, armed with this information (i.e., student is high in Other-Control symptomology), a teacher might be advised to "yield on some points when possible, demonstrate a willingness to negotiate, and hold negative interactions in mind for later discussion when appropriate" (Pearlman, 2003, p. 19). The teacher might also be advised to create opportunities for this student to demonstrate leadership. When viewed through the lens of CSDT, it becomes clear that teachers 
with strong self-control needs themselves may not be the best fit for this type of student, unless they can operate at a high level of self-awareness in this area.

An alternative explanation for the finding that students' with higher TABS Other-Control scores had less positive ratings of the student-teacher relationship is that these students may be more direct and overt in their expressions. Although there is a lack of research to support this alternative conclusion, it appears feasible theoretically. According to CSDT, if they have developed beliefs that "I need to be in control or, otherwise, I will be controlled," they may be more likely to share their true negative feelings about another person than a student who, for example, has negative trauma beliefs about herself. It is possible that students' with other types of trauma symptomology are simply less honest or more afraid to share their negative opinion about a teacher, than those who have higher Other-Control scores. CSDT posits that individuals vary in their ability to feel safe or trusting enough to reveal their feelings or thoughts as they relate to their trauma history and many individuals can remain cautious in order to protect themselves from being hurt or abused again (McCann \& Pearlman, 1992b; Pearlman, 2003; Ungar et al., 2009). Additionally, trauma theory informs us that an individual may be in a state of denial of trauma because of current needs (e.g., must function in her current environment) and the level of perceived support from others (Wilson, Friedman \& Lindy, 2001). These factors may influence both what the student is willing to report on the TABS as well as what she thinks of her teachers and therefore should be considered as alternative possible meanings of the study's results. 
Overall, however, the finding that a specific type of trauma symptomology was predictive of students' perception of the student-teacher relationship is a helpful reminder that a student's TABS scores can be useful information for teachers in this setting. It helps the teacher learn that students who experienced similar kinds of traumatic events may respond to the trauma in psychologically different ways. For example, one student may respond with more negative beliefs about others while another, with a similar trauma history, may respond with more negative beliefs about oneself, one may feel less safe while another may feel out of control (van der Kolk et al., 2005). This understanding encourages the teacher to know her students individually, rather than relying solely on what trauma history she may know about them. In general, these findings suggest that there need to be different strategies for connecting to students who vary in the type of trauma symptomology they report. It also suggests that the student-teacher relationship and the classroom setting present different relational dynamics than relationships typically studied (i.e. parent, family, therapist-client) for the effects of trauma. Exploring these differences should be continued in future research and explaining these differences may also be an important addition to the Risking Connection training.

\section{Conclusion 2: Teacher Characteristics are Important Considerations in} Understanding the Student-Teacher Relationship Because Teachers Who Generally Endorse a Trauma-Informed Model Maintain More Positive Relationships with Traumatized Students 
The second main conclusion drawn from the study is that in a residential treatment center setting, teachers who endorse trauma-informed treatment beliefs appear to have positive relationships with this type of student population. This conclusion is supported by several findings in this study. First, the degree to which teachers believed in the effectiveness of trauma-informed care for this population was a significant predictor of positive student perceptions of the student-teacher relationship. Second, teacher endorsements of trauma-informed care and emotionally supportive behavior in the classroom were moderate to high both before and after the teacher training, indicating a fair amount of traumainformed practice throughout the study. Simultaneously, student ratings of the student-teacher relationship were generally positive and stable throughout all four time points which, in light of the attachment disturbances many of these students have, is an important triumph for these teachers.

\section{Teacher Beliefs about Trauma-Informed Care}

Results of this study indicate that the higher a teacher's endorsement of the effectiveness of trauma-informed care, the more likely her students were to rate their relationship positively. The significant amount of variance explained by this teacher characteristic suggests that teacher beliefs about how best to help the traumatized population they teach are as essential as student characteristics for understanding the dynamics of the student-teacher relationship in a residential treatment center. This particular finding is understandable in light of attachment theory. The student-teacher relationship is seen as an extension of the parent-child relationship and can be thought of as a reciprocal 'dance' between both partners 
(Marvin \& Whelan, 2003; Davis, 2003). It seems that each partner, the student and the teacher, bring personal characteristics that significantly influence the student-teacher relationship. Teachers who appear to recognize their students as traumatized instead of viewing them through a disease-model lens (i.e., they have a disorder and need to be fixed by an expert) have better relationships with their students (Downey, 2007; Kennedy \& Kennedy, 2004; Shaw \& Paez, 2007).

The predictive nature of the Trauma-Informed Care Beliefs Measure suggests that teachers who subscribe to the underlying principles of the Risking Connection training curriculum may develop more positive relationships with their students (Downey, 2007). Results from this study imply that teachers who a) appreciate the value of working toward a safe, trusting relationship with these students, b) are able to recognize the strengths in their students, and c) evaluate negative student behaviors as adaptations to traumatic events may be better able to develop positive student-teacher relationships (National Child Traumatic Stress Network, 2008). For example, the Trauma-Informed Care Beliefs Measure asks about strength-based and adaptive value statements such as "the clients I work with are generally doing the best they can at any particular time" and also includes self-awareness statements such as "having intense anger at a client or sadness for a client is a sign that I am letting the work affect me too much." Higher endorsements of these types of statements also may indicate that teachers who have some awareness of the self-care they need when working with a traumatized student population are possibly more effective at building the studentteacher relationship. 
Furthermore, even though the classroom behavior measure was not a statistically significant predictor of student-teacher relationships, the significant correlation between the teachers' beliefs about trauma-informed care and their supportive behavior in the classroom $(r=.45, p<.01)$ demonstrates a connection between what the teachers believe about their students and how they interact with them in the classroom. Overall, the implications of the teacher data for teaching practice and teacher training are all offered very cautiously due to the low sample size of teachers $(n=6)$. Future research should be focused on studying these teacher characteristics with a much larger sample of teachers whose students have experienced early childhood trauma.

\section{General Stability of Positive Student-Teacher Relationship}

The second conclusion is also supported by the general stability of positive student-teacher relationship scores. When viewed through the lens of attachment theory, maintaining some stability, rather than showing significant decline or lability, in relationships while in a residential treatment facility may be interpreted as a positive outcome (Baker et al., 2005; Brady \& Caraway, 2002; Gauthier et al., 2004). Also, because these students likely have attachment-related disturbances, the fact that they would rate any relationship in their lives as positive (or at least not negative) is noteworthy. Overall the relationship ratings for teachers remained relatively stable and generally positive. This implies that these teachers are doing something right (i.e., endorsing trauma-informed care and displaying emotionally supportive behavior in the classroom) in order for these types of students to perceive the student-teacher relationships positively. 
The context of the student-teacher relationship in this study is particularly relevant in order to fully understand the importance of this finding. Residential treatment by its very nature is disruptive to the normal development of children and adolescents in that it means removal from a current placement (Brady \& Caraway, 2002). For many in this population, this change in placement may be one of several changes that have occurred throughout childhood. Combined with the effects of abuse and neglect from primary caregivers, these students have had to adjust to new rules, new teachers, new staff, new therapists, and new communities of peers multiple times (Baker, Archer, \& Curtis, 2005). As stated in Maryhurst Inc.'s description of its residential population, "their issues are further complicated by years of multiple placements in foster care and hospital settings. In fact, prior to their involvement with Maryhurst, any one of our children is likely to have experienced an average of 20 out-of-home placements" (Maryhurst, Inc., 2009). Therefore, maintaining a relatively stable relationship with a teacher after being placed in a new setting again can be seen as a success, particularly when the relationship is generally positive.

The general stability of positive student-teacher relationship scores might alternatively be explained by something other than the teachers' beliefs about trauma-informed care and emotionally supportive behavior in the classroom. While research is lacking in the residential treatment school setting and for this student population, alternative explanations of the positive teacher scores of this study can be evaluated in light of the research in other education settings, particularly universities. In fact, the validity and usefulness of student ratings of 
teachers has generally been a concern for several decades (Greenwald, 1997). In Greenwald's (1997) review of the literature on the validity of student ratings of teachers, he noted that the possible effect of grades on ratings. Early evidence supported a notion that a teacher can get a "good" rating simply by assigning "good" grades; however more recent evidence has suggested "that rather than signaling possible contamination and invalidity of student evaluations, the observed relation between grades and student ratings might reflect expected, educationally appropriate relations" (Howard, Conway, \& Maxwell, 1985, p. 187) Greenwald (1987) concludes that, in general, student ratings tend to be statistically reliable, valid, and relatively free from bias more so than any other data used for evaluation, but this issue remains a prevalent topic in educational literature (Delucchi \& Pelowski, 2000; Norman, 2010) and worthy of consideration in this study. Similarly, it is also possible the results of this study could be attributed to the measure (Your Relationship with This Teacher) not accurately or fully assessing the quality of the student-teacher relationship since this study is the first to empirically use it.

Conclusion 3: Training Programs for Teachers May Need to Be More Time Intensive, Frequent, or Specifically Related to the Classroom Setting in order to Increase and Sustain Impact

The third conclusion of this study is that training programs such as Risking Connection, used to educate teachers about trauma-informed care (and ultimately impact their long-term teaching practices with traumatized students), may need to be more intensive, more specifically related to the environment of 
school, or have frequent or intense "booster" sessions following the initial training. This conclusion emerged from results of the analyses examining change in both teacher and student characteristics after teachers were trained in Risking Connection as well as personal communication with Dr. Joan Gillece, the Program Director of the National Center for Trauma-Informed Care (NCTIC) funded by the United States Substance Abuse and Mental Health Services Administration (SAMHSA) and literature on other types of teacher trainings. Dr. Gillece also works directly with Dr. Rivard, the principle investigator of the research being done on the Sanctuary Model.

This was the first time Risking Connection training was given to a group of teachers and, due to teacher time constraints, it was reduced from its typical three-day format to a two-day format. The post-data collection occurred approximately ten weeks after the training. The teachers received a one hour "booster session" at a faculty meeting that occurred in between the training and the post-data collection. This session consisted of a discussion of some of the Risking Connection concepts and its application to students.

\section{Lack of Significant Change in Teacher Scores following Teacher Training Intervention}

The analyses of teacher change primarily consisted of evaluating descriptive statistics and effect sizes of pre and post scores on the following four teacher measures: Risking Connection Curriculum Assessment, Trauma-Informed Care Beliefs Measure, CLASS-Emotional Support, and Risking Connection 
Fidelity Measure. It was hypothesized that teacher scores would increase after the training and booster session; however, the teacher findings indicated there were no significant differences in the teacher characteristics (Risking Connection knowledge, trauma-informed beliefs, emotionally supportive classroom behavior, and fidelity to the Risking Connection approach) ten weeks after the Risking Connection teacher intervention occurred. The research design would have been improved if teacher data had been collected both directly following the training as well as time points similar to the student post data collections. This would have provided information about what teacher change occurred immediately after the training as well as what changes, if any, were sustained and for how long. The post data collection for teachers, as it was, appears to be more of a follow-up of sustained change since it occurred ten weeks after the training occurred.

It is important to note that even if the training did have a positive effect on teachers initially (which was not captured in the teacher data collections), student and teacher scores suggest that any change that may have occurred did not last, assuming the measures in this study were sensitive enough to assess teacher changes. Overall, teacher scores indicate that teacher characteristics ten weeks after the training were very similar to teacher characteristics before the training occurred. The very slight decrease in scores on the CLASS-Emotional Support and fidelity measures after the training may not be reflective of a decrease in supportive classroom behavior or the teachers' actual use of Risking Connection strategies because the observers only watched teachers in the classroom for an hour and many possible scenarios did not present themselves in that timeframe. 
The minimal fluctuation in the teacher scores may represent a regression to the mean rather than practical change, as they were generally high at time point 1.

Two possible explanations for this finding support the third conclusion drawn from this study: (a) the shortened training and single booster session were not enough to inform teachers about the Risking Connection model; and/or (b) the training was not translated enough to the teacher or educational setting (e.g. did not include information about how trauma affects achievement which may have increased teacher interest and investment). These possible explanations were supported by personal communication with Dr. Joan Gillece, the Program Director of the National Center for Trauma-Informed Care (NCTIC) who is acknowledged in the trauma field as an expert in this area (Institute on Violence, Abuse \& Trauma, 2010). However, it is also possible that the training was efficient as it was implemented and other variables accounted for the lack of change in teachers. This was equally supported by Dr. Gillece. For example, alternative explanations for this finding are: (a) teachers were experiencing a burn-out effect at the very end of the school year when the data were collected and (b) the teachers were already implementing at least some of the strategies because the overall results at both the pre and post data collections for teachers' beliefs about this type of care and their emotionally supportive behaviors in the classroom were moderate to high (Pianta, La Paro, \& Hamre, 2008). The possibility that teachers were experiencing a burn-out effect at the end of the school year is supported by literature on this topic. It is generally acknowledged that teaching is a profession characterized by high levels of burnout and emotional 
exhaustion, particularly when teaching emotion or behavior disordered students (Maslach, Schaufeli, \& Leiter, 2001). In her review of the literature in this area, Chang (2009) suggested several factors that contribute to teacher burnout, including personal characteristics, organizational or institutional context, and the culmination of unpleasant emotions and experiences over time (throughout a school year and throughout a career). Alternatively, in a longitudinal study related to teachers learning technology integration into the urban high school classroom, Mouza (2009) concluded that three factors influenced teacher learning and change over time: (1) beliefs about student characteristics; (2) availability of resources, including technical and administrative support; and (3) collegial support. Although this research is not directly related to the residential treatment center school setting, each of these factors may also be alternative explanations for the teacher results in this study.

Finally, Dr. Gillece offered the additional possibility that the established and historic "rules" of the agency prevented the teachers from implementing what they had learned in the trauma-informed training. For example, teachers may have had an opportunity in the classroom to explore a student's motive for disruptive behavior, but not allowed to leave the classroom (because of an established rule) in order to walk this student out of the classroom and spend a few minutes helping the student emotionally regulate. Other examples might be what a teacher is "allowed" to let students do in her classroom, how much time a teacher is provided to attend treatment meetings, or how much control a teacher has in cocreation of restorative tasks. Dr. Gillece shared that often times when the National 
Center for Trauma-Informed Care directly assists facilities in creating a traumainformed model, they implement a "rule-busting" session in which every policy and procedure of the facility is challenged to assess its necessity and its promotion or restriction of providing trauma-informed care (J. Gillece, Ph.D., personal communication, September 13,2010). The possibility of teacher change occurring right after the training is discussed below in light of the student data that were collected just four weeks after the Risking Connection teacher training.

\section{Possible Trend in Student Scores following Teacher Training Intervention}

Change in students after the teacher intervention was evaluated by examining trends in the student-teacher relationship scores across all four time points. If changes in student ratings of the student-teacher relationship occurred after the teacher training, this suggests change in teachers may have occurred, at least initially. The examination of student scores indicated that scores for Your Relationship with This Teacher at time point 3 , the data collection that occurred closest to the Risking Connection teacher training (although still a month afterwards), revealed slightly higher student scores for perceptions of the studentteacher relationship and slightly higher trauma symptomology (see Figure 1). These student scores at time point 3 suggest that something positive may have occurred with the teachers and the students immediately following the training; however, the changes in scores were not statistically significant. As such, these scores should be viewed, overall, as relatively stable through time. This discussion point is related to a very nuanced fluctuation in scores and therefore its 
relevance is offered cautiously. These final conclusions should only be taken as suggestions for future study or further investigation with additional data.

With that caveat, it is possible that teachers initially felt a "boost" from the training (e.g., they were more enthusiastic, inspired, motivated), such that even when students reported higher levels of trauma, they also felt a positive connection to their teachers at that time (because even with higher trauma symptomology, student-teacher ratings were stable). It is also possible that teachers were able to create safer emotional environments and, as a result, students were more honest about their trauma beliefs. CSDT indicates that individuals need to feel safe and supported in order to honestly reveal their vulnerabilities related to their trauma histories (Pearlman, 2003). As suggested by Pearlman, students may fear letting down their guard, particularly those who have disrupted safety and trust schema. For example, a student who previously reported not feeling scared (a typical indicator of trauma) may have felt emotionally safe enough to admit feeling scared. Therefore, the trend of slightly higher student scores at time point 3 indicates that the teacher training may have done something to influence student characteristics. It is equally possible that these conclusions are not the case. Regardless, it illustrates the importance of gathering data directly following the training intervention.

It is additionally noted that the lowest student-teacher relationship scores occurred at the last time point (although this difference is very minimal; again, overall scores were generally stable). As further discussed below, it is possible to expect decline in relationships during an adolescent's placement in a residential 
treatment center, especially during times of transitions. Because the last data collection occurred at the end of the school year when several teachers were leaving for the summer break, it is possible that students with attachment disturbances would rate their relationships less positively as a way to guard themselves from being hurt (McCann \& Pearlman, 1992b; Pearlman, 2003; Ungar et al., 2009). This last note about student scores would also be worth further examination in related research and a consideration for how long and when teacher training is implemented and evaluated in this setting. This leads to the final conclusion of the study.

\section{Conclusion 4: Significant Changes in Student-Teacher Relationships within Residential Treatment Centers Probably Requires Many Months}

Generally, the non-significant findings related to the changes in teachers and students before and after the Risking Connection teacher training and the Rivard (2004) study of the Sanctuary Model inform the final conclusion of this study. That is, in a residential treatment center school, it may require many months to both fully implement a new trauma-informed model and to observe considerable changes in the student-teacher relationship. This conclusion was additionally supported by Dr. Gillece. Even though the teachers in this study appeared to have been implementing several concepts of trauma-informed care prior to the training, it is possible that the integration of the school into the overall new treatment model of the facility may require additional time for short- and long-term effects to be evident. It is possible that issues such as general communication between the teachers and staff outside of the school (e.g., 
therapists and direct-care staff) may not have been addressed in order to fully benefit from the new model. For example, if teachers do not yet feel comfortable or lack opportunities to communicate with clinical or direct-care staff, actual implementation of what was learned in the Risking Connection training may not yet be happening to the degree it could be.

Despite the fact that students rated their relationships with their teachers relatively high, the findings of the study may support the basic idea that it is a difficult (and a potentially longer process than the timeframe of this study) to significantly improve these student-teacher relationships (Moses, 2000; Schwartz \& Davis, 2006). The tenets of attachment theory and CSDT indicate that individuals with repeated insecure relationships are more likely to understandably bring their negative beliefs about others, particularly adults, (or a well-established negative internal working model) to new relationships. Because of their established negative frame of reference, CSDT offers a framework to understand how basic human needs, such as building trust, are different for those who have traumatic histories than those who do not; therefore, growth in these relationships takes place gradually. "Gradual," of course, is difficult to define and due to the subjective experience of trauma, also explained by CSDT, the length of time it takes to establish and then improve relationships varies among individuals (National Child Traumatic Stress Network, 2008). Attachment theory also suggests relationships for these adolescents, particularly those who already feel abandoned, are likely to deteriorate due to the adolescents' fear of who may leave them (Karp \& Butler, 1996; Mukaddes et al., 2000). For this reason, evaluating 
the changes in teachers and students throughout an entire school year offers more opportunity to observe decline or growth in the student-teacher relationship. The possible trends noted in this study's timeframe may appear much different when viewed across many more months.

This conclusion is further supported by the findings in the Rivard (2004) study of the Sanctuary Model that was implemented with a similar student population. Rivard examined changes in relationships within the residential treatment center (not student-teacher relationships) and did not find significant increases in relationship-building (i.e., social problem solving, perceived sense of community cohesiveness) until six months after implementing the traumainformed (Sanctuary) model. Rivard concluded that as the implementation of the Sanctuary Model was "becoming stronger with time," the treatment environments were functioning better (p.5). Indeed, some of the most important lessons learned from the Rivard project are similar to the lessons learned in this study. For example, Rivard specifically suggested that future focus needs to be on supporting "implementation efforts with more intensive onsite technical assistance," promoting "ongoing evaluation to assess change in the treatment environments and youth over time," and "incorporating the use of brief behavior checklists that can be used as part of the regular program operations" that may be more sensitive to change than student self-report measures (p. 5). 


\section{Limitations of the Study}

\section{Timeframes}

The total timeframe of the study was four months. The first data collection occurred in late January and the last occurred in late May, roughly coinciding with the spring school semester. This only allowed for one one-hour "booster" session for teachers after the teacher training. In order to detect changes in teacher beliefs and behavior, the student-teacher relationship, and students' reported trauma symptomology, a longer timeframe for the training with additional booster sessions and data collections could have improved the study design. As stated, the Rivard (2004) study that evaluated positive changes in residents after a similar trauma-informed model was implemented in a residential treatment center did not show significant results until assessments at six months after the intervention when the model was more fully implemented. Details of how their traumainformed model became better implemented through time were not discussed but more intensive, onsite assistance from trainers was suggested.

Additionally, the shortened Risking Connection training for teachers was not ideal. If Risking Connection trainings typically implemented for audiences of clinical and direct care staff require a three day training, than teachers in this setting appear to need the same or more training. Clinical and direct care staff presumably have at least some background or prior knowledge about trauma, or minimally chose to work with a traumatized population. This is often not true for teachers in this setting. Therefore, it seems that teachers would likely need 
additional training, or at least the same amount, as those individuals. The Risking Connection trainers directly acknowledged the time frame allowed for the teachers was not preferred, but agreed that some training is better than none (S. Brown, Psy.D., personal communication, January 15, 2010). Due to the fact that this was the first time they trained teachers, information gathered from this study was extremely valuable in designing future trainings for the teacher audience.

\section{Measures}

The measures used in this study, specifically those related to the Risking Connection training (Risking Connection Curriculum Assessment, TraumaInformed Belief Measure, Risking Connection fidelity measure), and the Relationship with Your Teacher measure are only beginning to be empirically tested. Furthermore, quantitative methods in general may not capture the complexity of trauma, adolescence, and treatment of those who have been traumatized (Karp \& Butler, 1996; Park \& Ai, 2006). It is a limitation to have only quantitative data and imperfect support for the measures used (Shadish, Cook, \& Campbell, 2002; Teddlie \& Tashakkori, 2009). This is due to the fact that research in this area is lacking and more robust measures simply do not currently exist (Brady \& Caraway, 2002; Moses, 2000; Scholte \& Van der Ploeg, 2000).

\section{Data Collection Procedure}

Using effective data collection strategies with adolescents who have experienced pervasive trauma and who are placed in this setting can be daunting. 
In this study, the data collection consisted of having students complete lengthy questionnaires. Although, each data collection session included a lunch break, the number of questions may have been too much for these students to provide accurate responses in one session (Hindman, 1990; Karp \& Butler, 1996). The two student measures used in this dissertation were only part of what was collected during the pilot study. Students were actually asked to complete five measures with a total of 364 items. Obviously, it would have been preferable to only have the students complete the two measures specifically related to the research goals of this study, but this is a limitation of using archival data. In reality, if that had occurred it may have decreased the number of incomplete measures due to physical or emotional fatigue or boredom and may have allowed the students to consider the items more deeply.

\section{Sample size}

A clear limitation is the very low sample size of teachers $(n=6)$ and the relatively low sample size of students ( $n=32$ for students who completed all time points). Also, the teacher group consisted of only female teachers, four of which were Caucasian. These sample characteristics ultimately impact the power of the study and its generalizability (Shadish, Cook, \& Campbell, 2002).

\section{Lack of comparison group}

The second and third questions of the current study compared pre and post scores before and after the Risking Connection teacher intervention. This study did not have a comparison group within the Maryhurst residential treatment center 
or in any other similar residential treatment center, and this has implications. Specifically, the lack of a comparison group decreases the ability to conclude that changes occurred as a result of the teacher intervention. The possible influence of extraneous variables is less controlled without a comparison group. Ultimately, questions 2 and 3 did not result in statistically significant findings; however, the design of future related studies would benefit from a control or comparison group in order to better determine the impact of the training intervention.

\section{Lack of information about teacher characteristics}

Also related to the generalizability of the study is the lack of information gathered about the teachers. Specifically, data were not collected related to the experience the teachers have working with this population of students, the training they have related to teaching traumatized students, or the reason they are choosing to teach this population. This information could help illuminate how these teacher characteristics influence the student-teacher relationship for this type of student. If data suggested that teachers with training and experience are rated more positively by students, this would lend support to the hypothesis that training teachers about trauma-informed care is important. It could also help discern whether a training intervention such as Risking Connection is more or less useful for teachers who are new to teaching this population or to ones who did not purposely choose to work with traumatized students. 


\section{Directions for Future Research}

This research study is the first of its kind to evaluate the dynamics of the student-teacher relationship in the context of residential treatment for adolescents with trauma histories. Furthermore, this study explores what can be done to train teachers in this type of setting to positively impact this population of students. The findings revealed that students' reported trauma symptomology (related to Other-Control) and teachers' beliefs about the effectiveness of trauma-informed care such as the Risking Connection framework, are predictive of students' perceptions of their teacher relationships. Findings also suggest that trainings such as Risking Connection for teachers and subsequent booster sessions may need to be longer, more substantial, more frequent, and/or more specifically related to school and learning in order to significantly impact teacher knowledge, beliefs and classroom behavior as they relate to trauma-informed care for this population. The end goal, of course, is to positively impact students who have been traumatized. This study offers several directions for future research in this critical area.

\section{Qualitative Interviews with Teachers and Students}

A mixed-method research design is optimal for further understanding clinical populations (Park \& Ai, 2006; Teddlie \& Tashakkori, 2009). Studying adolescents who have experienced childhood trauma and currently placed in a residential treatment center is a complex endeavor. According to Park and $\mathrm{Ai}$ (2006), using quantitative approaches is limiting in that they do not provide the 
data to adequately understand the phenomenon of trauma. "To more fully understand the impact of trauma and survivors' making of meaning, quantitative approaches should be combined with more in-depth qualitative means, an approach that promises to yield great insight" (p. 400). Adding qualitative measures that include directly interviewing the teachers and students is a natural extension of the current study. Given what is at stake for the students, understanding the nuances of teacher and student beliefs related to trauma and the meanings of their behaviors is extremely important, albeit challenging. Providing a forum that allows the traumatized students to use their own words to describe their experiences would promote further understanding of findings from the quantitative data collected for this study as well as the population and setting in general. Park and Ali (2006) add that qualitative information may offer not only new hypotheses to be tested by quantitative research but suggest implications for intervening with specific types of trauma as well. Regarding the current study, qualitative questions for the teachers and students about how they perceive the student-teacher relationship could lead to follow-up questions about why they believe the relationship is either positive or negative. It would be additionally beneficial to directly ask the teachers how the training initially impacted them cognitively, emotionally, and behaviorally as well as if the impact lasted. Qualitative questions could also ascertain their opinions about what was helpful and what was not in the training and why. The answers to these questions would provide a richer understanding of the quantitative results of the study as well as additional routes for future investigation. 


\section{Additional Measures and Follow-up Data Collection}

Related future research studies include adding other data measures such as those that are collected by the residential treatment center (and school) as part of their documentation procedures. For example, to further understand the effects of the teacher training, researchers could also examine the change in such things as of physical interventions by staff, student grades, and annual student satisfaction surveys before and after the Risking Connection teacher training. This information could demonstrate the behavioral, academic, and socio-emotional changes in students before and after the teacher training was implemented. Another possible addition is the data already collected during the pilot study, and thus a part of the archival data available for investigation. To further understand the dynamics of the student-teacher relationship, data from the Teacher Behavior Questionnaire (collected from students in the pilot) could be used in an additional regression model. Specifically, to what extent does student trauma symptomology predict how a student perceives the behaviors of their teacher as measured by the Teacher Behavior Questionnaire? Because this measure asks about many specific teacher behaviors (120 items), this additional information could further the understanding of how a students' trauma symptomology is associated with their perceptions of others' behaviors, particularly their teachers. This information could then further enlighten teachers (and researchers) about how specific teacher behaviors are interpreted by students with certain types of trauma beliefs.

Adding follow-up assessments for students and teachers before and after supplementary Risking Connection teacher training and booster sessions could 
provide information regarding the impact of more training. This type of continued assessment could also establish trends in the student-teacher relationship throughout time in residential treatment and/or throughout the school year.

\section{Further Adaptation of the Risking Connection Curriculum for Teachers}

The Risking Connection trainers involved in this project typically train clinical and direct-care staff in residential treatment centers. The training for teachers that was implemented in this study was adapted for the first time from its typical use with that audience to an audience of teachers. As stated earlier, the training was also reduced by one day from its typical format. While the trainers attempted to use as many school-based scenarios as possible, they acknowledged the need to specifically relate the Risking Connection curriculum to teachers in a more precise way (S. Brown, Psy.D. \& P. Wilcox, MSW, personal communication, March 12, 2010). For example, additions to a Risking Connection curriculum for teachers might include much more information about how trauma affects cognitive development as evidenced by the biological research and classroom management strategies addressing trauma-related disturbances in a group setting. Results of this study also suggest that the Risking Connection curriculum for all audiences may be strengthened with explanations about trauma beliefs that are related to the self and those that are related to others. Interventions related to each type of trauma symptomology, especially Other-Control, could be specified and added. 


\section{Summary}

Undoubtedly, trauma is a complicated issue and adolescence is a challenging stage of development (Giovacchini, 2001; Kalke et al., 2007; Novick \& Novick, 2001). Treating adolescents who have experienced early childhood abuse and neglect and subsequently removed from their family, their home, their school, and their community multiple times adds additional layers of complexity (Giovacchini, 2001). This adolescent population in residential treatment centers across the country is only beginning to be empirically investigated even though these issues have concerned many for decades. The research knowledge we do have about the important role a teacher can play in a student's life must be applied to this vulnerable population. Teachers are in an incredible position to provide a stable, consistent, and supportive adult relationship for developing adolescents who have lacked this experience and desperately need it. Teachers who understand the effects of trauma on learning, who are able to develop teaching practices to help them, and "who are able to participate actively and collaboratively in the systems designed to support traumatized children will not only improve their educational outcomes but will assist in their healing and recovery" (Downey, 2007, p. iv). But, this is a difficult task and teachers must be prepared and educated about the students they teach. Understanding the unique dynamics of the student-teacher relationship in this context is critical to understand how best to use that relationship to help these students develop cognitively and socio-emotionally so they can prosper in adulthood. 


\section{REFERENCES}

Aber, J. L., Allen, J. P., Carlson, V., \& Cicchetti, D. (1989). The effects of maltreatment on development during early childhood: Recent studies and their theoretical, clinical, and policy implications. In V.Carlson \& D.Cicchetti (eds.), Child maltreatment: Theory and research on the causes and consequences of child abuse and neglect (pp. 579-619). New York: Cambridge University Press.

Abramowitz, R. \& Bloom, S. L. (2003). Creating sanctuary in residential treatment for youth: From the "well-ordered asylum" to a "living-learning environment." Psychiatric Quarterly, 74, 119-135.

Ainsworth, M., Blehar, M., Waters, E., \& Wall, S. (1978). Patterns of attachment: A psychological study of the Strange Situation. Hillsdale, NJ: Erlbaum.

Alloy, L. B. \& Abramson, L. Y. (2007). The adolescent surge in depression and emergence of gender differences: A biocognitive vulnerability-stress model in developmental context. In D. Romer \& E.F. Walker (Eds.), Adolescent psychopathology and the developing brain: Integrating brain and prevention science (pp. 284-312). New York: Oxford University Press.

American Academy of Child and Adolescent Psychiatry (2003). Practice parameters for the assessment and treatment of children and adolescents with reactive attachment disorder of infancy and early childhood. Unpublished manuscript. 
American Psychiatric Association. (2000). Diagnositic and statistical manual of mental disorders $\left(4^{\text {th }}\right.$ ed. Text revision) Washington, DC: Author.

Armstrong, K. L., Fraser, J. A., Dadds, M. R., \& Morris, J. (2000). Promoting secure attachment, maternal mood and child health in a vulnerable population: A randomized controlled trial. Journal of Pediatric and Child Health, 36, 555-562.

Baker, A. J. L., Archer, M., \& Curtis, P. A. (2005). Age and gender differences in emotional and behavioural problems during the transition to residential treatment: the Odyssey project. International Journal of Social Welfare, 14, 184-194.

Bakermans-Kranenburg, M. J., Van IJzendoorn, M. H., \& Juffer, F. (2005). Disorganized infant attachment and preventive interventions: A review and meta-analysis. Infant Mental Health Journal, 26(3), 191-216.

Bates, B. C. \& Dozier, M. (2002). The importance of maternal state of mind regarding attachment and infant age at placement to foster mothers' representations of their foster infants. Infant Mental Health Journal, 23(4), 417-431.

Becker-Weidman, A. (2006). Treatment for children with trauma-attachment disorders: Dyadic developmental psychotherapy. Child and Adolescent Social Work Journal, $23,147-171$.

Bergin, C. \& Bergin, D. (2009). Attachment in the classroom. Educational Psychology Review, 21, 141-170.

Bess, R. (2002). The cost of protecting vulnerable children. Urban Institute Research of Record. Retrieved from http://www.urban.org/url.cfm?ID=310586 
Bowlby, J. (1969). Attachment (Vol. 1). New York: Basic Books.

Bowlby, J. (1982). Attachment and Loss ( $2^{\text {nd }}$ ed.). New York: Basic Books.

Bowlby, J. (1954). The diagnosis and treatment of psychological disorders in childhood. Health Education Journal, 12, 59-68.

Brady, K. L. \& Caraway, J. (2002). Home away from home: Factors associated with current functioning in children living in a residential treatment setting. Child Abuse \& Neglect, 26, 1149-1163.

Briere, J. (1995). Trauma Symptom Inventory professional manual. Odessa, FL: Psychological Assessment Resources.

Carman, G.O., Dorta, N., Kon, D., Martin, J., \& Zarrilli, M.A. (2004). Special education in residential treatment. Child and Adolescent Psychiatric Clinics of North America, 13, 381-394.

Casey, B. J., Giedd, J. N., \& Thomas, K. M. (2000). Structural and functional brain development and its relation to cognitive development. Biological Psychology, $54,241-257$.

Catalano, R., Haggerty, K., Oesterle, S., Fleming, C. \& Hawkins, D. (2004). The importance of bonding to school for healthy development: Findings from the social development group. Journal of School Health, 74, 252-261.

Chaffin, M., Hanson, R., Saunders, B. E., Nichols, T., Barnett, D., Zeanah, C., et al. (2006). Report of the APSAC task force on attachment therapy, reactive attachment disorder, and attachment problems, Child Maltreatment, 11, 76-89. 
Chang, K., Gallelli, K., \& Howe, M. (2007). Early identification and prevention of earlyonset bipolar disorder. In D. Romer \& E. F. Walker (Eds.), Adolescent psychopathology and the developing brain: Integrating brain and prevention science (pp. 315-346). New York: Oxford University Press.

Children's Alliance (2007). Kentucky's voice for at-risk children \& families: 2007 Directory of services for children in need. Frankfort, KY.

Cicchetti, D. \& Toth, S. L. (1995). Developmental psychopathology perspective on child abuse and neglect. Journal of the American Academy of Child and Adolescent Psychiatry, 34, 541-565.

Clausen, J. M., Landsverk, J., Ganger, W., Chadwick, D., \& Litrownik, A. (1998). Mental health problems of children in foster care. Journal of Child and Family Studies, 7, 283-296.

Coates, S. W. (2004). John Bowlby and Margaret S. Mahler: Their lives and theories. Journal of the American Psychoanalytic Association, 52, 571-600.

Coles, J. \& Mudaly, N. (2010). Staying safe: Strategies for qualitative child abuse researchers. Child Abuse Review, 19, 56-69.

Cooper, N. S., Feder, A., Southwich, S. M., \& Charney, D. S. (2007). Resilience and vulnerability to trauma: Psychobiological mechanisms. In D. Romer \& E.F. Walker (Eds.), Adolescent psychopathology and the developing brain: Integrating brain and prevention science (pp. 347-372). New York: Oxford University Press. 
Chang, M. (2009). An appraisal perspective of teacher burnout: Examining the emotional work of teachers. Educational Psychology Review, 21, 193-218.

Davis, H. A. (2003). Conceptualizing the role and influence of student-teacher relationships on children's social and cognitive development. Educational Psychologist, 38, 207-234.

Delucchi, M. \& Pelowski, S. (2000). Liking or learning: The effect of instructor likeability and student perceptions of learning on overall ratings of teaching ability. Radical Pedagogy. Retrieved from http://radicalpedagogy.icaap.org/content/issue2_2delpel.html

Downey, L. (2007). Calmer classrooms: A guide to working with traumatized children. Melbourne, Australia: Child Safety Commissioner.

Dozier, M., Higley, E., Albus, K. E. \& Nutter, A. (2002). Intervening with foster infants' caregivers: Targeting three critical needs. Infant Mental Health Journal, 23(5), $541-554$.

Dozier, M., Peloso, E., Lindhiem, O., Gordon, M. K., Manni, M., Sepulveda, S., Ackerman, J., Bernier, A., \& Levine, S. (2006). Developing evidence-based interventions for foster children: An example of a randomized clinical trial with infants and toddlers. Journal of Social Issues, 62, 767-785.

Dutton, M. A., Burghardt, K. J., Perrin, S. G., Chrestman, K.R., \& Halle, P.M. (1994). Battered women's cognitive schemata. Journal of Traumatic Stress, 7, 237-255. 
Eckenrode, J., Laird, M., \& Doris, J. (1993). School performance and disciplinary problems among abused and neglected children. Developmental Psychology, 29, $53-62$.

Edwards, E. P., Eiden, R. D., \& Leonard, K. E. (2004). Impact of fathers' alcoholism and associated risk factors on parent-infant attachment stability from 12 to 18 months. Infant Mental Health Journal, 25, 556-579.

Egeland, B., Sroufe, L.A., \& Erickson, M. (1983). The developmental consequences of different patterns of maltreatment. Child Abuse \& Neglect, 7, 459-69.

Epstein, S. (1985). The implications of cognitive-experimental self-theory for research in social psychology and personality. Journal for the Theory of Social Behavior, 15, 283-310.

Garrett, C. J. (1985). Effects of residential treatment on adjudicated delinquents: A metaanalysis. Journal of Research in Crime \& Delinquency, 22, 287-308.

Gauthier, Y., Fortin, G., \& Jeliu, G. (2004). Clinical application of attachment theory in permanency planning for children in foster care: The importance of continuity of care. Infant Mental Health Journal, 25, 379-396.

Giedd, J. N. (2004). Structural magnetic resonance imaging of the adolescent brain. Annals of the NY Academy of Science, 1021, 77-85.

Giovacchini, P. L. (2001). Dangerous transitions and the traumatized adolescent. The American Journal of Psychoanalysis, 61, 7-22. 
Goodman, L. A., \& Dutton, M. A. (1996). The relationship between victimization and cognitive schemata among episodically homeless, seriously mentally ill women. Violence and Victims, 11, 159-174.

Greenberg, M. T., Weissberg, R. P., Obrien, M. U., Zins, J. E., Fredericks, L., Resnik, H., \& Elias, M. J. (2003). Enhancing school-based prevention and youth development through coordinated social, emotional, and academic learning. American Psychologist, 58, 466-474.

Greenwald, A. G. (1997). Validity concerns and usefulness of student ratings of instruction. American Psychologist, 52, 1182-1186.

Gregory, A. \& Weinstein, S. R. (in press). A window on the discipline gap: Defiance or cooperation in the high school classroom. Journal of School Psychology.

Hall, S. E. K \& Geher, C. (2003). Behavioral and personality characteristics of children with reactive attachment disorder. The Journal of Psychology, 137(2), 145-162.

Hamre, B. K., Mashburn, A., Pianta, R. C., Downer, J. (2006). Validation of 3-factor model for classroom quality across preschool to fifth grade. Manuscript submitted for publication.

Hamre, B. K., \& Pianta, R. C. (2001). Early teacher-child relationships and the trajectory of children's school outcomes through eighth grade. Child Development, 72, 625638. 
Henricsson, L., \& Pydell, A. (2004). Elementary school children with behavior problems: Teacher-child relations and self-perception. A prospective study. Merrill-Palmer Quarterly, 50, 111-138.

Hindman, J. (1990). Just before dawn: From the shadows of tradition to new reflections in trauma assessment and treatment of sexual victimization. $\mathrm{LaGrande}, \mathrm{OR}$ : AlexAndria Associates.

Holmbeck, G. N., \& Kendall, P. C. (2002). Introduction to the special section on clinical adolescent psychology: Developmental psychopathology and treatment. Journal of Consulting and Clinical Psychology, 70, 3-5.

Horowitz, M. J. (1975). Intrusive and repetitive thoughts after experimental stress. Archives of General Psychiatry, 32, 1457-1463.

Hussey, D. L. \& Gua, S. (2005). Forecasting length of stay in child residential treatment. Child Psychiatry \& Human Development, 36, 95-111.

Institute on Violence, Abuse, \& Trauma (2010). $15^{\text {th }}$ International Conference on Violence, Abuse and Trauma. Alliant University. San Diego, CA

Johnson-Reid, M. \& Barth, R. P. (2003). Probation foster care as an outcome for children exiting child welfare foster care. Social Work, 48, 348-361.

Johnson-Reid, M., Scott Jr., L. D., McMillen, J. C., \& Edmond, T. (2007). Dating violence among emancipating foster youth. Children and Youth Services Review, $29,557-571$. 
Juffer, F., Bakermans-Kranenburg, M., \& van Ijzendoorn, M. H. (2005). The importance of parenting in the development of disorganized attachment: Evidence from a preventive intervention study in adoptive families. Journal of Child Psychology and Psychiatry, 46(3), 263-274.

Kalke, T., Glanton, A., \& Cristalli, M. (2007). Positive behavioral interventions and supports: Using strength-based approaches to enhance the culture of care in residential and day treatment education environments. Child Welfare, 86, 151174.

Karp, C. L. \& Butler, T. L. (1996). Treatment strategies for abused children: From victim to survivor. Thousand Oaks, CA: Sage Publications.

Kaufman, J., \& Cicchetti, D. (1989). Effects of maltreatment on school-age children's socioemotional development: Assessments in a day-camp setting. Developmental Psychology, 25, 516-524.

Kennedy, J. H. \& Kennedy, C. E. (2004). Attachment theory: Implications for school psychologists. Psychology in the Schools, 41, 247-249.

Kobak, R., Little, M., Race, E., \& Acosta, M. C. (2001). Attachment disruptions in seriously emotionally disturbed children: Implications for treatment. Attachment and Human Development, 3, 243-258.

Langelier, C. A. \& Connell, J. D. (2005). Emotions and learning: Where brain based research and cognitive-behavioral counseling strategies meet the road. Rivier College Online Academic Journal, 1, 1-13. 
Larrieu, J.A., Heller, S.S., Smyke, A.T., Zeanah, C.H. (2008) Predictors of permanent loss of custody for mothers of infants and toddlers in foster care. Infant Mental Health Journal, 29, 48-60.

LeDoux, J. E. (1996). The emotional brain. New York: Simon and Schuster.

Lyons-Ruth, K., Connell, Grunebaum, H. U., Botein, S. (1990). Infants at social risk: Maternal depression and family support services as mediators of infant development and security of attachment. Child Development, 61, 85-98.

Main, M., \& Hesse, E. (1990). Parents unresolved traumatic experiences are related to infant disorganized attachment status: Is frightened and/or frightening parental behavior the linking mechanism? In M.T. Greenberg, D. Cichetti, \& E. Cummings (Eds.) Attachment in the preschool years: Theory, research, and intervention (pp. 161-182). Chicago, IL: University of Chicago Press.

Main, M., \& Solomon, J. (1990). Procedures for identifying infants as disorganized/disoriented during the Ainsworth Strange Situation. In M.T. Greenberg, D. Cicchetti, \& E.M. Cummings, (Eds.), Attachment in the preschool years: Theory, research, and intervention (pp. 121-182). Chicago: The University of Chicago Press.

Mansheim, P. (1982). A Comparison of two models of education in residential treatment. Hospital \& Community Psychiatry, 33, 844-846.

Martin, A. J., Marsh, H. W., McInerny, D. M., Green, J., \& Dowson, M. (2007). Getting along with teachers and parents: The yields of good relationships for students' 
achievement motivation and self esteem. Australian Journal of Guidance and Counselling, 17, 109-125.

Marvin, R. S. \& Whelan, W. F. (2003). Disordered attachments: Toward evidence-based clinical practice. Attachment \& Human Development, 5(3), 283-288.

Mas, K. (1992). Disrupted schemata in psychiatric patients with a history of childhood sexual abuse on the McPearl Belief Scale. Unpublished doctoral dissertation, California School of Professional Psychology, Fresno.

Maslach, C., Schaufeli, W. B., \& Leiter, M. P. (2001). Job burnout. Annual Review of Psychology, 52, 397.

McCann, I. L. \& Pearlman, L. A. (1992a). Constructivist self-development theory: A theoretical framework for assessing and treating college students. College Health, 40, 189-196.

McCann, I. L. \& Pearlman, L. A. (1992b). Constructivist self-development theory: A theoretical model of psychological adaptation to severe trauma. In D.K. Sakheim (Ed.) Out of darkness: Exploring Satanism and ritual abuse (pp. 185-206). Lanham, MD: Lexington Books.

McMillen, J. C. \& Raghavan, R. (2009). Pediatric to adult mental health service use of young people leaving the foster care system. Journal of Adolescent Health, 44, 7 13.

Moses, T. (2000). Attachment theory and residential treatment: A study of staff-client relationships. American Journal of Orthopsychiatry, 70, 474-490. 
Mouza, C. (2009). Does research-based professional development make a difference? A longitudinal investigation of teacher learning in technology integration. Teachers College Record, 111, 1195-1241.

Mukaddes, N. M., Bilge, S., Alyanak, B., \& Kora, M. E. (2000). Clinical characteristics and treatment responses in cases diagnosed as reactive attachment disorder. Child Psychiatry \& Human Development, 30, 273-287.

National Child Traumatic Stress Network (NCTSN) (2008). Child trauma toolkit for educators. Washington, D.C.: SAMHSA, USHHS.

Nelson, C. A., Bloom, R. E., Cameron, J. L., Amaral, D., Dahl, R. E., \& Pine, D. (2002). An integrative, multidisciplinary approach to the study of brain-behavior relations in the context of typical and atypical development. Development and Psychopathology, 14, 499.

Nickerson, A. B., Brooks, J. L., Colby, S. A., Rickert, J. M., \& Salamone, F. J. (2006). Family involvement in residential treatment: Staff, parent, and adolescent perspectives. Journal of Child and Family Studies, 15, 681-694.

Norman, A.D. (2010). Assessing accomplished teaching: Good strides, great challenges. Theory Into Practice, 48, 203-212.

Novick, J. \& Novick, K. K. (2001). Trauma and deferred action in the reality of adolescence. The American Journal of Psychoanalysis, 61, 43-61. 
Nylen, K.J., Moran, R. E., Frankline, C. L., \& O’Hara, M. W. (2006). Maternal depression: A review of relevant treatment approaches for mothers and infants. Infant Mental Health Journal, 27, 327-343.

O'Connor, T., \& Zeanah, C. (2003). Attachment disorders: Assessment strategies and treatment approaches. Attachment \& Human Development, 5, 223-245.

Park, C. L. \& Ai, A. L. (2006). Meaning making and growth: New directions for research on survivors of trauma. Journal of Loss and Trauma, 11, 389-407.

Peacock, C. \& Daniels, G. (2006). Applying an antiracist framework to a residential treatment center: Sanctuary, a model for change. Racism and Racial Identity. Retrieved from http://jea.haworthpress.com on September 16, 2009.

Pearlman, L. A. (2003). Trauma and attachment belief scale (TABS) manual. Los Angeles: Western Psychological Services.

Pearlman, L. A. \& Courtois, C. A. (2005). Clinical applications of the attachment framework: Relational treatment of complex trauma. Journal of Traumatic Stress, $18,449-459$.

Pecora, R. J., Kessler, R. C., O’Brien, K., While C. R., Williams, J., Hiripe, E., English, D., White, J., Herrick, M. A. (2006). Educational and employment outcomes o fadults formerly placed in foster care: Results from the Northwest Foster Care Alumni study. Children and Youth Services Review, 28, 1459-1481.

Pianta, R. C. (1999). Enhancing relationships between children and teachers. Washington, DC: American Psychological Association. 
Pianta, R. C., La Paro, K., \& Hamre, B. K. (2008). Classroom Assessment Scoring System (CLASS). Baltimore: Paul H. Brookes.

Pryce, C. R., Dettling, A. C., Spengler, M., Schnell, C. R., \& Feldon, J. (2004). Deprivation of parenting disrupts development of homeostatic and reward systems in marmoset monkey offspring. Biological Psychiatry, 56, 72-79.

Reddy, R., Rhodes, J. E., \& Mulhall, P. (2003). The influence of teacher support on student adjustment in the middle school years: A latent growth curve study. Development and Psychopathology, 15, 119-138.

Rivard, J.C. (2004). Initial findings of an evaluation of trauma recovery framework in residential treatment. Residential Group Care Quarterly, 5, 3-5.

Rivard, J. C., Bloom, S. L., Abramowitz, R., Pasquale, L. E., Duncan, M., McCorkle, D., \& Gelman, A. (2003). Assessing the implementation and effects of a traumafocused intervention for youths in residential treatment. Psychiatric Quarterly, 74, $137-154$.

Rivard, J. C., McCorkle, D., Duncan, M., Bloom, S. L., \& Abramowitz, R. (2004). Implementing a trauma recovery framework for youths in residential treatment. Child and Adolescent Social Work Journal, 21, 529-550.

Roeser, R., Eccles, J., \& Sameroff, A. (1998). Academic and emotional functioning in early adolescence: Longitudinal relations, patterns, and prediction by experience in middle school. Development and Psychopathology, 10, 321-352. 
Roeser, R. W., Midgley, C., \& Urdan, T. C. (1996). Perceptions of the school psychological environment and early adolescents' psychological and behavioral functioning in school: The mediating role of goals and belonging. Journal of Educational Psychology, 88, 408-422.

Roth, S. \& Cohen, L. J. (1986). Approach, avoidance, and coping with stress. American Psychologist, 41, 813-819.

Saakvitne, K. W., Tennen, H., \& Affleck, G. (1998). Exploring thriving in the context of clinical trauma theory: Constructivist self development theory. Journal of Social Issues, 54, 279-299.

Saakvitne, K.W., Gamble, S., Pearlman, L.A., \& Lev, B. (2003). Risking connection: A training curriculum for working with survivors of childhood abuse. Lutherville, MD: Sidran Institute.

Salinger, S., Feldman, R. S., Hammer, M., \& Rosario, M. (1993). The effects of physical abuse on children's social relationships. Child Development, 64, 169-187.

Scholte, E. M. \& Van der Ploeg, J. D. (2000). Exploring factors governing successful residential treatment of youngsters with serious behavioural difficulties: Finding from a longitudinal study in Holland, Childhood, 7, 129-153.

Schore, A. N. (2001). Effects of a secure attachment relationship on right brain development, affect regulation, and infant mental health. Infant Mental Health Journal, 22, 7-66.

Schwartz, E. \& Davis, A. S. (2006). Reactive attachment disorder: Implications for school readiness and school functioning. Psychology in the Schools, 43, 471-479. 
Seeman, T. E., Singer, B. H.,\& Ryff, C. D. (2002). Social relationships, gender, and allostatic load across two age cohorts. Psychosomatic Medicine, 64, 395-406.

Shadish, W. R., Cook, T. D., \& Campbell, D. T. (2002). Experimental and quasiexperimental designs for generalized causal inference. Boston: Houghton Mifflin Company.

Shaw, S. R. \& Paez, D. (2007). Reactive attachment disorder: Recognition, action, and considerations for school social workers. Children \& Schools, 29, 69-74.

Shonk, S. M., \& Cicchetti, D. (2001). Maltreatment, competency deficits, and risk for academic and behavioral maladjustment. Developmental Psychology, 37, 3-17.

Sheperis, C. J., Renfro-Michel, E. L., \& Doggett, R. A. (2003). In-home treatment of Reactive Attachment Disorder in a therapeutic foster care system: A case example. Journal of Mental Health Counseling, 25(1), 76-88.

Skinner, E. A., \& Belmont, M. J. (1993). Motivation in the classroom: Reciprocal effects of teacher behavior and student engagement across the school year. Journal of Educational Psychology, 85, 571-581.

Sowell, E. R., Thompson, R. M., Leonard, C. M., Welcome, S. E., Kan, E., \& Toga, A. W. (2004). Longitudinal mapping of cortical thicknesses and brain growth in normal children. Journal of Neuroscience, 24, 8223-8231.

Sprang, G., Clark, J., Kaak, O., \& Brenzel, A. (2004). Developing and tailoring mental health technologies for child welfare: The comprehensive assessment and training services (CATS) project. American Journal of Orthopsychiatry, 74, 325-336. 
Sroufe, L. A. (1996). Emotional development: The organization of emotional life in the early years. New York: Cambridge University Press.

Stafford, B., Zeanah, C. H., \& Scheeringa, M. (2003). Exploring psychopathology in early childhood: PTSD and attachment disorders in DC: 0-3 and DSM-IV. Infant Mental Health Journal, 24, 398-409.

Svanberg, P. O. G. (1998). Attachment, resilience and prevention. Journal of Mental Health, 7(6), 543-578.

Teddlie, C. \& Tashakkori, A. (2009). Foundations of mixed methods research: Integrating quantitative and qualitative approaches in the social and behavioral sciences. Thousand Oaks, CA: Sage Publications.

Teti, D. M., Gelfland, D. M., Messinger, D. S., \& Isabella, R. (1995). Maternal depression and the quality of early attachment: An examination of infants, preschoolers, and their mothers. Developmental Psychology, 31, 364-376.

Tobin, D., Wardi-Zonna, K., \& Yezzi-Shareef, A. M. (2007). Early recollections of children and adolescents diagnosed with Reactive Attachment Disorder. The Journal of Individual Pscyhology, 63(1), 86-95.

Toth, S. L, Rogosch, F. A., Manly, J. T., \& Cicchetti, D. (2006). The efficacy of toddlerparent psychotherapy to reorganize attachment in the young offspring of mothers with major depressive disorder: A randomized preventive trial. Journal of Consulting and Clinical Psychology, 74(6), 1006-1016. 
Toth, S. L., Rogoshch, F. A, Sturge-Apple, M. \& Cicchetti, D. (2009). Maternal depression, children's attachment security, and representational development: An organizational perspective. Child Development, 80, 192-208

Ungar, M., Barter, K., McConnel, S., Tutty, L., \& Fairholm, J. (2009). Patterns of abuse disclosure among youth. Qualitative Social Work, 8, 341-356.

U. S. Department of Health and Human Services, Administration on Children, Youth and Families, Children's Bureau (2009). Foster Care Statistics. Retrieved from www.childwelfare.gov on August 10, 2009.

Vacca, J. S. (2008). Foster children need more help after they reach the age of eighteen. Children and Youth Services Review, 30, 485-492.

van der Kolk, B. A., Roth, S., Pelcovitz, D., Sunday, S. \& Spinazzola, J. (2005). Disorders of extreme stress: The empirical foundation of a complex adaptation to trauma. Journal of Traumatic Stress, 18, 389-399.

Wan, M. W. \& Green, J. (2009). The impact of maternal psychopathology on childmother attachment. Archives of Women's Mental Health, 12, 123-134.

Wentzel, K. R. (1998). Social relationships and motivation in middle school: The role of parents, teachers, and peers. Journal of Educational Psychology, 90, 202-209.

Wethington, H. R., Hahn, R. A., Fuqua-Whitley, D. S., Sipe, T. A. Crosby, A. E., Johnson, R. L., Liberman, A. M., Moscicki, E., Price, L. N., Tuma, R. K., Kalra, G., Chattopadhyay, S. K. (2008). The effectiveness of interventions to reduce 
psychological harm from traumatic events among children and adolescents - A systematic review. American Journal of Preventive Medicine, 35, 287-313.

White, C. R., O’Brien, K., Pecora, P. J., English, D., Williams, J. R., \& Phillips, C. M. (2009). Depression among alumni of foster care: Decreasing rates through improvement of experiences in care. Journal of Emotional and Behavioral Disorders, 17, 38-48.

Winslow, J. T. (2005). Neuropeptides and nonhuman primate social deficits associated with pathogenic rearing experience. International Journal of Developmental Neuroscience, 23, 245-251.

Wilson, S. L. (2001). Attachment disorders: Review and current status. The Journal of Psychology, 135(1), 37-51.

Zeanah, C. H., Smyke, A. T., \& Dumitrescu, A. (2002). Attachment disturbances in young children II: Indiscriminate behavior and institutional care. Journal of the American Academy of Child and Adolescent Psychiatry, 41, 983-989.

Zeanah, C. H. \& Zeanah, P. D. (1989). Intergenerational transmission of maltreatment: Insights from attachment theory and research. Psychiatry, 52, 177-196.

Zetlin, A. (2006). The experiences of foster child and youth in special education. Journal of Intellectual \& Developmental Disability, 31, 161-165. 


\title{
CURRICULUM VITAE
}

\author{
AMY B. GONSHAK \\ 4031 Firestone Way, Shelbyville, KY 40065 (502) 523-1863 \\ amy.gonshak@louisville.edu
}

\section{EDUCATION}

- Doctoral Candidate, Counseling Psychology, University of Louisville, anticipated graduation August 2011

- Master of Counseling, Community Counseling, University of Phoenix, 2003

- Bachelor of Arts, Art with Psychology minor, Xavier University, 1995

\section{APA ACCREDITED PRE-DOCTORAL INTERNSHIP}

\section{Federal Medical Center - Lexington, Kentucky, Federal Bureau of Prisons}

\section{- Residential Drug Abuse Program Rotation}

- Serving as a primary Drug Treatment Specialist providing case management and treatment planning services for male inmates in the Residential Drug Abuse Program

- Participating in Substance Abuse/Dependence assessment interviews

- Facilitating inpatient/residential and outpatient/non-residential groups: Assessing Substance Abuse, Challenging Destructive Thinking, Building Healthy Relationships, Recovery Maintenance, Anger Management, Emotional Awareness; Mindfulness/Meditation

- Utilizing clinical hypnosis in individual therapy

- Participating in supervision training

\section{- General Population Rotation}

- Served as a mental health treatment provider to male inmates on a general housing unit and female inmates at a low security camp

- Provided long-term, brief, solution-focused, and crisis counseling covering diverse array of treatment needs

- Facilitated therapy groups and psychoeducational workshops: Seeking Safety (Substance Abuse \& Trauma), Trauma Workshops, Values \& Thinking Errors, Grief, Forgiveness, Parenting, Stress Management, Relaxation Training, Understanding \& Managing Anger

- Adminstered and scored psychological tests for use in pre-trial evaluations

- Monitored inmates on psychotropic medications

- Conducted weekly intakes

- Trained inmates serving in the Suicide Cadre Watch Program 
- Performed monthly mental status reviews (suicidality) of inmates in the Special Housing Unit

\section{CLINICAL PRACTICA}

Veterans Affairs, Louisville, Polytrauma, Neuropsychology Assessment, 2009

- Conducted neuropsychological assessments for OEF/OIF veterans in the polytrauma unit

- Assisted with psychological assessments for veterans in inpatient or outpatient units as needed

- $\quad$ Adult clients

\section{University of Louisville Counseling Center, 2009}

- Conducted college students psychological assessments for learning disabilities and ADHD;

- Implemented feedback sessions to students with specific recommendations to enhance learning

- Adolescent \& Adult clients

Maryhust, Inc. Residential Treatment Center, Assessment Practicum, 2008-2009

- Provided cognitive and social/emotional psychological assessments for adolescents placed in residential treatment for severe physical and sexual abuse and neglect

- Provided individual and group therapy and treatment planning utilizing TraumaInformed therapy

- Adolescent clients

Weisskopf Child Evaluation Center, University of Louisville Hospital, 2008

- Provided individual and group social skills training to children and adolescents diagnosed with Autism Spectrum Disorders

- Counseled family members and created treatment plans

- Provided psychological assessments for Disorders Usually First Diagnosed in Infancy, Childhood, or Adolescence (i.e., Autism Spectrum Disorders, Tourette's Disorder, ADHD, depression \& anxiety disorders)

- Child, Adolescent, \& Family clients

University of Louisville, Kent School of Social Work, Juvenile Sexual Offender Counselor Certification Practicum, 2007

- Provided individual therapy to adolescents who had sexually offended and who had also experienced sexual abuse

- Created and implemented training for therapists related to similar treatment for multiple problem behaviors

- Adolescent \& Family clients

\section{Family Transitions - Sex Offender Treatment Center, Phoenix, AZ, 2003}

- Provided individual, group, and couples therapy to convicted sexual offenders, and primary and secondary survivors

- Adult clients 
University of Phoenix Counseling Center, 2002

- Provided Community/University Mental Health services; Individual therapy

- Adult clients

\section{RELATED EMPLOYMENT}

\section{Supervisor/Therapist, Maryhurst, Inc., Louisville, $K Y$}

$2003-2007$

- Completed comprehensive assessments, case notes and individual treatment plans for residential adolescent clients with history of physical or sexual abuse and/or neglect

- Provided individual, family, and group therapy

- Designed and implemented training for staff

- Supervised two therapeutic after school programs located in "at-risk" communities

- Created a 3-month curriculum and organized monthly schedule for program participants

- Provided psycho-educational groups; individual and family support and advocacy

- Managed budget for both programs

- Provided weekly supervision to 5 staff

- Created and implemented ongoing team building retreats and training for staff

Juvenile Probation Officer, Maricopa County, Phoenix, AZ $1999-2003$

- Supervised a caseload of $40+$ probationers

- Acquired family social histories and victim impact statements

- Provided pertinent information to the juvenile court through oral and written reports

- Made recommendations regarding services and consequences for each juvenile

- Created, planned and implemented high school programs pertaining to educational and personal growth (i.e. social skills, sexual health, multiculturalism)

- Advised and counseled students on various personal, academic, and social concerns

- Facilitated conflict resolution; Maintained school safety

- Graduated from Probation Officer Certification Academy

- Graduated from Law Related Education (LRE) Academy

Caseworker, Southwest Keys Outreach \& Tracking, Phoenix, AZ

$1998-1999$

- Created and implemented psycho-educational groups and activities

- Maintained accountability of juveniles by physically tracking them at school, work and home

- Documented statistics and produced progress reports for the juvenile court

- Provided recommendations to the juvenile court

\section{TEACHING \& TRAINING EXPERIENCE}

\section{University of Louisville, College of Education \& Human Development - Instructor}

- Human Development and Learning (ECPY 507/607) - Instructor, two sections, graduate level, Summer 2010

- Human Development and Learning (ECPY 507/607) - Invited Guest Lecturer on "Attachment," graduate level, Spring 2010

- Human Development and Learning (EDTP 107) - Instructor, four sections, undergraduate level, Fall 2009, Spring 2010

- Intro to Counseling \& Psychotherapy (ECPY 600) - Invited Guest Lecturer on "Existentialism," graduate level, Fall 2008 
Maryhurst, Inc. Residential Treatment Center - Trainer

- "Trauma Informed Care for Teachers-Research Initiative" - Training for Teachers, 2009

- "Effects of Vicarious Trauma" - Training for Direct Care and Therapeutic Staff, 2007

- "Treating Sexual Offenders" - Training for Therapeutic Staff, 2007

- "Effectively Communicating with Concrete Thinkers" - Training for Therapeutic Staff, 2007

- "Trauma Informed Care" - Training for Direct Care and Therapeutic Staff, 2006

Lone Cactus Alternative High School, Phoenix, AZ - Resource Officer/Guest Teacher

- Taught Social Skills, Sexual Health, Law Related Education to students involved in juvenile justice system, 2002-2003

\section{RESEARCH}

Dissertation: Analysis of Trauma Symptomology, Trauma-Informed Care, and Student-Teacher Relationships in a Residential Treatment Center Oral Defense Completed: November 2010

Educational Psychology Lab, 2008-2010

- Project 1-Significantly contributed to the design and implementation of a study examining the impact of a trauma-informed training intervention for teachers in residential treatment settings. Assisted with data collection and data entry, Led presentation of findings to residential treatment centers, school district, and TREATI, Inc.

- Project 2 - Contributed to literature review related to attachment theory and writing paper submission for effects of child temperament on peer relationships

\section{Research Synthesis/Meta-Analysis Lab, 2008-2009}

- Participated in literature review and coding process for multiple meta-analyses related to school-based prevention programs (i.e violence, sexual abuse, academic failure)

\section{Developmental Neuropsychology Lab, 2007-2008}

- Participated in data collection of long-term neuropsychological study of reading and math development;

- Completed 20 hours of instructional training related to electromagnetic imaging and equipment, data collection processes, neuropsychological research, and brain anatomy

Research Assistant, Office of Research, University of Louisville, 2007 - 2009

- Completed ongoing targeted searches for grant funding and literature searches in support of funding applications;

- Maintained database of faculty research publications and presentations;

- Facilitated relationship building between university faculty researchers and outside agencies 


\section{Presentations:}

Gonshak, A. B. (2010). Analysis of trauma symptomology, trauma-informed care, and studentteacher relationships in a residential treatment center. Workshop presented at the $2010 \mathrm{KPA}$ Convention, Louisville.

Gonshak, A. B. (2010). Student-teacher relationships in residential treatment: Contributions of student trauma symptomology and teacher beliefs and behavior. Poster presented at the $15^{\text {th }}$ Annual International Conference on Violence, Abuse, and Trauma, San Diego.

Niehaus, K., White, J., Rudasill, K., Wolf, J., \& Gonshak, A. B. (2009). Children's temperament and the quality of early peer relationships. Poster presented at the annual meeting of the Kentucky Psychological Association, Lexington.

Valentine, J. C., Burnett, J. B., Nichols, A., Gonshak, A. B., Tong, S., Whitten, M., \& Pickering, M. (2009). Validity characteristics of randomized and quasi-experiments in studies of schoolbased prevention programs. Poster presented at the annual meeting of the American Psychological Association, Toronto.

\section{COMMUNITY \& UNIVERSITY SERVICE}

- Guest on National Public Radio "State of Affairs" program, Trauma-Informed Treatment, 2011

- Guest on Dr. Stan Frager Radio show, Effects of Trauma in Adolescents, 2010

- Doctoral Leadership Committee, 2007-2010

- Research and Faculty Development Committee, 2008-2009

- Tri-State Universities (UL, UK, UC) Spring Research Conference Chair, 2008-2009

\section{SELECTED PROFESSIONAL TRAINING}

- $15^{\text {th }}$ Annual International Conference on Violence, Abuse, and Trauma (Institute on Violence, Abuse, and Trauma, 2010)

- Prochaska: Stages of Change (KPA, 2009)

- Complex Post-Traumatic Stress Disorder: Understanding, Assessing \& Intervening (KPA, 2008)

- Trauma-Informed Treatment: The Restorative Approach - Training for Trainers (Trauma Research, Education, and Training Institute, Inc., 2006 \& 2007)

- Suicide Prevention \& Griefwork, 3-day Conference (Kentucky Department of Mental Health, 2005)

- Safe Crisis Management (Maryhurst, Inc. 2004 - 2007)

- Council on Prevention and Education: Substances (Creating Lasting Family Connections, 2004-2006)

- Developing Effective Work Teams (University of Louisville, 2004)

- Best Practices in Community-Based Prevention and Intervention Programs (U.S. Department of Justice, 2004)

- Risk Assessment, Treatment, and Family Reunification with Young Adult Sex Offenders Conference (Arizona Association for Treatment of Sexual Abusers, 2003)

- A Framework for Understanding Poverty (Maricopa County Juvenile Justice, 2003) 


\section{AWARDS \& RECOGNITIONS}

- Certificate of Appreciation \& Innovation from Maricopa County Superintendent, 2002

- Caseworker of the Year award, Maricopa County, Phoenix, AZ, 1998

- Invited Participant in Graduate Teaching Academy sponsored by the School of Interdisciplinary and Graduate Studies, University of Louisville, 2009-2010

\section{PROFESSIONAL MEMBERSHIPS \& CERTIFICATIONS}

- American Psychology Association (APA)

- Kentucky Psychology Association (KPA)

- National Certified Counselor (NCC)

- Certified Juvenile Sex Offender Counselor (JSOCC)

- Professional Mediation Certification, University of Phoenix, 2003 